ANDRÉ LUÍS LIMA DE OLIVEIRA

\title{
AVALIAÇÃO COMPARATIVA DE DIFERENTES MODELOS DE INTERFACES GRÁFICAS EMPREGADAS NO ENSINO DE GEOMETRIA, SEGUNDO OS CONCEITOS DE USABILIDADE
}

Dissertação apresentada à Escola Politécnica da Universidade de São Paulo para obtenção do título de Mestre em Engenharia. 
ESCOLA POLITÉCNICA DA UNIVERSIDADE DE SÃO PAULO DEPARTAMENTO DE ENGENHARIA DE CONSTRUÇÃO CIVIL

ANDRÉ LUÍS LIMA DE OLIVEIRA

\begin{abstract}
AVALIAÇÃO COMPARATIVA DE DIFERENTES MODELOS DE INTERFACES GRÁFICAS EMPREGADAS NO ENSINO DE GEOMETRIA, SEGUNDO OS CONCEITOS DE USABILIDADE
\end{abstract}

Dissertação apresentada à Escola Politécnica da Universidade de São Paulo para obtenção do título de Mestre em Engenharia.

Área de Concentração: Engenharia de Construção Civil e

Urbana

Orientador:

Prof. Dr. Eduardo Toledo Santos

São Paulo

Agosto de 2005 
Este exemplar foi revisado e alterado em relação à versão original, sob a responsabilidade única do autor e com a anuência do seu orientador.

São Paulo, 30 de setembro de 2005

Assinatura do autor

Assinatura do orientador

\section{FICHA CATALOGRÁFICA}

Oliveira, André Luís Lima de

Avaliação comparativa de diferentes modelos de interfaces gráficas empregadas no ensino de geometria, segundo os conceitos de usabilidade/ André Luís Lima de Oliveira. -- São Paulo, 2005.

p. 116

Dissertação (Mestrado) - Escola Politécnica da Universidade de São Paulo. Departamento de Engenharia de Construção Civil.

1. Interface 2. Interface homem-computador 3. Ensino por computador I. Universidade de São Paulo. Escola Politécnica. Departamento de Engenharia de Construção Civil II. t. 
"Este trabalho é dedicado ao meu pai Paulo Oliveira Becker, minha mãe Vanda Lima de Oliveira e ao meu irmão Paulo César Lima de Oliveira". 


\section{AGRADECIMENTOS}

Primeiramente a minha família (pai, mãe e irmão) pelo apoio e compreensão, pois sem eles nada disso teria sentido!

Ao meu orientador Prof. Dr. Eduardo Toledo Santos - PCC/EPUSP.

O presente trabalho foi realizado com o apoio do Conselho Nacional de Desenvolvimento Científico e Tecnológico-CNPq-Brasil.

Ao bolsista de Iniciação Científica Leandro Lourenzoni, membro da nossa equipe e quem implementou o aplicativo Risko.

Ao Prof. Dr. João Roberto D. Petreche - PCC/EPUSP.

Aos amigos: Rogério M. Alves, Rovilson Mafalda, Sérgio L. Ferreira e Rodrigo D. Seabra bem como os muitos colegas e professores do Grupo de Pesquisa SUP (Sistema de Suporte ao Projeto) da Escola Politécnica da USP.

Aos colaboradores que participaram dos testes experimentais realizados.

À Profa. Dra. Roseli de Deus Lopes - PSI/EPUSP.

À Profa. Dra. Lúcia L. V. Filgueiras - PCS/EPUSP.

Às bibliotecárias e em especial à Vilma A. André.

Ao Departamento de Engenharia de Construção Civil da Escola Politécnica da USP.

Aos demais amigos(as) que no dia a dia estiveram do meu lado, incentivando! 


\section{ÍNDICE}

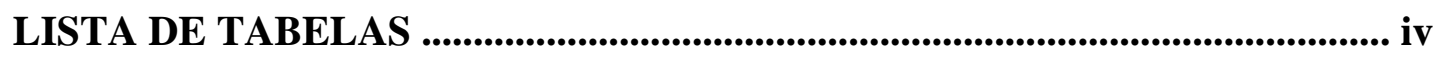

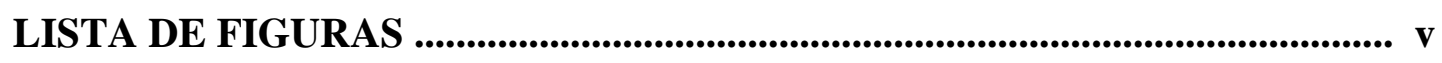

LISTA DE ABREVIATURAS E SIGLAS .................................................... vi

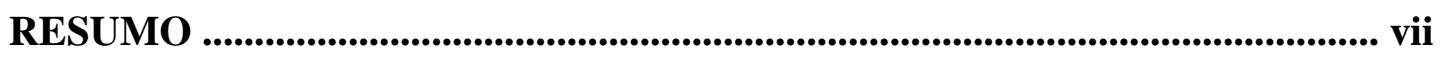

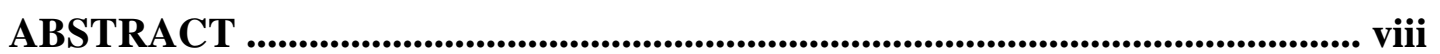

1. O ENSINO DE GEOMETRIA...................................................................................1

1.1 Introdução .........................................................................................................1 1

1.2 Objetivos..........................................................................................................11

1.2.1 Objetivos Específicos ...................................................................... 11

1.3 Organização dos Capítulos ...........................................................................11

2. REVISÃO DA LITERATURA .............................................................................13

2.1 Usabilidade..................................................................................................................13

2.2 Estilos de Interação .........................................................................14

2.2.1 Padrão “WIMP》".............................................................................. 16

2.2.2 Manipulação Direta ......................................................................22

2.3 Metáforas de Interfaces Gráficas ...............................................................24

2.3.1 Metáforas do Mundo Real............................................................ 25

2.3 .2 Classificação das Metáforas.................................................26

2.4 Ferramentas para Interfaces .........................................................................28

2.5 Programas Similares ...................................................................................30

2.6 Métodos de Especificação de GUI.............................................................31

2.7 Conclusão do Capítulo ...........................................................................................34

3. DESCRIÇÃO FUNCIONAL DAS INTERFACES ............................................35

3.1 Descrição da Interface do iGeom .................................................................35

3.1.1 Мепи Textual............................................................................36

3.1.2 Ícones Primários e Secundários...............................................36

3.1 .3 Caixa de Mensagens .................................................................38

3.1.4 Area de Trabalho .......................................................................39

3.2 Descrição da Interface do Risko.................................................................39

3.2.1 “Affordances" dos Instrumentos Reais de Desenho ...............39 
3.2.2 Apontador....................................................................................42

3.2.3 Lápis/Borracha .......................................................................43

3.2.4 Compasso............................................................................................45

3.2.5 Esquadros.................................................................................46

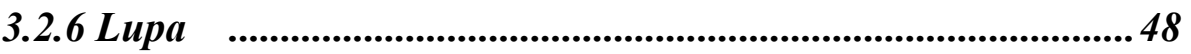

3.3 Conclusão do Capítulo .........................................................................................49

4. PERFIL DO USUÁRIO E ANÁLISES DE USABILIDADE ..........................50

4.1 Perfil do Usuário .....................................................................................................50

4.2 Análises de Usabilidade Realizadas .................................................52

4.2 .1 Análises Heurísticas ........................................................................55

4.2 .2 Análise Funcional...................................................................56

4.2 .3 Análise de Tarefas..................................................................59

4.3 Conclusão do Capítulo ...................................................................................60

5. AVALIAÇÃO COMPARATIVA ................................................................62

5.1 Método de Avaliação Desenvolvido.......................................................62

5.1 .1 Grupo Usabilidade ..................................................................65

5.1 .2 Grupo Eficiência......................................................................67

5.2 Procedimentos Experimentais ..........................................................67

.3 Mecanismos de Coleta dos Dados......................................................................70

5.3 .1 Teste Prático................................................................................ 70

5.3.2 Questionário Pós-teste ............................................................ 72

5.4 Conclusão do Capítulo ...................................................................................77

6. RESULTADOS E TRATAMENTO ESTATÍSTICO ......................................78

6.1 Critérios e Métodos para as Avaliações................................................78

6.1.1 Obtenção da Amostra..............................................................80

6.1.2 Classificação das Variáveis ..................................................80

6.2 Análise dos Dados Obtidos com o Teste Prático....................................81

6.2.1 Avaliação do atributo "1.1 Intuitividade" "............................... 83

6.2.2 Avaliação do atributo "1.2 Facilidade para interpretar as

funcionalidades"..............................................................................85

6.2.3 Avaliação do atributo "2.1 Eficiência"...................................89

6.3 Análise dos Dados Obtidos com o Questionário Pós-teste ..................91 
6.4 Análise dos Vídeos .................................................................................102

6.5 Conclusão do Capítulo .................................................................................110

7. CONCLUSÕES ................................................................................................................111

7.1 Conclusão Final..............................................................................................111

7.2 Sugestões para Trabalhos Futuros.............................................................115 REFRÊNCIAS

ANEXOS

APÊNDICES 
Tabela 3.1 - Ícones primários e secundários do $i$ Geom..........................................37

Tabela 3.2 - Ações dos instrumentos reais ("affordances")....................................40

Tabela 4.1 - Classificação atribuída para as tarefas avaliadas..............................59

Tabela 5.1 - Total de ocorrências e frequiência relativa das tarefas na resolução

do conjunto de exercícios......................................................................69

Tabela 5.2 - Correlação das tarefas com as ("affordances")................................72

Tabela 6.1 - Resumo do método em uso para avaliação das GUI .........................79

Tabela 6.2 - Resumo dos valores obtidos sobre os erros e as desistências............83

Tabela 6.3 - Tempo médio para executar cada tarefa ...............................................84

Tabela 6.4 - Tempo gasto para o entender o funcionamento.................................85

Tabela 6.5 - Somatório dos dados pareados para a tarefa 1..................................86

Tabela 6.6 - Análise da significância pelo p-valor ..................................................88

Tabela 6.7 - Cálculo da amostra necessária n ..........................................................89

Tabela 6.8 - Resumo do Teste de Wilcoxon para os itens da questão "B x D".102 


\section{LISTA DE FIGURAS}

Figura 1.1 - Gabarito de um exercício clássico de desenho geométrico..................3

Figura 2.1 - Interfaces "WIMP" apresentadas pelos Sistemas CAD.....................17

Figura 2.2 - Interfaces dos programas: $i$ Geom e "Geometer's SketchPad".........21

Figura 2.3 - Interface do programa "Geoplan"...........................................................22

Figura 2.4 - Algumas ferramentas apresentadas pelo "HabilisDraw".................30

Figura 2.5 - Uso combinado das ferramentas para criar formas compostas ......31

Figura 3.1 - Interface do Risko...............................................................................42

Figura 3.2a - Apontador no modo padrão "default".............................................43

Figura 3.2b - Apontador no modo "pan".........................................................................43

Figura 3.3 - Lápis/Borracha.........................................................................................44

Figura 3.4 - Compasso e suas partes a serem configuradas......................................45

Figura 3.5 - Vínculos para os esquadros......................................................................47

Figura 3.6 - Lupa para ajuste de visualização ..........................................................48

Figura 5.1 - Resolução das tarefas feita com a interface do $i$ Geom ......................71

Figura 5.2 - Resolução das tarefas feita com a interface do Risko.........................71

Figura 5.3 - Conversão para a escala de Likert ..........................................................73

Figura 6.1 - Interface com a resolução das tarefas pelo usuário experiente .......90

Figura 6.2 - Gráfico referente à freqüiência de uso do computador.....................92

Figura 6.3 - Gráfico comparativo sobre a credibilidade dos programas..............93

Figura 6.4 - Gráfico comparativo de preferência de uso em um curso.................94

Figura 6.5 - Gráfico referente às dificuldades em realizar as tarefas...................95

Figura 6.6 - Gráfico comparativo de tempo consumido..........................................96

Figura 6.7 - Gráfico comparativo de preferências por aplicativo.........................97

Figura 6.8 - Gráfico comparativo referente as dificuldades de uso ......................98

Figura 6.9 - Gráfico comparativo sobre a confiabilidade transmitida ................99

Figura 6.10 - Gráfico comparativo das notas médias por sub-item ......................99 


\section{LISTA DE ABREVIATURAS E SIGLAS}

\begin{tabular}{|c|c|}
\hline CAD & - "Computer Aided Design" \\
\hline GD & - Geometria Dinâmica \\
\hline GUI & - "Graphical User Interface" \\
\hline “WIMP” & - "Window, Icon, Menu \& Pointer" \\
\hline ISO & - "International Organization for Standardization" \\
\hline MD & - Manipulação Direta \\
\hline GOMS & - "Goals, Operators, Methods, and Selection Rules' \\
\hline UAN & - "User Action Notation" \\
\hline
\end{tabular}




\section{RESUMO}

O presente trabalho consiste em desenvolver e aplicar um método para avaliar comparativamente modelos distintos de interfaces gráficas computacionais, quando empregados como ferramenta de auxílio ao ensino e aprendizado de Geometria Gráfica para um específico grupo de usuários. A motivação que originou esta pesquisa foi a necessidade de avaliar, comparativamente, a interface inovadora de um programa de desenho denominado Risko, que foi desenvolvido com o propósito de atender às necessidades específicas do ensino de desenho. Como diferencial, o aplicativo usa, em sua interface, uma metáfora do mundo real e apresenta instrumentos de desenho virtuais: compasso, esquadros, lápis e borracha, que substituem as ferramentas abstratas (ícones e menus) inerentes ao padrão "WIMP" que é a alternativa largamente utilizada pelos aplicativos destinados ao ensino do tema. O método proposto utiliza-se de dois instrumentos: um teste prático com usuários e um questionário. Os testes com as interfaces são realizados tanto por usuários iniciantes quanto por aqueles já experientes com elas, registrando-se o número de erros cometidos bem como o tempo para completar tarefas pré-definidas, em ambas as interfaces. O questionário procura avaliar aspectos subjetivos como preferência por uma ou outra interface e percepção de precisão. Os resultados são todos analisados de forma comparativa entre as interfaces e o nível de significância é controlado estatisticamente.. A avaliação das interfaces contribui para o desenvolvimento das ferramentas computacionais educativas apontando as falhas e virtudes dos aplicativos em questão. Em linhas gerais, o trabalho estabelece um método que permite avaliar, comparativamente, distintos modelos de interfaces gráficas com enfoque para as necessidades dos usuários potenciais. 


\begin{abstract}
This work is about the development and application of a method for the comparative evaluation of different computer graphics interface models when used as a tool for teaching and learning Graphic Geometry by a specific user group. The motivation at the origin of this research was the need to evaluate, comparatively, the innovative interface of a drawing software called Risko, which was developed aiming at the specific needs of drawing teaching. As a distinguishing feature, this application uses a real world metaphor in its interface, presenting virtual drawing instruments: compass, triangles, pencil and eraser, which replace the abstract tools (icons and menus) intrinsic to the WIMP standard, the alternative widely used in software for teaching that subject. The proposed method uses two instruments: a practical test with users and a questionnaire. The interface tests are performed both by beginners and experienced users. The number of errors made as well as the time taken to complete pre-defined tasks are recorded. The questionnaire seeks to evaluate subjective aspects like preference for one of the interfaces and users' perception of their precision. All the results are analyzed comparing the two interfaces, statistically controlling the significance level. The evaluation of the interfaces improves the development of didactic computer tools by pointing their faults and merits... In general terms, this work establishes a method that allows the comparative evaluation of different graphics interfaces centered on the potential user's needs.
\end{abstract}




\section{CAPÍTULO 1}

\section{O ENSINO DE GEOMETRIA}

\subsection{Introdução}

O tema Geometria pode ser dividido em dois grupos: inicialmente as Geometrias Gráficas e depois as Geometrias Analíticas ou Algébricas. Ambas tratam os mesmos assuntos, no entanto, utilizam métodos distintos para representá-los. A Geometria Gráfica está relacionada ao uso das representações de figuras enquanto a Geometria Analítica trata de uma parte da Matemática que permite estudar a Geometria Gráfica, ou seja, as figuras geométricas valendo-se da álgebra. A Geometria Analítica foi introduzido, posteriormente a Geometria Gráfica, pelo filósofo e matemático francês René Descartes (1596 - 1650) no século XVII. Descartes inventou um sistema de coordenadas chamado de eixos cartesianos que permite representar numericamente as propriedades geométricas das figuras.

Apresentadas as Geometrias, é importante dizer que o presente trabalho trata especificamente as Geometrias Gráficas onde estão inseridos os temas: Geometria Plana, Geometria Descritiva e Geometria Cotada. Tais temas são de extrema importância no que diz respeito a formação de profissionais, principalmente daqueles que necessitam lidar com as representações gráficas e, por isso vêm sendo ministrados há muitos anos a um grande número de alunos dos cursos de Engenharia, Arquitetura e Tecnologia dentre outros. $\mathrm{O}$ ensino destes assuntos pode ser apresentado de maneiras distintas no diferentes cursos, entretanto, na maioria deles o tema ainda é ensinado valendo-se da metodologia em que o professor ministra aulas presenciais, expondo a teoria juntamente com a demonstração de como se utiliza 
corretamente os instrumentos de desenho (compasso, esquadros, lápis, etc.) para executar as construções geométricas.

A despeito de sua simplicidade e elegância, o aprendizado da Geometria Gráfica representa um desafio a grande parte dos alunos, que consideram difícil a aquisição do conhecimento sobre o tema. Usualmente e até os dias de hoje, a maneira mais eficaz de se aprender o tema é estudando os exercícios resolvidos. Hawk (1962) apresenta um estudo que mostra a eficácia do uso de gabaritos de exercícios resolvidos para o aprendizado de Geometria Descritiva. Sem comprometer o bom resultado que foi comprovado por Hawk (1962), o uso dos gabaritos de exercícios resolvidos também é válido para o aprendizado das demais geometrias gráficas, entretanto, o ensino do tema em sala de aula apresenta alguns desafios:

"La resolución de ejercicios en la pizarra requiere gran habilidad y precisión, no siempre favorecidas por este soporte material. Esto se agrava en los casos en que las construcciones geométricas exigen bastante área vertical de la pizarra. Otro problema se refiere al hecho de que la velocidad de aprendizaje individual varia bastante entre los alumnos de una misma clase, exigiendo la explicación de cada paso muchas veces, lo que puede comprometer la concentración necesaria a la aprendizaje, especialmente en ejercicios de dificil visualización espacial."

(SANTOS, 1999, p.142)

Tais dificuldades podem contribuir para o desinteresse dos alunos em aprender e explorar as riquezas oferecidas pelo tema. E adicionalmente, estudos realizados por Gòrska et al. (1998) comprovaram a existência da variação da habilidade de visualização espacial entre os estudantes de um mesmo grupo ou turma de alunos. O domínio da visualização espacial é fundamental e exerce influência direta no ritmo de aprendizagem de cada aluno de um mesmo curso de Geometria. Tais falhas e a disparidade de habilidade não podem ser sanadas simplesmente com o uso dos recursos tradicionais de ensino do tema e o emprego de gabaritos de exercícios impressos em papel não supre por completo as necessidades do ensino moderno. Os gabaritos em papel não conseguem transmitir todas as informações requeridas no processo de aquisição do conhecimento e principalmente da habilidade 
de visualização espacial. As informações contidas nos gabaritos são limitadas e raramente trazem com clareza a seqüência completa de todas as construções geométricas feitas e, mesmo que elas sejam apresentadas, é comum os alunos não conseguirem identificar a ordem das construções ou sequer achar por onde se inicia a resolução do exercício!

Para ilustrar alguns dos problemas citados, é apresentado um gabarito contendo uma das possíveis soluções para um problema clássico que foi proposto por Apolônio de Perga (262-190 a.C). No enunciado do exercício, pede-se para determinar um arco que seja tangente às duas retas e ao arco dados como mostra a Figura 1.1 onde eles são vistos na cor preta em linhas mais espessas. Na mesma figura os dois arcos na cor vermelha representam duas possíveis soluções para o problema. Os demais pontos e traçados nas cores: preto, verde, azul claro e azul escuro foram criados apenas para auxiliar a busca pelas respostas.

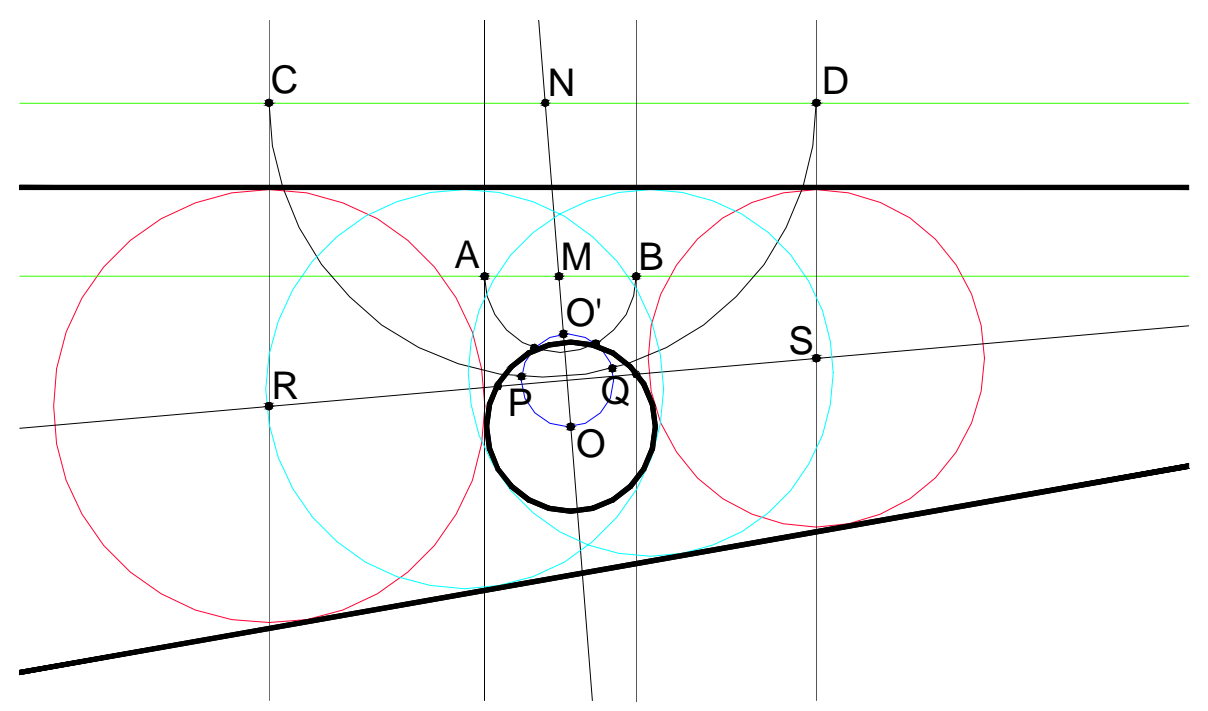

Figura 1.1 - Gabarito de um exercício clássico de desenho geométrico

Deve-se ressaltar que este exercício foi resolvido com o auxilio do computador e, por isso, algumas construções auxiliares foram desnecessárias se comparada a uma resolução feita com os instrumentos de desenho convencionais. E apesar desta imagem ser colorida, tal qualidade visual nem sempre é apresentada pelos materiais de estudo impressos. Visivelmente a imagem apresentada na Figura 
1.1 é bastante confusa por apresentar algumas construções auxiliares que não pertencem às duas possíveis respostas encontradas. Além da questão visual, as figuras auxiliares dificultam identificar a seqüência em que foram realizadas as construções até se chegar à resposta final. Na tentativa de minimizar este problema usualmente são apresentadas legendas vinculadas as figuras, na Figura 1.1 as letras, e que são amparadas por textos explicativos. De outro lado e difícil para o professor, construir este mesmo exercício em sala de aula. Pois, ele deve ser feito em grande escala, no quadro que é marcado com giz ou pincel, usando instrumentos de desenho com tamanho proporcional à escala do desenho, manipulados no plano vertical com apenas duas mãos e sem contar com a ajuda da gravidade que é favorável ao plano horizontal. Obviamente, a alta precisão e a boa qualidade de apresentação são comprometidas.

Diante destes problemas, alguns educadores, principalmente aqueles que trabalham com alunos universitários, vêm testando ferramentas auxiliares ao ensino de Geometria Gráfica. E um dos recursos mais explorados é o uso das ferramentas computacionais apresentados na forma de aplicativos gráficos, que vêm sendo cada vez mais incorporados ao método de ensino. Ocorre que a maioria destes aplicativos não foram desenvolvidos exclusivamente para o uso didático, e por isso não atendem às necessidades específicas dos alunos, professores e muito menos das atuais grades curriculares dos cursos que lidam com o tema Desenho Gráfico. Talvez seja esta a razão principal por não existirem estudos significativos que comprovem os ganhos efetivos do uso de tais ferramentas, quando aplicadas ao ensino de desenho nos referidos cursos. Mesmo porque, os fabricantes destes aplicativos de desenho não criaram seus produtos exclusivamente para uso acadêmico, e sim para fins comerciais, o que justifica suas múltiplas funcionalidades destinadas aos mais diferentes perfis de usuários.

Este fato nos deixa claro que o emprego dos aplicativos de desenho, que seguem os padrões comerciais, para fins educacionais não é o caminho mais adequado para solucionar os problemas citados. Ocorre que a maioria dos aplicativos empregados como ferramenta auxiliar ao ensino são aplicativos comercias como, por exemplo, os Sistemas CAD - "Computer Aided Design" e os programas de Geometria, que não foram desenvolvidos exclusivamente para fins didáticos. Um 
aplicativo educacional deve, essencialmente, privilegiar e considerar as necessidades específicas dos alunos e professores de desenho, simplificando o seu uso e estimulando os usuários iniciantes.

\begin{abstract}
"Os usuários não se importam com o que está dentro da caixa, pelo menos enquanto ela faz o que eles precisam. Qual processador é utilizado? A linguagem de programação é orientada a objetos? Ela trabalha com transações simultâneas? Possui algum outro jargão popular recente? Nada disso é levado em consideração. Os usuários querem conveniência e resultados, mas o que eles enxergam é a interface. Até onde o consumidor está envolvido, a interface é o produto."
\end{abstract}

(RASKIN, 2000, p.5 apud RODRIGUES, 2002, p.8)

Dada a devida importância à interface que é apresentada por um aplicativo, é fato que a maioria dos Sistemas CAD e dos programas de Geometria utilizam um modelo de GUI - "Graphical User Interface" que segue o padrão "WIMP” “Window, Icon, Menu \& Pointer" (veja cap. 2, item 2.2.1). Ocorre que o uso de aplicativos com interfaces que seguem o padrão "WIMP" são adequados e eficientes quando se almeja a produtividade e, por isso, o padrão tornou-se tão popular não só entre os programas de desenho, mas em praticamente todos os aplicativos computacionais.

"Por melhores que sejam o processo de desenvolvimento e a tecnologia utilizada na elaboração de um produto, sua interface não será bem sucedida se não corresponder às necessidades do usuário."

(RODRIGUES, 2002, p.44)

Comprovadamente, os aplicativos computacionais são adequados não só à produtividade, mas também ao ensino, entretanto eles devem prover recursos diferenciados, iniciando por uso de interfaces específicas a cada situação. Ocorre que o uso das interfaces que seguem o padrão "WIMP” para o ensino de Geometria Gráfica gera alguns inconvenientes: 
a) não são intuitivas: um aplicativo destinado a um curso de desenho deve ter funções estritamente educacionais com uma interface altamente intuitiva/simples de aprender a usar;

b) aumentam demasiadamente o tempo de treinamento: estes aplicativos, geralmente, são utilizados somente no período em que o estudante cursa a disciplina de desenho, portanto, o domínio do uso deve ser adquirido num tem breve, o que não é o caso dos Sistemas CAD;

c) recursos em excesso: algumas interfaces "WIMP" têm recursos em demasia, por serem destinados a muitas finalidades e distintos grupos de usuários. Geralmente trazem mais de uma maneira para comandar as suas funcionalidades (ícones, menus e em alguns casos as linhas de comando), isso aumenta significativamente a carga cognitiva e conseqüentemente o tempo necessário para dominar a ferramenta;

d) permitem construções imediatas: os aplicativos com interfaces "WIMP" possibilitam a construção de figuras geométricas com um simples comando como, por exemplo, para construir uma reta paralela ou um segmento tangente à um arco, basta um simples clique em um ícone ou escolher um determinado menu que o objeto é construído instantaneamente.

Inevitavelmente, as construções imediatas ou ações instantâneas abstraem não só as construções auxiliares, mas principalmente os conceitos teóricos envolvidos se considerarmos o processo completo que é feito ao usarmos os instrumentos de desenho. Em um curso de Geometria Gráfica, um dos objetivos é justamente demonstrar ao aprendiz os conceitos de como se constrói, passo a passo, por exemplo, a reta paralela ou o segmento tangente a um arco, juntamente à maneira correta de utilizar os instrumentos de desenho. Neste caso, os ícones e menus disponíveis numa interface "WIMP" substituem os instrumentos de desenho, e conseqüentemente são responsáveis pela omissão dos conceitos fundamentais para o processo de aprendizagem dos alunos de um curso de Desenho. Assim, os alunos que aprendem o tema usando aplicativos com interfaces "WIMP", provavelmente não 
conseguem manusear corretamente os instrumentos de desenho, e podem ter dificuldades para desenhar em situações onde o ambiente computacional não está presente como, por exemplo, nas provas.

O uso das ferramentas computacionais é necessário e indiscutivelmente de grande valia para a educação e principalmente no desenvolver das habilidades dos profissionais em formação a fim capacitá-los no uso das ferramentas que na prática são empregadas pelos profissionais atuais. Entretanto, os aplicativos com GUI que seguem o padrão "WIMP" podem não ser o mais adequado para o ensino de desenho, o que nos deixa clara a necessidade de se buscar outras alternativas que atendam com maior excelência ao publico em questão. Talvez o caminho mais curto para obtenção de bons resultados seja estudar e alterar o conceito das interfaces em uso para o ensino de Desenho.

Um outro ponto de vista que também justifica estudar e investir no desenvolvimento das GUI, é apresentada no estudo realizado por Browne (1994) que mostra um quadro referente às economias que podem ser alcançadas com um bom projeto de desenvolvimento de uma interface. No referido estudo, o autor afirma que cerca de $55 \%$ do código do aplicativo é destinado aos elementos da interface, que ela tem um custo de aproximadamente $30 \%$ de todo o programa e que $60 \%$ dos gastos com manutenções estão relacionados as alterações na GUI caso ela não seja desenvolvida corretamente.

Diante disso, o grupo de pesquisa a que este trabalho está relacionado desenvolveu um aplicativo, exclusivamente, para ser usado como ferramenta de auxílio ao ensino de Geometria Gráfica. Diferentemente das demais interfaces, o aplicativo desenvolvido traz uma interface que segue uma metáfora do mundo real de como são realizados os desenhos. Para isso, são disponibilizados virtualmente os seguintes objetos: folha de papel, compasso, esquadros e um lápis com borracha, todos com aparência e comportamento similar aos seus correspondentes do mundo real (SANTOS, 2004). Esta linguagem metafórica busca unir o melhor dos dois mundos, a intuitividade dos instrumentos de desenho reais com as possibilidades oferecidas pelo mundo virtual (precisão, visualização, etc). A interface foi desenvolvida visando atender às necessidades específicas de um perfil de usuários, 
bem como suprir algumas das deficiências encontradas nas interfaces "WIMP", quando aplicadas ao ensino de Desenho Gráfico. Portanto, espera-se que a interface com os instrumentos virtuais permita:

a) alta precisão e facilidade para desenhar: as construções gráficas podem ser realizadas, ou demonstrados, de maneira mais prática, passo a passo e com mais precisão dos que as construções feitas num quadro com giz ou pincel, na posição vertical e valendo-se dos instrumentos de desenho especiais para lousa;

b) boa visualização: com um recurso de multimídia é possível projetar a construção de exercícios em sala de aula, numa tela que substitua o quadro negro/branco, permitindo visualizar a maneira correta de manipular os instrumentos de desenho e acompanhar todos os passos até a obtenção da resposta do exercício. Assim o professor consegue apresentar a teoria com a maneira correta de manipular os instrumentos de desenho;

c) registro: é possível registrar todas as construções feitas e salvá-las em arquivo para posterior visualização passo a passo. Neste caso, as resoluções feitas em sala de aula podem ser disponibilizadas aos aprendizes como, por exemplo, na Internet ou num ambiente de ensino gerenciado por um sistema (VALENTE, 2003). Com isso, os alunos podem estudar impondo o seu próprio ritmo de aprendizagem, fator crucial para obtenção de altos padrões de aprendizado (DIB, 2002);

d) uso dos instrumentos: a constante demonstração de como são resolvidos os exercícios, valendo-se dos instrumentos de desenho, permite aos alunos aprender a maneira correta de manipulá-los. Demonstrar o uso correto de tais instrumentos impõe uma velocidade menor às construções gráficas, pois exclui a possibilidade de executar as construções instantâneas oferecidas por ícones ou menus. Conseqüentemente os alunos acompanham todos os raciocínios do professor o que facilita o entendimento do tema. 
Visando atender a estas necessidades, a interface desenvolvida utiliza somente os conceitos de Manipulação Direta (MD). Pois a MD permite representar continuamente os objetos as ações de interesse, utilizando ações físicas ou cliques em botões ao invés de usar sintaxes complexas, propiciando operações rápidas e reversíveis cujo efeito no objeto de interesse é imediatamente visível (SHNEIDERMAN, 1992). Espera-se que uma GUI destinada ao ensino de desenho, composta por instrumentos virtuais, ofereça adicionalmente os benefícios:

a) rápido aprendizado: novos usuários devem dominar em pouco tempo de treinamento ou sem ele as funcionalidades básicas, pois só existirão funções para desenhar;

b) baixa carga cognitiva: usuários ocasionais devem conseguir, facilmente, reter conceitos operacionais pela metáfora em uso que por associar o mundo virtual com algo conhecido do mundo real. Tudo que é visto já está culturalmente assimilado;

c) mensagens de erro: não são necessárias, pois o resultado da ação é visto imediatamente na tela;

d) domínio do sistema: o usuário comanda completamente as ações do sistema, pois ele inicia as ações e imediatamente vê o resultado, portanto ele se sente no controle das operações.

A metáfora empregada traz o desafio de codificar os instrumentos reais em instrumentos virtuais. Tal conversão exerce influencia direta na maneira físicamecânica de manusear os instrumentos de desenho virtuais. Pois, no mundo real, os instrumentos de desenho são manipulados normalmente com as duas mãos, enquanto no mundo virtual a manipulação dos "mesmos" instrumentos é feita por apenas uma das mãos, aquela que aciona o mecanismo de entrada dos comandos para a GUI, o mouse!

As funcionalidades do aplicativo desenvolvido foram concebidas por uma equipe de pesquisa composta, no caso pelo orientador, o autor desta dissertação e um aluno de iniciação científica. A este último integrante coube a implementação do 
código do aplicativo que recebeu o nome de Risko1 ("a Realistic Interface for Simulating a Kit of Objects”).

Diante do que foi introduzido, o autor deste trabalho pretende contribuir com a criação de um método que permita avaliar comparativamente distintas interfaces gráficas quando empregadas ao ensino de Geometria Gráfica. Seqüencialmente, o método proposto será testado comparando o padrão de interface "WIMP", tradicionalmente utilizado, frente ao padrão de MD pura, composto por instrumentos de desenho virtuais, respectivamente as interfaces dos aplicativos $i$ Geom e Risko. O método desenvolvido utiliza os experimentos práticos para obtenção dos dados utilizados para testar as hipóteses pré-formuladas. Tais experimentos são realizados parte pelo usuário experiente, neste caso o autor e parte pelos usuários iniciantes, que são os participantes dos testes selecionados conforme o perfil postulado para o estudo. Os experimentos são constituídos com dois mecanismos de coleta de dados, um teste que simula a realização de tarefas de desenho com ambas as interfaces e um questionário pós-teste. Os dados gerados com os mecanismos de coleta são validados estatisticamente para garantir a confiabilidade do resultado obtido no teste de hipóteses.

Adicionalmente, caso os experimentos realizados gerem dados suficientes, pretende-se apontar qual dos modelos atende melhor às finalidades a que se destinam, em suma, oferecer aos seus usuários as facilidades de uso sem requerer grandes esforços ou treinamentos extensivos para o domínio de uma ferramenta computacional. Alguns autores comentam:

"O Desenho e a Geometria têm características peculiares, cujos requisitos de aprendizagem provavelmente não serão satisfeitos pelas soluções desenvolvidas para nenhuma outra área. Cabe à comunidade do ensino gráfico, por meio de pesquisa e desenvolvimento, atender a esta demanda que, dada a velocidade de evolução das tecnologias da informação, logo será urgente."

(SANTOS e MARTINEZ, 2000, p.7)

\footnotetext{
${ }^{1}$ http://risko.pcc.usp.br
} 
Ao término deste trabalho será disponibilizado não só uma ferramenta alternativa, específica ao ensino/aprendizado de Geometria Gráfica, mas principalmente, será apresentado um método que permite avaliar comparativamente diferentes modelos de GUI.

\subsection{Objetivos}

Desenvolver e aplicar um método para avaliar comparativamente modelos distintos de GUI, quando empregadas como ferramenta de auxílio ao ensino de Geometria Gráfica para suprir as necessidades específicas de um grupo de usuários pré-estabelecido.

\subsubsection{Objetivos Específicos}

- Desenvolver um método que possibilite avaliar de maneira comparativa modelos distintos de interfaces gráficas, neste caso, ("WIMP", apresentada pelo aplicativo $i$ Geom e de Manipulação Direta Pura, apresentada pelo aplicativo Risko), quando empregadas como ferramenta de auxílio ao ensino de Desenho Gráfico presencial para um grupo específico de usuários.

- Testar o método desenvolvido numa avaliação comparativa envolvendo interfaces gráficas de diferentes aplicativos computacionais ( $i$ Geom e Risko) empregados como ferramenta de auxílio ao ensino de Geometria Gráfica para um grupo específico de usuários.

Não é meta, porém, ao término do trabalho, pretende-se disponibilizar gratuitamente o programa criado na Internet.

\subsection{Organização dos Capítulos}

Este trabalho é dividido em seis capítulos. Segue um breve resumo sobre os assuntos abordados em cada um deles: 
CAPITULO 2 - Revisão da Literatura: é apresentada uma revisão bibliográfica sobre os principais conceitos e aspectos referentes a: usabilidade, interfaces de Manipulação Direta, metáforas existentes, modelos de ferramentas para GUI e métodos para especificação funcional de interfaces gráficas.

CAPITULO 3 - Descrição Funcional das Interfaces: mostra a linguagem interativa funcional utilizada por cada aplicativo em estudo, $i$ Geom e Risko apresentando as funcionalidades dos instrumentos que compõem cada uma delas. Levantamento das ações oferecidas pelos instrumentos reais de desenho "affordances".

CAPITULO 4 - Perfil do Usuário e Análises de Usabilidade: apresenta o perfil postulado para o usuário a quem se destinam as interfaces em avaliação e os resultados das análises de usabilidade (Heurística, Funcional e de Tarefas) realizadas com as interfaces.

CAPITULO 5 - Avaliação Comparativa: composto por uma segunda revisão bibliográfica sobre normativas para a construção e avaliação de GUI, onde são apresentados também: a arquitetura dos testes, os experimentos bem como os mecanismos que foram utilizados para coletar os dados referentes ao método em uso.

CAPITULO 6 - Resultados e Tratamento Estatístico: mostra os resultados obtidos com a aplicação do Método de Avaliação desenvolvido e a descrição dos procedimentos que foram empregados para as análises dos dados obtidos com os mecanismos utilizados.

CAPITULO 7 - Conclusões: apresenta a conclusão do trabalho desenvolvido e perspectivas futuras para outros trabalhos. 


\section{CAPÍTULO 2}

\section{REVISÃO DA LITERATURA}

Academicamente, para desenvolver, criar ou estudar uma um tema complexo como as GUI é necessário conhecer tanto as diretrizes gerais quanto as diretrizes específicas destinadas à construção de "software". A seguir serão apresentados os conceitos fundamentais relacionados as GUI e que são utilizados neste trabalho.

\subsection{Usabilidade}

Inicialmente, é preciso estabelecer qual é a definição mais adequada para o termo usabilidade para este estudo de GUI considerando a sua aplicação. Dentre as várias definições de usabilidade, a mais utilizada é também a mais genérica e é apresentada pela NBR 9241-11 que a define como sendo:

"Medida na qual um produto pode ser usado por usuários específicos para alcançar objetivos específicos com eficácia, eficiência e satisfação em um contexto especifico de uso."

(ISO 9241, 1998, apud NBR 9241-11, 2002, p.3)

No entanto, esta definição para usabilidade é muito ampla, e para o caso deste trabalho, uma definição mais precisa é:

"A qualidade da interface homem-computador que permite que o usuário realize com eficiência e conforto as atividades a que o sistema se destina." 
Independentemente da primeira ou da segunda definições, fica claro que ambas evidenciam a boa qualidade que deve ser apresentada por uma GUI tendo como finalidade satisfazer as necessidades dos usuários a que se destinam. Visando garantir isso, o pesquisador norte americano Nielsen (1993) que é vinculado ao grupo "Microsoft ${ }^{\text {TM" }}$ definiu cinco aspectos de usabilidade que devem ser observados:

a) aprendizagem: o sistema deve ser fácil de aprender de modo que o usuário possa rapidamente obter os resultados desejados;

b) eficiência: o uso do sistema deve ser eficiente de modo que, uma vez que o usuário aprendeu a usá-lo, um alto grau de produtividade seja possível;

c) memorização: o sistema deve ser fácil de recordar de forma que um usuário ocasional seja capaz de reutilizar o sistema sem ter que aprender tudo novamente, depois de algum período sem utilizá-lo;

d) erros: o uso do sistema deve ter uma baixa taxa de erros de modo que os usuários sejam conduzidos a cometer poucos erros ao usá-lo e, caso cometam erros, sua correção ou tratamento seja simples. Não devem ocorrer erros catastróficos;

e) satisfação: o sistema deve ser agradável de usar de forma que os usuários se sintam subjetivamente satisfeitos ao utilizá-lo.

Para o escopo dos aplicativos em questão os atributos de aprendizagem e memorização são fundamentais bem como a baixa taxa de erros e a satisfação dos usuários. Porém, o atributo eficiência não é tão relevante já que as ferramentas são destinadas a auxiliar o ensino e o treinamento de alunos, por isso, a produtividade das tarefas desenvolvidas não é relevante mas sim a excelência na boa aprendizagem.

\subsection{Estilos de Interação}

"Um estilo de interação é um padrão especifico que determina algumas características que o modelo de interação de uma interface deve ter. Existem diversos estilos de interação que podem ser classificados de 
diversas maneiras. E uma mesma interface pode permitir ao usuário a interação em diversos estilos."

(LEITE, 2000, cap. 2, p.1)

Independentemente do estilo ou da interação promovida por uma interface, o objetivo sempre é promover o uso facilitado da ferramenta computacional para o usuário. Os estilos de interação mais encontrados são: Linguagens de Comandos, Escolha por Menus, Linguagem Natural, Preenchimento de Formulário, Manipulação Direta, “WIMP”, Realidade Virtual, Hipertexto, etc. Com exceção para as interfaces de Linguagem de Comandos, todos os outros estilos citados são apresentados indiretamente pelo Sistema que visualmente disponibiliza uma forma qualquer de GUI, que teoricamente têm como função facilitar o uso do mesmo. No caso deste trabalho, somente os estilos de interação que são apresentados na forma de interfaces gráficas e que seguem os padrões "WIMP" ou de Manipulação Direta são considerados.

A enciclopédia eletrônica "thefreedictionary", consultada em Dezembro de 2004, apontou como provável criador da primeira interface gráfica o pesquisador Ivan Sutherland membro do MIT ("Massachusetts Institute of Technology"), que em 1963 desenvolveu um programa para a criação de figuras: linhas, círculos e pontos. Este programa foi chamado de "SketchPad" e é hoje considerado o primeiro Sistema CAD de que se tem registro.

Posteriormente ao "SketchPad", vários outros programas surgiram apresentando suas interfaces gráficas baseadas nas mesmas características encontradas no aplicativo criado por Sutherland. Atualmente muitos programas, de diferentes modelos, são utilizados como ferramenta de auxílio ao desenho. No entanto, somente os programas classificados como sendo de Geometria Gráfica, ou seja, aqueles destinados à construções de figuras relacionadas aos temas de Geometria (Plana, Descritiva e Cotada) e que trazem interfaces nos padrões "WIMP" ou de Manipulação Direta são abordados neste estudo. Excluem-se os aplicativos de desenho que apenas geram figuras geométricas ou trazem funções para edição de imagens, como por exemplo: "Corel", "Photoshop", "Paint”, etc. 


\subsubsection{Padrão “WIMP”}

O padrão “WIMP” - (Window, Icon, Menu \& Pointer) recebeu este nome por permitir que um sistema integrado de software seja totalmente operado pelos recursos: janelas, ícones, menus e um indicador de tela controlado por um mouse.

Atualmente o padrão "WIMP” é o mais popular, por isso é largamente utilizado não só pelos aplicativos de Desenho Geométrico, mas pela maioria dos programas computacionais. Como exemplo, são mostrados alguns programas de desenho que utilizam em suas interfaces o padrão "WIMP":

a) Sistemas CAD: os dois sistemas CAD que mais se destacam são: o AutoCAD ${ }^{\circledR}$ e o MicroStation ${ }^{\circledR}$, ambos apresentam interfaces “WIMP”, como mostra a Figura 2.1 com as respectivas interfaces. Apesar dos Sistemas CAD serem utilizados como ferramenta de auxílio ao ensino de desenho, os próprios fabricantes atestam que seus programas foram primordialmente desenvolvidos para a criação de desenhos técnicos (projetos) de engenharia e, por isso, visam eficiência e alta produtividade, o que justifica o uso do padrão "WIMP". 

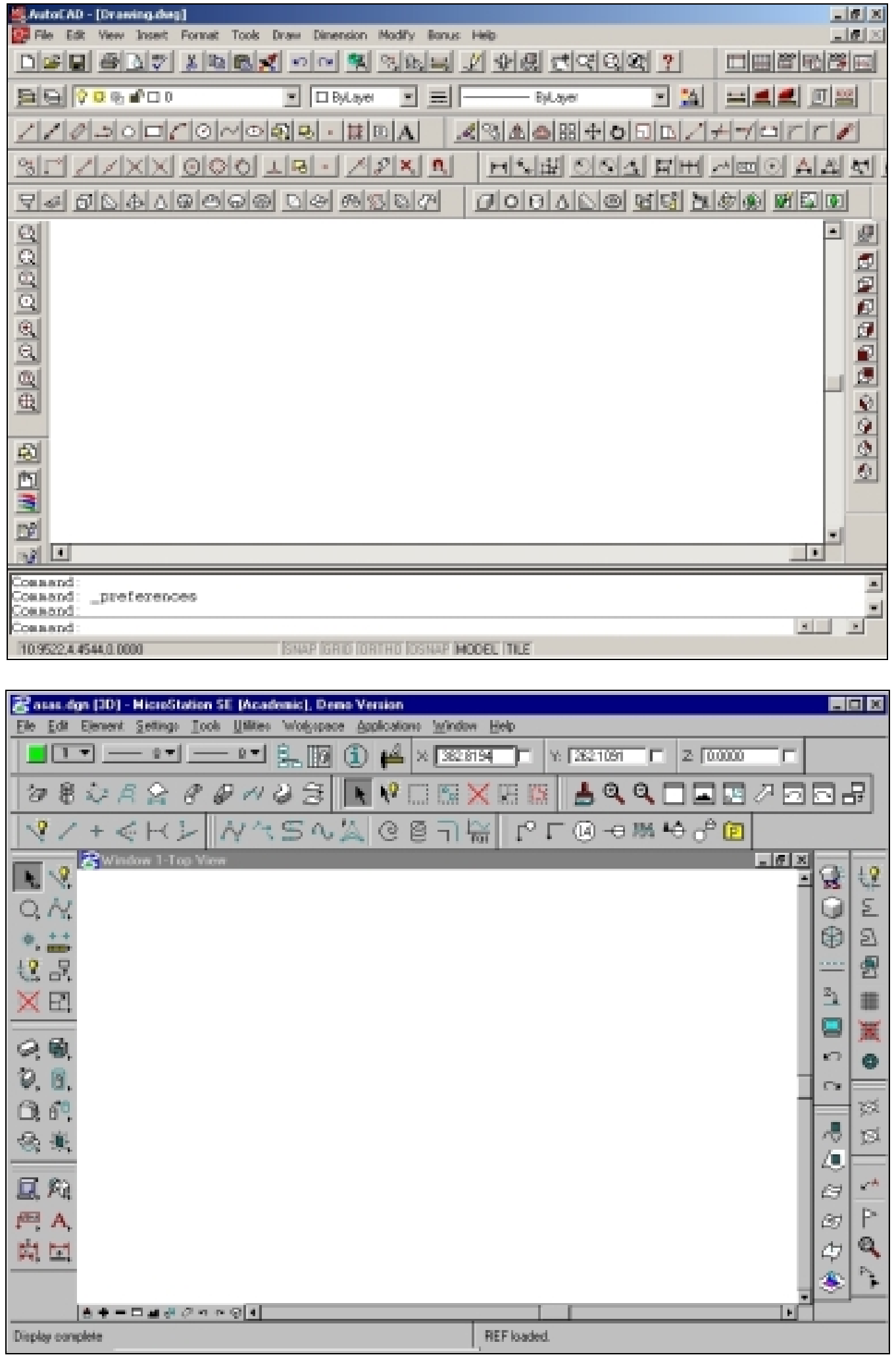

Figura 2.1 - Interfaces “WIMP” apresentadas pelos Sistemas CAD 
As interfaces "WIMP" apresentadas por estes dois programas permitem o uso de três distintos estilos de interação para comandar o sistema: linhas de comandos, menus ou ícones. Os usuários que conhecem a sintaxe textual a ser digitada ou se recordam dos caminhos a serem percorridos no menu para acionar cada comando, podendo dispensar os ícones expostos na tela obtendo maior aproveitamento do espaço para desenhar. Evidentemente, estas duas maneiras de comandar os sistemas requerem o completo domínio por parte do usuário. Portanto, não são estilos adequados para os programas que trazem muitas funcionalidades ou são destinados a aprendizes com pouco tempo designado ao domínio de uso da ferramenta. Neste caso, aos usuários iniciantes e com curto período de tempo para dominar o uso da interface, resta a opção de utilizar os ícones, que é a mais adequada dentre as três opções oferecidas. Num primeiro instante, os ícones facilitam a identificação das funcionalidades do sistema por associar pequenas imagens com objetos conhecidos e encontrados no mundo real, como exemplo, impressora, tesoura, disquete, etc. No entanto, a desvantagem de usar os ícones em determinadas ocasiões é que são necessários muitos comandos para desenhar, e conseqüentemente os vários ícones (figuras) dispostos na tela ocupam boa parte da área de trabalho. Outro problema encontrado em alguns ícones está relacionado a sobreposição de comandos que é uma "solução" aplicada para otimizar o espaço ocupado pelas barras de comandos dispostas na tela. Tal modelo de sobreposição de ícones é conhecido como "pulldown2,", e a "solução inicial" retoma o problema dos menus que exige do usuário a memorização não só dos ícones, mas também dos comandos que estão sobrepostos. Adicionalmente, alguns comandos trazem como "default" configurações que podem ou devem ser alteradas para que a ferramenta atenda às necessidades específicas dos usuários. Ocorre que, dificilmente, um usuário iniciante consegue abstrair esta possibilidade de alterar o modo padrão das ferramentas.

Piegl (2005) realizou um estudo referente ao tempo necessário para utilizar confortavelmente um Sistema CAD e menciona que um usuário iniciante necessita de semanas para simplesmente entender, e que este período de aprendizagem pode durar de seis meses a um ano para o usuário dominar o programa. Se considerarmos

\footnotetext{
${ }^{2}$ Forma de ícone exibido no vídeo que, ao se clicar e segurar o botão do mouse sobre ele, são exibidas outras opções (como abrir um leque), geralmente com comandos relacionados e pertencentes ao mesmo grupo de ações representadas pelo ícone base.
} 
este mesmo período (seis meses), para o caso de um professor que decide utilizar em toda sua vida acadêmica tal ferramenta, aprender um Sistema CAD é viável e recompensador o emprego do tempo para dominar qualquer uma das três linguagens de comando do sistema. Entretanto, se considerarmos os alunos que utilizam a ferramenta somente num curto período, ou seja, quando eles cursam uma disciplina de desenho na universidade, que dura no máximo um ano, grande parte do curso seria consumido no aprendizado da ferramenta ao invés do tema em questão, o Desenho. Surgem então as seguintes questões: numa disciplina universitária de desenho, sobra tempo suficiente para os alunos aprenderem com excelência todo o extenso conteúdo da disciplina de Desenho após consumirem semanas para dominar a ferramenta que será utilizada no curso? Supondo que o professor opte em usar um Sistema CAD como ferramenta auxiliar em suas aulas, surge uma segunda questão: qual das três maneiras de comandar o sistema ele deve apresentar aos seus aprendizes a fim de não sacrificá-los?

Dentre as muitas inconveniências citas estas questões levantadas evidenciam que o uso dos Sistemas CAD como ferramenta auxiliar para o ensino de desenho é inadequado, do ponto de vista do aluno.

b) programas de Geometria: este grupo pode ser subdividida em duas categoria: os que trazem o recurso da Geometria Dinâmicaß]e os que não apresentam tal recurso.

Referente a primeira categoria, que trata dos programas Geometria Dinâmica (GD), técnica esta de manipulação para a interface que permite que, uma vez feitas as construções geométricas, os elementos gráficos construídos podem ser movimentados livremente e o programa automaticamente trata de preservar as relações estabelecidas entre os elementos quando criados, como por exemplo: perpendicularismo, paralelismo, etc. "A trinca Cabri Géomètre, Cinderella e The Geometer's Sketchpad” são atualmente os programas de GD mais populares, segundo Rodrigues, (2002). Nesta mesma categoria também se enquadram os programas: "Euklid", "Geometry Inventor", "GEObject”, "The Geometric Supposer”, “C.a.R.” e além do $i$ Geom dentre vários outros. Este último aplicativo

\footnotetext{
${ }^{3}$ Na língua inglesa é conhecida como "Dynamic Geometry" e é marca registrada pela Key Curriculum Press.
} 
citado foi o escolhido para as avaliações pretendidas neste estudo comparativo, pois o $i$ Geom evoluiu a partir da parceria existente entre a Escola Politécnica (na figura do orientador deste trabalho) e o Instituto de Matemática e Estatística da USP (IME). Comum a todos os programas de GD citados são as suas interfaces que seguem o padrão “WIMP”. As figuras abaixo mostram as interfaces dos aplicativos $i$ Geom e “Geometer's SketchPad” que seguem o padrão descrito.

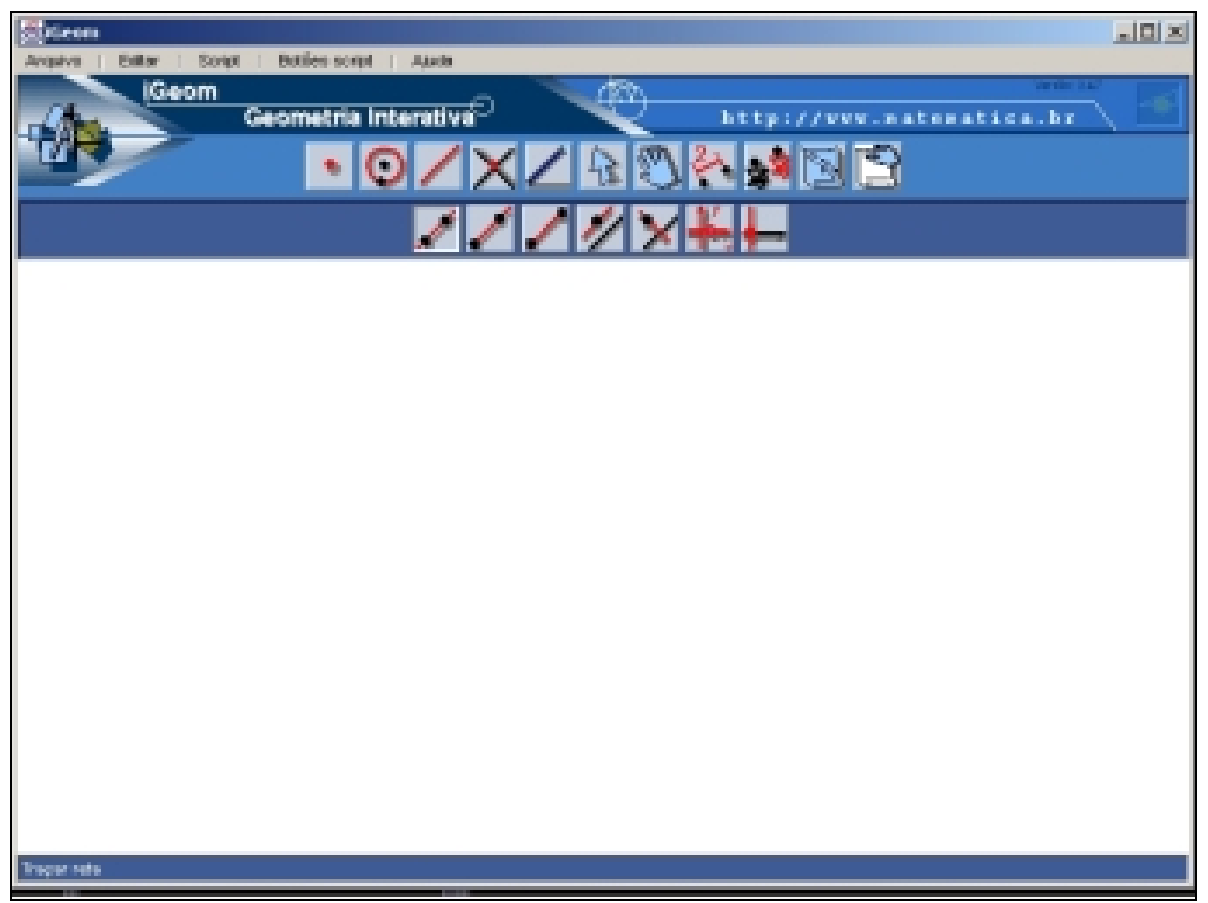




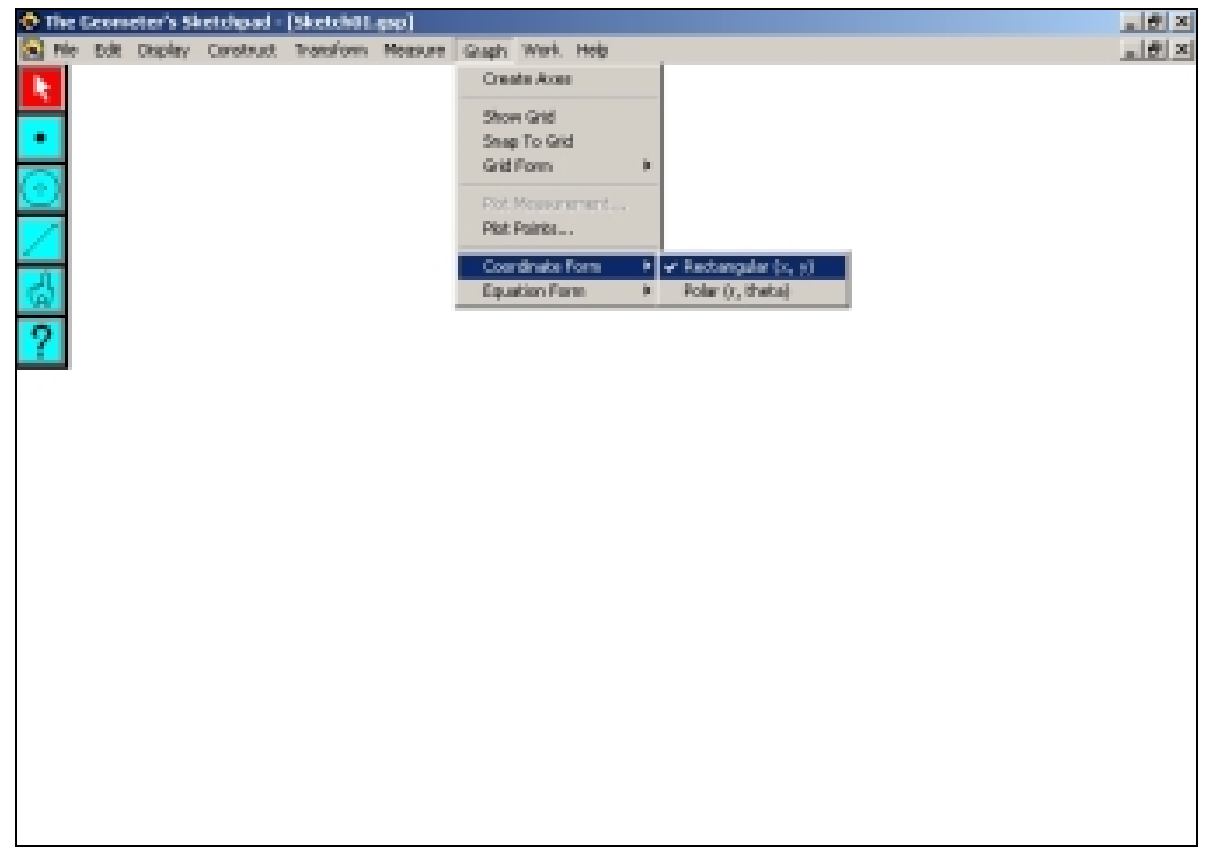

Figura 2.2 - Interfaces dos programas: iGeom e "Geometer's SketchPad"

Pelo fato dos programas de GD serem específicos ao desenho geométrico, isso diminui significativamente a gama de utilidades dos aplicativos e conseqüentemente suas funcionalidades quando comparados com os Sistemas CAD.

A segunda categoria agrega os aplicativos de geometria que não têm o recurso de GD. Como exemplo, temos os seguintes programas: “Geoplan 4 ], “Geospace”, “Wingeom”, etc. Estes também apresentam suas interfaces no padrão "WIMP". A Figura 2.3 mostra como exemplo a interface de um aplicativo que usa o padrão "WIMP" em sua interface.

\footnotetext{
${ }^{4}$ Disponível em http://www2.cnam.fr/creem/GeoplanW/geoplanw.htm
} 


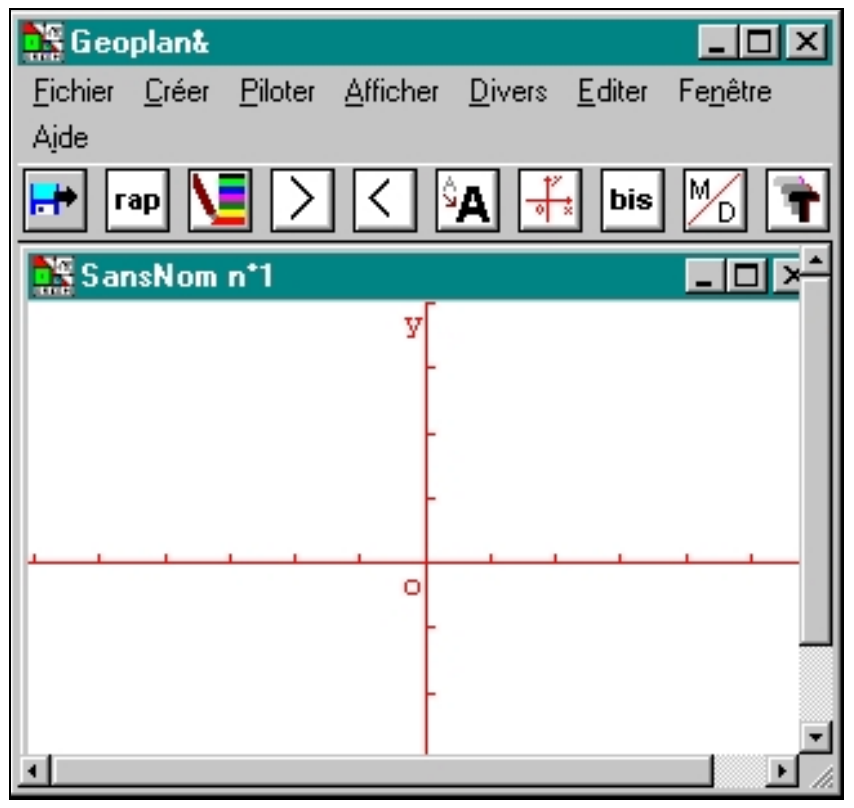

Figura 2.3 - Interface do programa "Geoplan"

É evidente que os programas com interfaces "WIMP", quando utilizados por aprendizes, são comandados por meio dos ícones devido às facilidades já mencionadas; e raramente um iniciante utiliza as linhas de comando ou os menus.

Uma outra desvantagem do padrão "WIMP”, quando utilizada para realizar construções gráficas, é fato do padrão agrupar um conjunto de funções em apenas um "signo" ou comando. Neste caso, os signos atuam indiretamente como tradutor intersemiótico.

\subsubsection{Manipulação Direta}

Além das interfaces que seguem o padrão "WIMP", existem ainda as interfaces de Manipulação Direta (MD) e as interfaces mistas que fundem os dois padrões citados.

Shneiderman (1992), que introduziu o termo "interface de Manipulação Direta", define três princípios fundamentais para que uma interface seja classificada como sendo de MD:

a) representação contínua dos objetos e ações de interesse; 
b) uso de ações físicas ou ativação de teclas ao invés de sintaxe complexa;

c) operações incrementais rápidas e reversíveis, cujo efeito no objeto de interesse é imediatamente visto.

Michels (1995), notou que as interfaces de MD são naturalmente orientadas a objetos e mencionou que os usuários deste modelo de interface raramente precisam, querem ou têm a idéia de fazer coisas de uma maneira notavelmente diferente daquela que é ditada pelo senso comum, porque neste estilo de representação é fácil fazer sentido e as ações fluem com naturalidade. Isso permite aos usuários pensarem em termos da aplicação (neste caso, o desenho) que já é familiar, ao invés de raciocinar sobre conceitos ligados à mídia computador. Sendo estas as características essenciais que são observadas para a MD e relevantes da para as interfaces em estudo neste trabalho.

Hutchins et al. (1986), já mencionavam explicitamente a esperança de que se popularizassem as interfaces de $\mathrm{MD}$ e que as pessoas passassem a despender seu tempo aprendendo as tarefas de seu domínio específico e não aprendendo a utilizar a interface da ferramenta. Esta é uma das metas que se deseja quando se constrói um aplicativo com uma interface de MD com fins educacionais.

As interfaces de MD, segundo (SHNEIDERMAN, 1992) apresentam os seguintes benefícios:

a) usuários iniciantes aprendem as funcionalidades básicas rapidamente;

b) usuários ocasionais podem reter os conceitos operacionais porque a interface é simples de ser memorizada;

c) baixa taxa de erros, com maior prevenção, pois mensagens de erro raramente são necessárias;

d) usuários podem visualizar imediatamente o resultado de suas ações e, sendo negativas, podem imediatamente tentar tratá-las;

e) usuários ficam menos ansiosos já que o sistema é compreensível e suas ações podem ser facilmente revertidas, encorajando a próatividade; 
f) usuários ganham confiança e domínio, porque são eles que iniciam as ações, sentindo-se no controle de todo o sistema que se torna previsível.

Como se vê, o uso de uma interface que apresente os conceitos de Manipulação Direta permite alcançar praticamente todos os objetivos almejados no desenvolvimento do Risko, sem que a essência do projeto seja ferida, desde que adequadamente implementados. Por outro lado, também são relatadas as seguintes desvantagens da MD:

a) requerem mais recursos tecnológicos como, por exemplo: processamento e memória por parte do sistema;

b) não são as mais adequadas para tarefas repetitivas;

c) o usuário é responsável pela exatidão por controlar as ações que requerem alta precisão.

Os problemas "a" e "b" mencionados acima, não têm efeito significativo no desenvolvimento da interface e, por isso, não serão tratados inicialmente, e os testes com usuários poderão comprovar a necessidade ou não de quaisquer alterações do Risko. Quanto ao problema apresentado no item "c", que trata a exatidão, pode ser resolvido com a implementação da ferramenta "snap", que traz o recurso de atrair, como se fosse um imã, uma ferramenta para um ponto/local de interesse, facilitando a precisão no ato do posicionamento.

\subsection{Metáforas de Interfaces Gráficas}

$\mathrm{Na}$ historia da computação, as metáforas que vêm sendo utilizadas evoluíram de acordo com o próprio desenvolvimento do computador. Inicialmente, para comandar o sistema, eram utilizadas as sintaxes textuais onde os dispositivos e as ações do próprio sistema recebiam nomes e correspondiam a cada uma das funcionalidades oferecidas pelo mesmo. Esta conversão textual que gera uma ação efetiva institui uma metáfora caracterizada pela codificação de uma coleção de caracteres em ações, mediada pela interface. Tal modelo de interação é conhecido como linguagem de linhas de comando. Posteriormente às interfaces comandadas por 
linhas de comandos, surgem as interfaces com metáforas que tentam simular o mundo real, para isso, elas utilizam: signos retratando figuras de objetos existentes e conhecidos no mundo real (ícones) e mais os cardápios contendo listas de "itens" comandos que são separados por grupos (menus). Os ícones e os menus se tornaram populares, por facilitarem o uso do sistema para os usuários iniciantes, no entanto os mais experientes e que já dominam o aplicativo preferem as linhas de comando. Existem ainda outras metáforas utilizadas por interfaces computacionais menos populares, porém somente estas duas metáforas estão relacionadas com este estudo.

\subsubsection{Metáforas do Mundo Real}

O uso de uma metáfora extraída do mundo real nada mais é do que a tentativa de reproduzir uma determinada situação já experimentada a ser vivenciada novamente, porém, em uma tela de computador, ou seja, virtualmente. Entretanto, tal codificação metafórica, por mais superficial que seja, não é tão trivial em termos de implementação computacional e para que o diálogo possa ser estabelecido com excelência é necessário ponderar, no mínimo, as linguagens naturais e formais envolvidas.

"O principal problema do diálogo com os computadores reside na diferença entre as linguagens formais, que regem o comportamento das máquinas, e as linguagens naturais utilizadas e compreendidas pelo homem em sua vida quotidiana."

(LÉVY, 1998, p.30, apud DOMINGUES, 2001, p.21)

Para minimizar este problema no uso das metáforas do mundo real, preferencialmente a conversão deve oferecer o reconhecimento imediato de situações que já estão incorporadas na cultura dos usuários. Podemos citar o clássico exemplo que ilustra esta situação que é a metáfora de representação do ambiente de trabalho vivenciado num escritório, esta metáfora é conhecida como "desktop metaphor" (metáfora do tampo de escrivaninha) por disponibiliza objetos de uso comum num escritório: arquivos, pastas, lixeira, etc. A introdução desta metáfora é considerada um marco na historia das interfaces computacionais, pois popularizou as interfaces que simulam ambientes reais e conseqüentemente o computador. No entanto, é 
inválido o esforço empregado para construir uma boa interface, fundamentada em uma metáfora do mundo real, se ela não for destinada a usuários potencialmente aptos a entendê-la. Isto é, se o usuário desconhece, no mundo real, o que está sendo codificado e apresentado no mundo virtual, dificilmente ele entenderá a metáfora que está sendo utilizada e conseqüentemente saberá utilizar o sistema.

Segundo Michels (1995), as interfaces providas com objetos que simulam o mundo real facilitam o reconhecimento das funcionalidades por parte dos seus usuários. No entanto, o uso de uma metáfora do mundo real pode gerar alguns problemas, pois, por melhor que seja a codificação realizada, ainda existirão diferenças relacionadas aos sentidos humanos: tato, visão, audição, etc. O usuário que reconhecer um objeto do mundo real, codificado para o mundo virtual, espera ou imagina que o mesmo objeto virtual apresente as mesmas funcionalidades inerentes ao seu correspondente original encontrado no mundo real. Mas, se no mundo virtual existir qualquer falha funcional fica evidenciado que a representação não foi realizada fielmente, podendo gerar conseqüências negativas.

Comprovadamente o uso das metáforas oriundas do mundo real traz benefícios significativos para os usuários iniciantes, no entanto, para os usuários experientes, algumas tarefas podem ser cansativas ou até mesmo exaustivas.

A opção pelo uso de uma metáfora do mundo real deve ser feita com cautela, e somente ser aplicada em casos onde os usuários e seus objetivos são conhecidos.

\subsubsection{Classificação das Metáforas}

Existem diversas maneiras para se classificar as inúmeras metáforas existentes e que são utilizadas por GUI. Dentre as classificações encontradas a que mais se aproxima do trabalho aqui desenvolvido considera: primeiro as suas funções e segundo as suas atribuições. As metáforas classificadas segundo as suas funções são apresentadas a seguir e estão sub-divididas em três categorias:

- "Organizational metaphors - the metaphor manifests inherent structure that can organize node-and-link information within these metaphor-based spaces." 
- "Functional metaphors - the metaphor is represented through visually recognizable objects that allow direct manipulation."

- "Navigational metaphors - the metaphor allows (inter)actions by the user that lets them move around in the hyperspace."

(VÄ̈̈NÄNEN e SCHMIDT, 1994, p.263)

No desenvolvimento da interface do Risko, somente a metáfora funcional ("functional metaphor") foi utilizada, por tratar da representação visual dos objetos de desenho que controlam as ações da interface por meio da MD. Neste caso, as metáforas funcionais utilizadas estão relacionadas diretamente com a aplicação, ou seja, o ato de desenhar, pois as informações têm suas estruturas relativamente simples e são criadas pelo próprio usuário no momento que ele realiza as construções gráficas. Assim, as metáforas organizacionais ("organizational metaphors") e de navegação ("navigational metaphors") foram descartadas para o modelo de interação em uso.

A classificação proposta por Väänänen e Schmidt (1994) conta ainda com as metáforas de atribuições:

- "Real-world metaphors (e.g. library) vs. non-real-world metaphors (e.g. UFO)."

- "Concrete metaphors (e.g. tree) vs. abstract/conceptual metaphors (e.g. family)."

- "Spatial metaphors (e.g. a house) vs. time-based metaphors (e.g. theatre)."

- "General metaphors (e.g. book) vs. application-dependent metaphors (e.g. train time table)."

- "Flexible and composite metaphors (e.g. desktop with recursive folder structures, or a house with books) vs. rigid metaphors (e.g. room with four walls)."

(VÄ̈̈NÄNEN e SCHMIDT, 1994, p.263)

As metáforas concretas (“concrete metaphors"), trazidas do mundo real, são as mais adequadas para os usuários iniciantes ou casuais, apesar de sua 
inflexibilidade, já que apresentam familiaridade e atratividade para a maioria dos usuários (VÄÄNÄNEN \& SCHMIDT, 1994). Por este fato elas foram utilizadas na interface do Risko e, conseqüentemente as demais metáforas de atribuição foram descartadas.

\subsection{Ferramentas para Interfaces}

Ao especificar uma interface, é necessário conhecer as ferramentas que propiciam as funcionalidades almejadas considerando questões como: metáfora em uso, linguagem de programação que será utilizada, mídia, perfil de usuários, etc. bem como a finalidade a que se destina o produto em desenvolvimento. No caso da interface do Risko, três ferramentas poderiam ser utilizadas: ferramentas locais, ferramentas poderosas e ferramentas compostas, para propiciar o resultado que é almejado com o aplicativo em desenvolvimento.

As ferramentas locais ("local tools"), depois de serem ativadas e utilizadas podem ser deixadas em qualquer lugar da área de trabalho tendo seu estado preservado (BEDERSON et al., 1996). Elas possibilitam executar diretamente as ações desejadas de maneira simplificada, suprimindo os longos caminhos geralmente percorridos pelos usuários de menus. Por exemplo, para encontrar uma determinada funcionalidade em uma interface contendo menus, primeiro é necessário identificar o grupo que representa tal função e, em seguida, selecionar a ferramenta desejada, o que normalmente provoca a mudança visual do apontador. Somente então é possível selecionar um dos vários atributos oferecidos pela ferramenta ativada. Este modelo de interação é comumente encontrado em ferramentas de aplicativos voltados para desenho, e que devem ser configuradas, uma a uma, para compor as atribuições desejadas. Para ilustrar o modelo citado de configuração de uma ferramenta, tomemos o modo "traçar linha" que é disponibilizado pela maioria dos aplicativos de desenho e que substituem o lápis ou a caneta. Nestes casos, geralmente é possível configurar: a cor, a espessura e o tipo do traço a ser feito, antes ou depois do desenho pretendido (configuração de "propriedades"). No caso das ferramentas locais, estas "propriedades" para serem configuradas de uma só vez, com a vantagem de serem preservadas para a reutilização caso a ferramenta permaneça na área de trabalho. 
Segundo Bederson et al. (1996), o recurso das ferramentas locais de Manipulação Direta reduz significativamente a carga cognitiva para os novos usuários, conforme mostram os estudos realizados por eles com crianças e jovens (com idade entre 4 e 13 anos). O referido estudo comparou o uso das ferramentas locais com interfaces que apresentam ferramentas no modelo de "tool palettes" e conclui que as interfaces de MD, ou seja, com ferramentas locais são mais intuitivas do que as interfaces com ferramentas que trazem funções similares seguindo o padrão “WIMP”. Este conceito de ferramenta local é central para a interface do Risko.

Outro recurso a ser utilizado em uma interface gráfica são as ferramentas poderosas ("power tools"). Estas ferramentas podem ser vistas nos trabalhos desenvolvidos por Daughtry e Amant (2003) e foram criadas usando como referência uma metáfora trazida do mundo real, no entanto elas só existem no mundo virtual e são encontradas principalmente nas interfaces de $\mathrm{MD}$. O fato de o programa Risko ser destinado ao treinamento bem como à demonstração de uso dos instrumentos reais de desenho, exclui a possibilidade do emprego das "power-tools" para não comprometer o realismo dos instrumentos a serem implementados e das etapas intermediárias necessárias para as contorções gráficas pretendidas.

O terceiro recurso refere-se às ferramentas compostas ("composite tools"), que são obtidas por meio do comportamento associativo entre duas ou mais ferramentas. As ferramentas de composição foram substituídas na interface do Risko pela interação simples entre os diversos instrumentos de desenho. Como exemplos, ao usar o lápis é necessário apoiá-lo em um dos bordos do esquadro a fim de executar uma reta com alta precisão, em outro caso os esquadros podem ser usados combinadamente, deslizando um encostado no outro a fim obter os posicionamentos desejados. Estes dois casos mostram o uso de ferramentas individuais que dependem umas das outra para resultar em uma ação efetiva, ou seja, o resultado final depende da composição de uso conjunto de mais de uma ferramenta. Assim a ideai das ferramentas compostas é utilizada porem a filosofia de representação dos objetos de desenho é mantida a risca na interface do Risko 


\subsection{Programas Similares}

Uma pesquisa objetivando encontrar programas de desenho, similares ao Risko, contendo interfaces puramente de Manipulação Direta composta por instrumentos de desenho foi realizada e de onde se constatou que, apenas um aplicativo chamado de "HabilisDraw" apresenta algumas características próximas as do projeto em desenvolvimento. O "HabilisDraw" foi desenvolvido pela equipe do Professor Robert St. Amant (AMANT, 2002; AMANT e HORTON, 2002a; AMANT e HORTON, 2002b; DAUGHTRY e AMANT, 2003) e é destinado a crianças e jovens que desejam realizar simples desenhos, sem qualquer compromisso com a precisão das construções realizadas. O "HabilisDraw" nos chama a atenção por oferecer em sua interface alguns instrumentos que lembram os instrumentos de desenho encontrados no mundo real, como por exemplo: canetas, percevejos, réguas, compasso, etc., mostrados na Figura 2.4. Mas, diferentemente da metáfora perseguida pela interface do Risko, os instrumentos que compõem a interface do "HabilisDraw" não tentam simular ou sequer imitar com rigor os seus similares oriundos do mundo real.
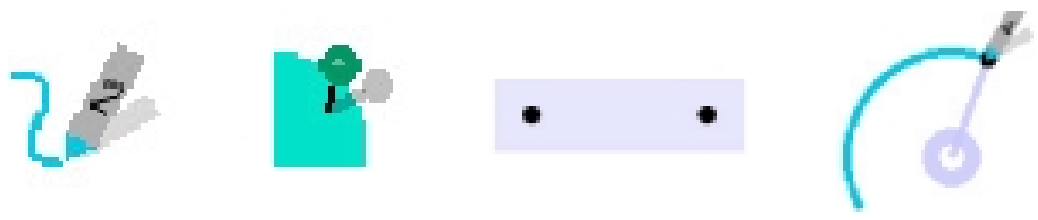

Figura 2.4 - Algumas ferramentas apresentadas pelo "HabilisDraw"

$\mathrm{Na}$ interface do "HabilisDraw" os instrumentos que desenham, jogo de canetas e o compasso, podem ser utilizados individualmente e os demais instrumentos existentes: régua, percevejos, etc., devem ser utilizados combinados ("composite-tools"), geralmente para auxiliar os instrumentos de desenho. A Figura 2.5 mostra o uso combinado entre os instrumentos do "HabilisDraw", onde uma régua foi fixada com a ajuda de dois percevejos (pontos pretos), e um traçado circular é realizado, quando o arco em construção encontra o bordo da régua (fixada), a trajetória do lápis é desviada e sua ponta desliza paralelamente ao bordo da régua 
gerando uma reta. Ao desencostar a ponta do compasso do bordo da régua, o arco retorna à sua trajetória circular natural que é regida pelo raio que foi estabelecido.

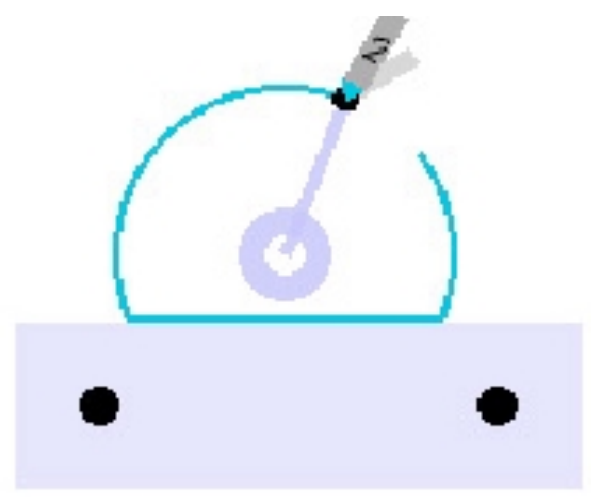

Figura 2.5 - Uso combinado das ferramentas para criar formas compostas

Diferentemente do Risko, o "HabilisDraw” é destinado aos usuários que simplesmente querem desenhar com auxílio do computador "como se fosse uma brincadeira de desenhar". No caso do Risko, ele foi desenvolvido estritamente para fins educacionais, ou seja, auxiliar o ensino de Geometria Gráfica e possibilitar o treinamento de uso dos instrumentos de desenho, onde as construções feitas são fundamentadas numa teoria, portanto devem ser criadas com alta precisão.

\subsection{Métodos de Especificação de GUI}

Idealmente, antes de se construir uma interface computacional que traga muitas funcionalidades e comandos, é essencial conceber uma descrição formal para guiar a equipe de programadores que cuidam da implementação. E para isso, existem várias técnicas de descrever a interface almejada, dentre elas, as mais utilizadas são as chamadas linguagens formais. As linguagens formais são definidas como cadeias ou coleções de cadeias compostas por símbolos de um alfabeto podendo ser, por exemplo, 0 e 1. Menezes (1998) enuncia que as linguagens formais surgem a partir de um conjunto finito $\sum$, chamado de alfabeto e o conjunto $\sum^{*}$, conjunto de todas as cadeias que podem ser formadas a partir dos elementos do $\sum$. Qualquer subconjunto do $\sum^{*}$ é chamado de linguagem formal. 
Idealizar uma interface computacional pode não ser uma tarefa tão simples quanto parece, isso se considerarmos que ela também será implementada pelo seu próprio criador. Ocorre que em muitos casos este trabalho é realizado em equipe, e nem sempre o criador é quem implementa, neste caso uma boa descrição formal da interface é fundamental para guiar os demais. Nela, as informações devem ser precisas, consistentes e sem ambigüidades a fim de facilitar o entendimento e a implementação do modelo por todos os componentes da equipe. Comprovadamente, o uso de uma linguagem formal para descrever as funcionalidades e as ações de uma interface diminui significativamente o esforço de todos que estão envolvidos no projeto, e principalmente dos programadores.

Existem várias técnicas para se descrever formalmente as interações entre os usuários e as tarefas oferecidas por uma interface. Dentre elas, as mais utilizadas são:

a) TAG ("Task-Action Grammar") (PAYNE e GREEN, 1989): trata diretamente a consistência nos níveis: léxico, sintático e semântico. Neste modelo, as ações são especificadas a partir das tarefas reconhecidas e que são representadas de forma categorizada em uma regra de produção;

b) GOMS ("Goals, Operators, Methods, and Selection Rules") (CARD et al., 1983): a linguagem é baseada na interação do usuário com o computador, podendo ser subdividida em três modelos de interação: o perceptivo, que trata a visão e a audição; o motor, que trata o movimento dos membros (braços, mãos, dedos e da cabeça incluindo os olhos); e o cognitivo, que trata do acesso à memória e as decisões tomadas. Estes comportamentos são definidos como:

- Metas ("goals"), descrita em uma hierarquia de sub-metas;

- Operadores ( “operators”), ações perceptivas, movimentação motora ou cognição que o usuário utiliza para concluir a tarefa desejada;

- Métodos ( "methods"), seqüência de ações ou comandos que o usuário escolhe para concluir uma tarefa ou atingir uma meta; 
- Regras de seleção ("selection rules"), ocasiões em que existem vários métodos para execução de uma mesma tarefa ou meta e surgem expressões como "condição ou ação" para auxiliar a decisão a ser tomada por um dos métodos.

c) Modelo “Keystroke-Level” (CARD et al., 1983): é similar ao modelo GOMS, mas atua em um nível mais baixo, tratando somente as atividades motoras. $\mathrm{O}$ método tenta prever o tempo necessário para executar as ações motoras: digitar, clicar num botão, posicionar o apontador, movimentar a mão até um dispositivo, realizar operações mentais e esperar por uma resposta do sistema. Os tempos para executar as tarefas são calculados sobre métodos e seqüências de operadores.

d) UAN ("User Action Notation") (HARTSON et al., 1990) e (HIX \& HARTSON, 1993): esta notação é a mais indicada para interfaces de manipulação direta, que é o caso da interface do Risko. Pois, a linguagem trata diretamente da interação do usuário com o sistema, ou seja, ela aponta quais tarefas e ações o usuário pode realizar, associando as ações realizadas ao "feedback" do sistema. Neste caso, a prioridade é sempre o ponto de vista do usuário.

Após serem avaliadas as vantagens e desvantagens de cada uma das linguagens citadas, a que mais se mostrou adequada as necessidades impostas ao trabalho em desenvolvimento, é a linguagem formal UAN. Porém, ela não será utilizada, pois, seria necessário criar e incorporar um grande número de novos símbolos para complementá-la a fim de atender às necessidades específicas e as ações que compõem a interface do Risko.

O fato de a equipe envolvida no projeto ser pequena, sendo composta por três membros, facilita a comunicação entre as partes para esclarecer quaisquer dúvidas no decorrer do trabalho o que dispensou a etapa de descrição formal da interface. No entanto, esta fase foi substituída por uma descrição textual que é mostrada no próximo capítulo. 


\subsection{Conclusão do Capítulo}

Neste capítulo foi apresentada a primeira parte da revisão bibliográfica que trata dos principais conceitos e aspectos sobre: usabilidade, estilos de interação, metáforas de interfaces gráficas, ferramentas para interfaces, programas similares analisados e métodos de especificação de GUI. Assuntos estes que subsidiam as informações necessárias para as fases subseqüentes do desenvolvimento do trabalho de avaliação.

Conforme a necessidade de novas informações para o bom andamento do estudo, outras revisões foram realizadas. 


\section{CAPÍTULO 3}

\section{DESCRIÇÃO FUNCIONAL DAS INTERFACES}

"Se atalho fosse bom, não existiriam as estradas"

Provérbio mineiro

Neste capítulo são apresentadas as funcionalidades oferecidas pelas interfaces dos programas que fazem parte do estudo comparativo proposto. Os aplicativos em questão são: $i$ Geom5 2.4 .5 versão "stand-alone” de 17 de junho de 2003 e que também disponibiliza gratuitamente na Internet uma versão “applet” com a mesma interface (BRANDÃO e ISOTANI, 2003) e Risko 0.8 versão “stand-alone” de 28 de março de 2005.

\subsection{Descrição da Interface do $i$ Geom}

A interface do $i$ Geom, conforme foi apresentada no item 2.2.1 do capítulo anterior, segue rigorosamente o padrão "WIMP" e ela será descrita neste capítulo. Para facilitar o entendimento das funcionalidades do aplicativo, os elementos que compõem a sua interface foram separados em 4 partes: menu textual, icones (primários e secundários), caixa de mensagem e área de trabalho, e que serão apresentadas a seguir.

\footnotetext{
${ }^{5} \mathrm{http}: / /$ www.matematica.br/igeom.
} 


\subsubsection{Menu Textual}

O menu textual é visualizado na parte superior da tela e traz 5 grupos de comandos que seguem o modelo "pull-down”: Arquivo, Editar, "Script”, Botões "script" e Ajuda. O primeiro grupo, Arquivo, é composto pelos comandos responsáveis pelo controle do sistema: abrir arquivo, abrir arquivo preservando desenho, gravar, gravar como, gerar "applet" e sair. O segundo grupo, Editar, permite editar as propriedades das construções gráficas ou configurar algumas das funções padronizadas pelo aplicativo: esconder, mostrar, reamostrar, limpar tracejados, limpar objetos, medir distância, medir arco, rotular, "grid" e eixos. A maior parte destes comandos também está disponível na forma de ícones. O terceiro grupo, "Script", inclui os comandos auxiliares para o uso da própria função "script" oferecendo as seguintes opções funcionais: executar, começar, finalizar, recorrência e executar passo a passo. O grupo, Botões "script" apresenta dois comandos: adicionar "script" e remover "script", que auxiliam a inserção ou a exclusão dos próprios "scripts". O último grupo, Ajuda, apresenta as seguintes opções: sobre e objetos com informações a respeito do aplicativo e das figuras geradas. Sendo estas as funções do menu trazido pelo $i \mathrm{Geom}$.

\subsection{2 Ícones Primários e Secundários}

$\mathrm{Na}$ interface do aplicativo existem duas barras com os ícones ou signos que acionam as funções, barras estas que estão alocadas logo abaixo do menu textual. A primeira barra apresenta os ícones primários, assim chamados por agrupar as categorias ou grupos funcionais do aplicativo. Por meio dos ícones primários as barras secundárias são ativadas trazendo os respectivos ícones, específicos, para então acionar cada uma das funções do programa. Sistema análogo ao utilizado pelos menus “pull-down”, porem, no lugar de textos são vistas as figuras (ícones).

Na primeira coluna da Tabela 3.1 são apresentados os 11 ícones primários, que permitem acessar os ícones secundários mostrados na segunda coluna da mesma tabela. Associada a cada um dos ícones está a descrição funcional que constitui a terceira coluna da Tabela 3.1. 
Tabela 3.1 - Ícones primários e secundários do $i \mathrm{Geom}$

(Extraído e adaptado de http://www.matematica.br/igeom, 2003)

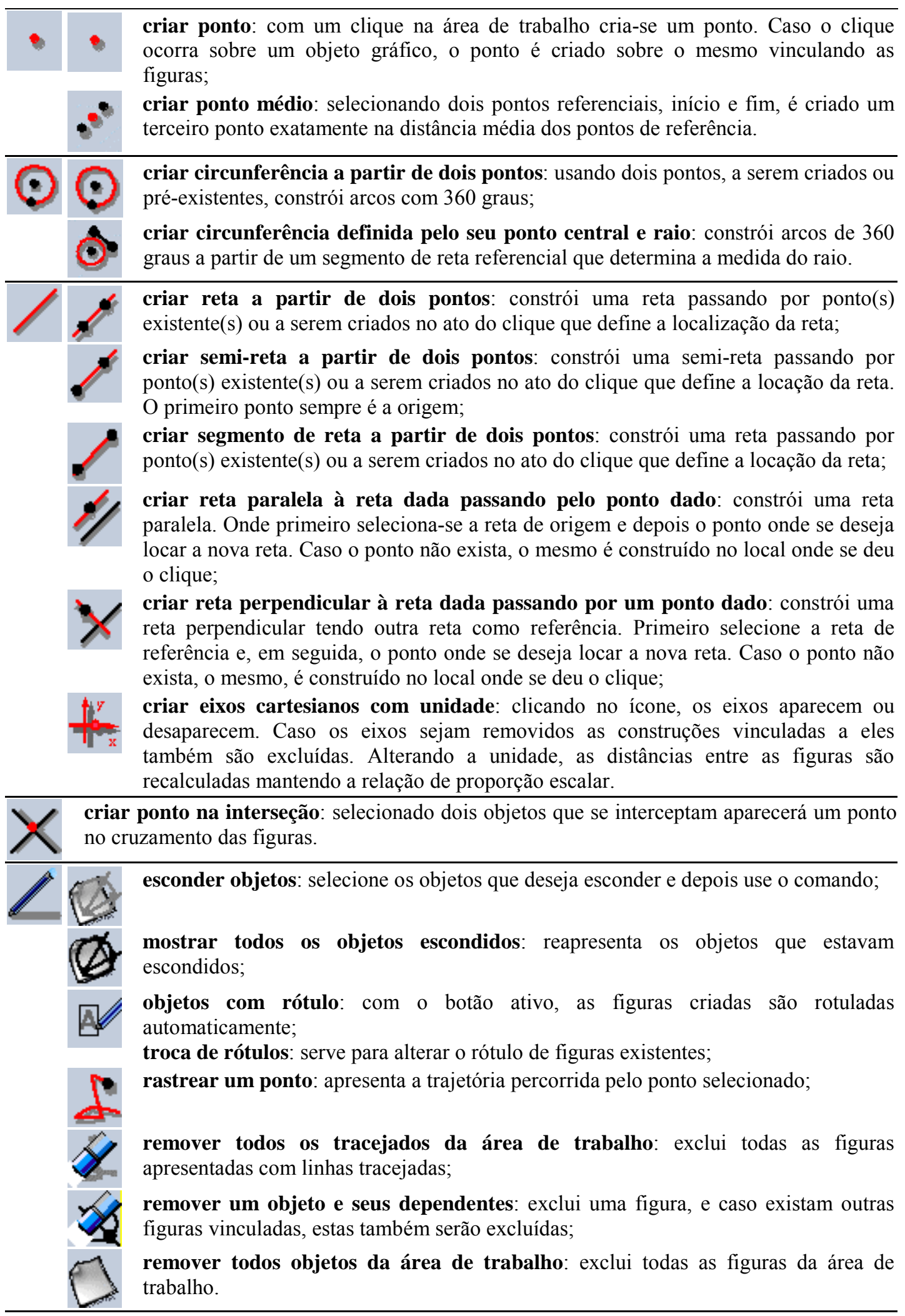


marcar ou desmarcar objetos: permite marcar ou desmarcar uma ou mais figuras alterando a cor padrão azul, passando para a cor amarela. Permite marcar várias figuras criando janelas de seleção;

arrastar objetos: selecionando uma figura e movendo o cursor na área de trabalho, a mesma percorre a trajetória do cursor. Um segundo clique solta a figura do cursor.

$2 \lambda$ abrir calculadora: aciona uma calculadora auxiliar;

2. medir distância entre dois pontos: mostra a distância entre dois pontos de referência

- após serem selecionados;

6. medir arco determinado por dois pontos de uma circunferência: mostra a distância entre dois pontos de referência de um arco. Após selecionar os dois pontos selecione também o próprio arco.

transladar objetos: selecione dois pontos de referência para definir a direção de translação e depois as figuras que deseja transladar;

refletir objetos: selecionada uma reta como referência para espelhar objetos, em seguida são marcadas as figuras a serem refletidas;

rotacionar objetos: selecione o arco ou o ângulo de rotação e, na seqüência, o centro de rotação. Então selecione as figuras que deseja rotacionar.

iniciar ou enviar anotação do "script": o primeiro clique abre a janela para o inicio da gravação contendo os passos das construções. $\mathrm{O}$ segundo clique salva o que foi feito. Esta função está disponível somente para a versão "stand-alone". No caso da versão "applet" o "script" é salvo no servidor;

anotar recorrência, durante a gravação de um "script": selecione os objetos e depois ative o comando;

anotar resposta: selecione os objetos que deseja destacar e depois ative o comando;

comentário em "script": grava as ações passo a passo num "script". Para isso, basta digitar o texto e selecionar um ponto durante a aplicação do "script" para que a caixa de texto contendo os comentários inseridos apareça posteriormente;

E. cancelar anotação do "script": cancela o arquivo gravado ou enviado para o servidor contendo o "script".

\subsubsection{Caixa de Mensagens}

$\mathrm{Na}$ parte inferior da interface (rodapé), é disponibilizada uma caixa de mensagens onde é apresentado o texto explicativo referente ao comando em uso corrente. Nesta caixa são apresentados somente os textos dos comandos acionados via ícone. Adicionalmente a interface do aplicativo traz o mesmo texto que é apresentado na caixa de mensagem nas "tooltips 6 ".

\footnotetext{
${ }^{6}$ Tarjas, geralmente na cor amarela, que surgem quando o apontador está posicionado sobre um objeto gráfico qualquer, contendo textos informativos a respeito da funcionalidade do mesmo.
} 


\subsection{4 Área de Trabalho}

A região central, área na cor branca, é destinada à realização das construções gráficas, é por isso é chamada de área de trabalho. A área de trabalho tem seu tamanho limitado pelos bordos da janela do aplicativo.

Estas são as 4 partes que compõem a interface do $i \mathrm{Geom}$, acionadas somente pelo mouse.

\subsection{Descrição da Interface do Risko}

"Uma boa interface gráfica não é fruto do acaso, só podendo ser obtida com um trabalho consistente que tenha como objetivo conhecer o usuário final, suas expectativas, sua experiência no uso de programas e a maneira pela qual realiza suas tarefas.",

(ARGOLLO et al., 1997, p. 10)

\subsection{1 “Affordances” dos Instrumentos Reais de Desenho}

Tanto o perfil dos usuários como as suas necessidades são conhecidas, e as metas a serem alcançadas já estão estipuladas. Entretanto, é necessário definir as peculiaridades, neste caso, as ações oferecidas pelos instrumentos reais de desenho que serão apresentados virtualmente na interface. Tais ações são definidas como:

"Affordances are the possibilities that an object or environment offers (or appears to offer) in order to perform an action upon it."

(DÜRSTELER, 2002)

Para o caso deste trabalho, foi realizado um levantamento das "affordances", que consistiu em identificar as características naturais de uso, oferecidas pelos instrumentos de desenho ao serem utilizados ou manipulados no mundo real.

O estudo realizado considerou o uso e as funções oferecidas pelos instrumentos de desenho quando manipulados individualmente e combinados entre si. A Tabela 3.2 lista as ações mapeadas, separadas para cada instrumento analisado nas duas situações descritas. 
Tabela 3.2 - Ações dos instrumentos reais ( "affordances")

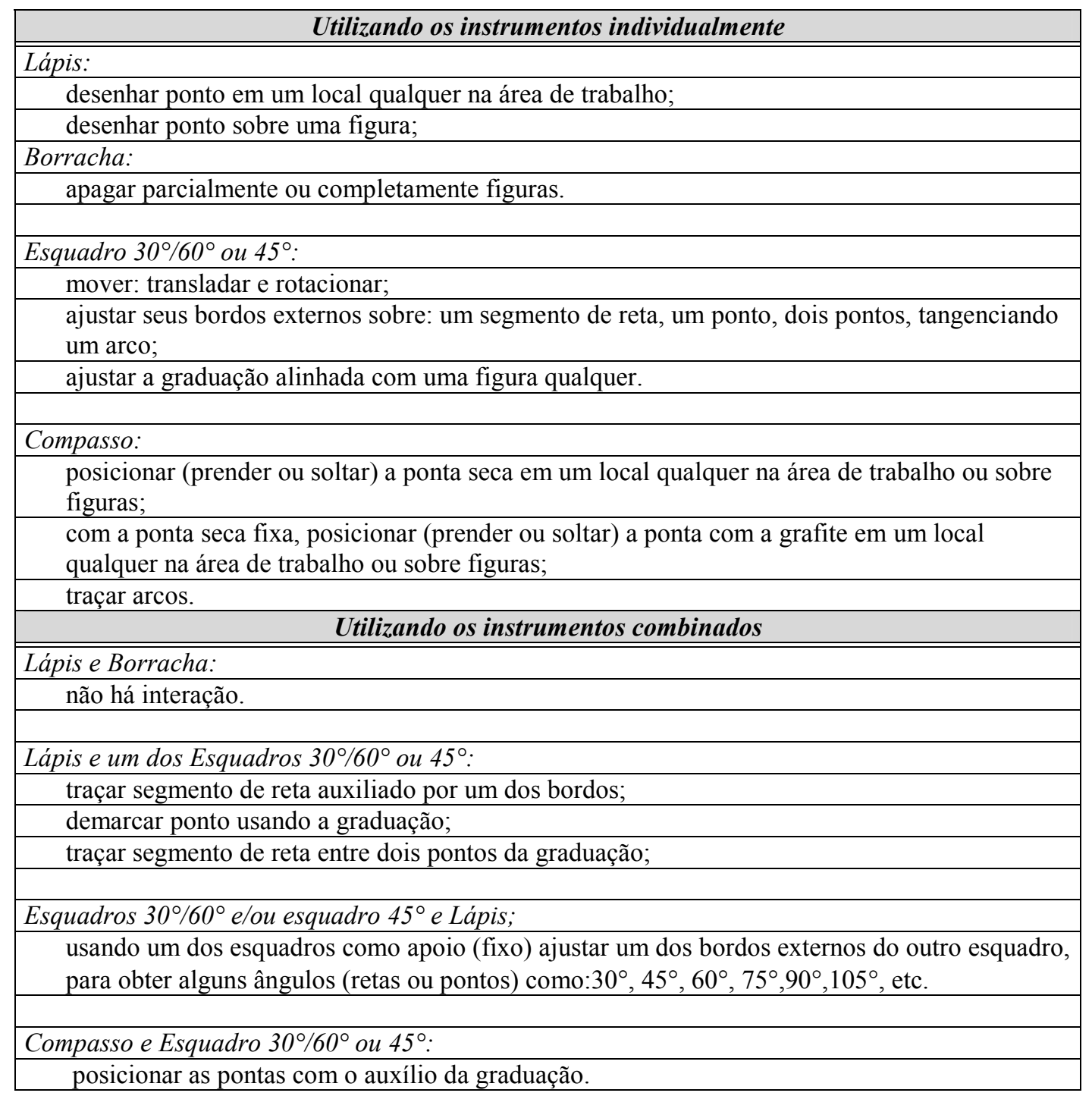

$\mathrm{Na}$ lista apresentada são expostas somente as funções relevantes para as construções geométricas. Entretanto, deve-se mencionar que os mesmos instrumentos, quando utilizados no mundo real, permitem várias outras ações consideradas "incomuns" como, por exemplo, é possível equilibrar um lápis apoiando o seu fundo perpendicularmente a um plano horizontal, com um lápis é possível escrever sobre outros instrumentos (borracha ou esquadros), facilmente se coloca um esquadro sobreposto ao outro ou até mesmo sobre a borracha e vice e versa, com a ponta seca do compasso é possível perfurar a borracha ou arranhar os esquadros, etc. Estas são algumas das ações "incomuns" possíveis de serem realizadas no mundo real, porém não têm qualquer utilidade no que diz respeito ao 
uso correto dos instrumentos de desenho ou para aquilo que eles se destinam, portanto tais "affordances" não nos interessam. Por isso, as ações consideradas “incomuns”, não são mencionadas na Tabela 3.2.

Por mais que metáfora de representação do mundo real seja buscada na construção de uma GUI, neste caso replicar as "affordances" dos instrumentos de desenho, um aplicativo educacional não deve permitir que os aprendizes executem ações sem benefícios didáticos. Portanto, ao converter os instrumentos reais em instrumentos virtuais, deve-se prever e impedir as ações inadequadas referentes ao uso dos instrumentos.

De posse das "affordances", o passo seguinte, para o desenvolvimento do Risko, foi a concepção de um projeto referencial para a implementação do modelo pretendido. Tal descrição visa facilitar o trabalho do membro da nossa equipe encarregado pela implementação do aplicativo.

Recomenda-se, para o bom desenvolvimento de um "software”, a realização de uma prototipação do modelo antes da sua efetiva implementação, no entanto, esta fase não foi realizada devido ao curto prazo para a construção e realização dos testes pretendidos com o aplicativo. A opção encontrada para sanar esta etapa foi realizar uma simulação em papel de algumas das funcionalidades inerentes aos instrumentos apresentados pela interface, lápis/borracha, compasso, esquadros.

O aplicativo desenvolvido por nossa equipo foi batizado, pelo orientador deste trabalho, com o nome de Risko - ("a Realistic Interface for Simulating a Kit of objects"). A Figura 3.1 mostra a interface do aplicativo e os instrumentos de desenho sobre a área de trabalho para o uso. 


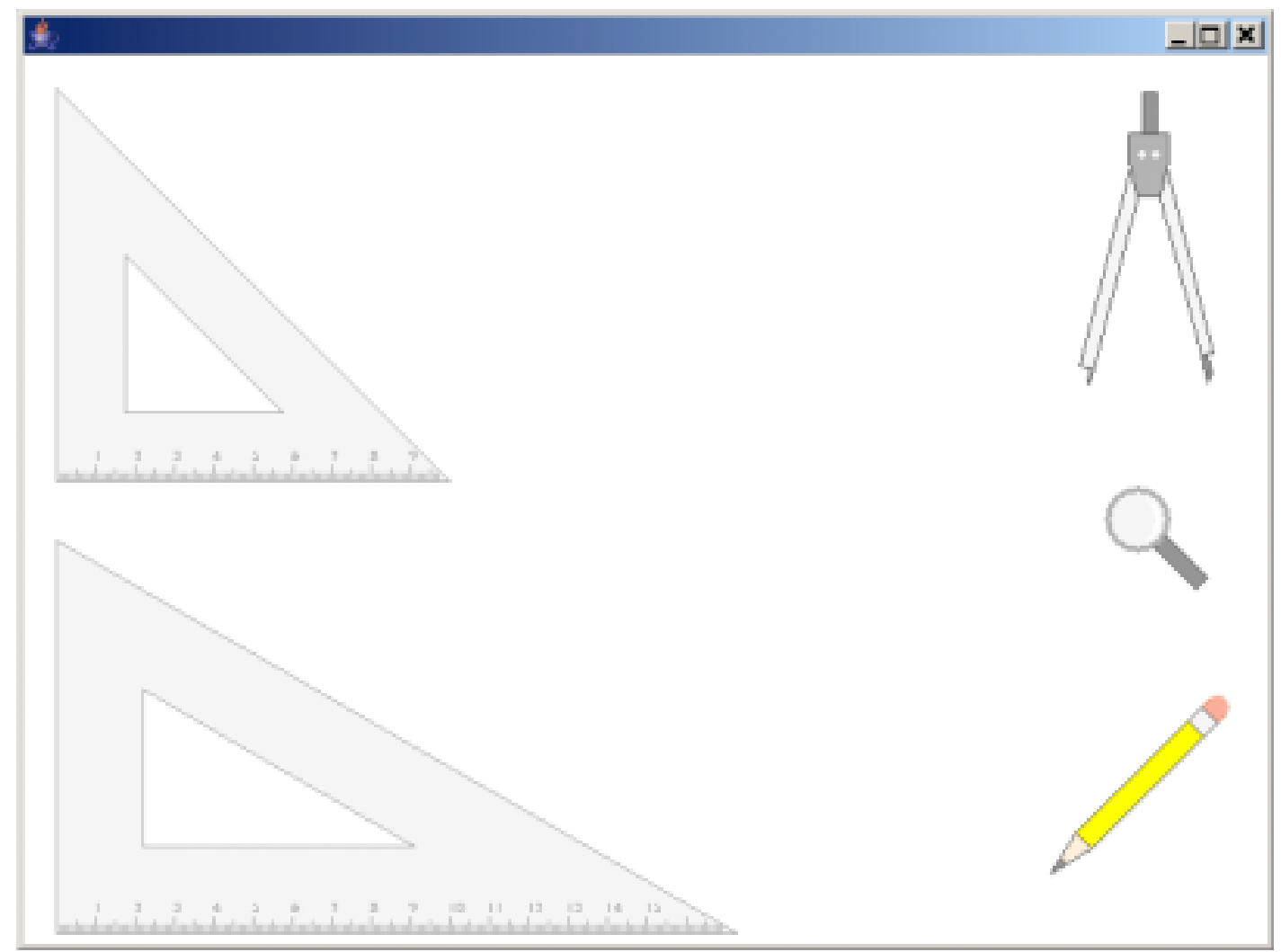

Figura 3.1 - Interface do Risko

A seguir são apresentadas as funcionalidades de cada um dos componentes da interface do programa.

\subsubsection{Apontador}

As funcionalidades oferecidas pela interface são acionadas somente com um botão do mouse (o esquerdo, caso tenha mais que um). O apontador é o mecanismo que referencia, no monitor, a posição do que está ativo e muda sua forma visual conforme a ação requerida:

a) o modo padrão “default”: nele o apontador é visualizado como uma pequena mão, como mostra a Figura 3.2a, indicando que não há instrumento ativo.

b) o modo "pan": quando o apontador se encontra no modo padrão, e está sobre a área de trabalho com o botão esquerdo pressionado, a função "pan" é ativada e o apontador assume a forma de uma cruz 
com setas nas pontas como mostra a Figura 3.2b. Esta função permite mover a área de trabalho em qualquer direção;

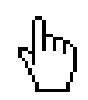

Figura 3.2a - Apontador no modo padrão "default"
Figura $3.2 \mathrm{~b}$ - Apontador no modo "pan"

c) o "snap": esta função é ativada quando um instrumento se aproxima de qualquer objeto gráfico desenhado na tela. Automaticamente, este se destaca visualmente, passando da cor padrão "cinza" para a cor "verde", indicando que será ativado o "snap". Caso o usuário solte o botão do mouse, faz com que o instrumento seja atraído para o objeto de interesse. A propriedade denominada "snap" serve para facilitar a interação com alta precisão e, como regra, apenas um objeto se destaca por vez - aquele que estiver mais próximo do instrumento em uso naquele instante. O "snap" é implementado para os bordos dos esquadros, pontas do compasso (seca e da grafite) e ponta com grafite do lápis.

\subsubsection{Lápis/Borracha}

O instrumento é dividido em três regiões que ativam suas funcionalidades: 1ponta com a grafite, 2- ponta com a borracha e 3-corpo (região na cor amarela) como é apresentado na Figura 3.3. 


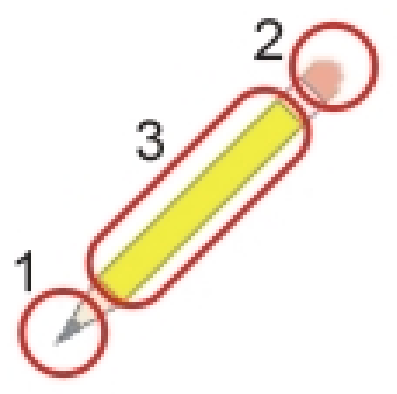

Figura 3.3 - Lápis/Borracha

O lápis deve ser arrastado pela região central (região 3 na figura 3.3) e movido até o local desejado para desenhar ou apagar. Para ativar qualquer uma das funções, é necessário clicar com o botão do mouse, mantendo-o pressionado sobre o instrumento na região próxima à extremidade que se deseja acionar. Estas regiões são chamadas de "hot-areas" conforme foi apresentado na Figura 3.3.

Com o lápis ativo são possíveis as seguintes ações:

a) marcar ponto: basta um simples clique com a ponta do instrumento na área de trabalho que é criado um ponto representado pelo símbolo:

b) traçar retas: com a ponta do lápis encostada em qualquer um dos bordos dos esquadros é possível traçar segmentos de retas. Para isso, é necessário arrastar o lápis paralelamente ao esquadro mantendo o botão esquerdo do mouse pressionado. Os traços feitos com o auxílio do esquadro são vistos na cor cinza indicando a precisão;

c) desenhar a mão livre: é possível desenhar à mão livre, no entanto, o traçado é visto na cor azul indicando que não há precisão.

Obs: quando a ponta do lápis é ativada e levada até o encontro do bordo do esquadro, o vínculo é mantido em função do "snap", isso restringe o seu movimento e facilita o desenho. Para encerrar o traçado o botão do mouse deve ser solto.

A borracha se encontra na ponta oposta à grafite, e é ativada da mesma maneira que esta, ou seja, com um clique na sua respectiva "hot-area", região 2 da Figura 3.3. Para apagar qualquer objeto gráfico, basta colocar a extremidade da borracha sobre o que se deseja excluir, fazendo movimentos de "vai e vem" com o 
botão do mouse acionado. Opcionalmente, pode-se apagar um objeto gráfico por completo com apenas um clique no mouse; neste caso, a borracha deverá ser colocada sobre o mesmo. Apesar deste comportamento de exclusão imediata não retratar o mundo real, ela foi implementada porque facilita o uso do aplicativo sem afetar a filosofia do projeto ou violar qualquer das "affordances" do mundo real.

Entre a borracha (cor marrom) e o corpo do lápis (cor amarelo) existe uma região retangular, na cor branca, que permite girar o lápis em torno da sua ponta. Tal função serve para ajustar o ângulo de inclinação do instrumento ou retirá-lo de cima de qualquer objeto. Apesar de não explícita, esta função é apenas de cunho prático, não sendo essencial para a operação completa do instrumento.

\subsubsection{Compasso}

O compasso é subdividido em quatro partes: 1- braço com ponta seca, 2braço com grafite na ponta, 3- junção dos braços e 4- ponta com a grafite, como mostra a Figura 3.4.

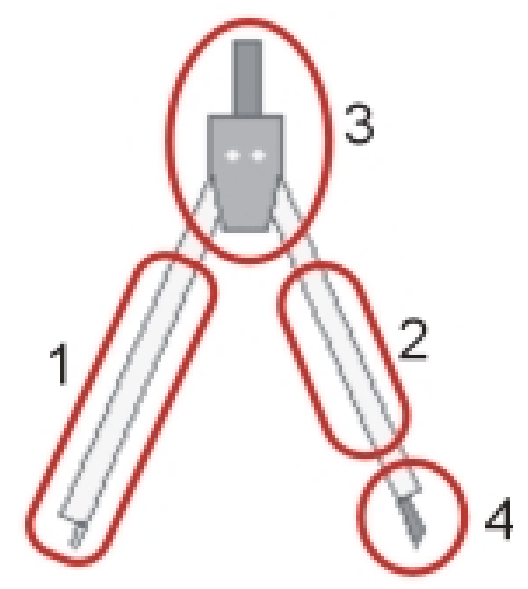

Figura 3.4 - Compasso e suas partes a serem configuradas

Cada uma das quatro partes do compasso possui uma função específica que deve ser ajustada antes do uso efetivo do instrumento. Para isso, existem as "hotareas" sensíveis que permitem ativar separadamente cada uma das quatro funções a serem configuradas: 
1. braço com a ponta seca: o compasso é transladado para qualquer local da área de trabalho. A ponta seca é fixada no momento em que o botão do mouse é solto determinando o centro do arco;

2. braço com grafite na ponta: ao arrastar o compasso por esta região, a ponta seca permanece imóvel enquanto o outro braço se move para determinar o raio de abertura do compasso e no momento em que o botão do mouse é solto a abertura é determinada.

Obs: para desenhar grandes arcos, o braço com a grafite pode ser prolongado sem limitação do seu comprimento.

3. junção ou manopla: é onde se encontram os braços do compasso. Ao manipular o instrumento por essa região, a ponta seca e o ângulo de abertura permanecem fixos. Como isso é possível determinar onde se inicia o arco;

4. ponta com a grafite: o braço com a grafite na ponta possui uma segunda região que se encontra mais próxima à extremidade, como mostra a Figura 3.4 referente à área 4 . Esta região é destinada a execução do traçado do arco, que ocorre enquanto o botão do mouse estiver pressionado.

\subsubsection{Esquadros}

Os dois esquadros são idênticos quanto às suas funcionalidades, a diferença está relacionada ao tamanho e ângulos internos. Os esquadros se movimentam como se possuíssem massa, simulando algumas das leis da física clássica que regem o movimento de corpos no plano. Isso impede que um esquadro passe, empurre ou se sobreponha ao outro. Arrastando-se um esquadro, é possível posicioná-lo em qualquer local da área de trabalho com movimentos de translação ou rotação.

a) vínculos: ao aproximar o esquadro de qualquer ponto (figura), a função “highlight兯' é ativada automaticamente, alterando a cor do ponto, que passa da cor cinza para a cor verde. Esta função facilita o

\footnotetext{
${ }^{7}$ Função que altera a cor de um objeto com o intuito de chamar a atenção.
} 
posicionamento do bordo do esquadro sobre o ponto em destaque. Se o instrumento é solto (liberação do botão do mouse) no instante em que o ponto está na cor verde, um vínculo é estabelecido e o ponto passa para a cor vermelha ("snap"). Existem dois tipos de vínculos:

i vínculo simples: ocorre quando o esquadro está vinculado a apenas um ponto. Neste caso, alguns dos seus movimentos são restringidos, fazendo com que seu bordo sempre mantenha contato com o ponto de vínculo. Para desfazer o vínculo, é necessário afastar o esquadro do ponto vinculado até que o bordo saia da região determinada pelo "snap";

ii vínculo duplo: ocorre somente após a criação do vínculo simples. O procedimento para criar o segundo vínculo é análogo ao usado para criar o vínculo simples, não sendo possível criar o vínculo duplo diretamente. Estabelecido o vínculo duplo não é mais possível rotacionar o esquadro, e o seu movimento fica restrito somente à translação no sentido da reta imaginária que existe entre os pontos aos quais ele está vinculado. Para desfazer o vínculo duplo é necessário afastar o instrumento da região do "snap", procedimento análogo ao usado para desfazer o vínculo simples, como mostra a Figura 3.5 .

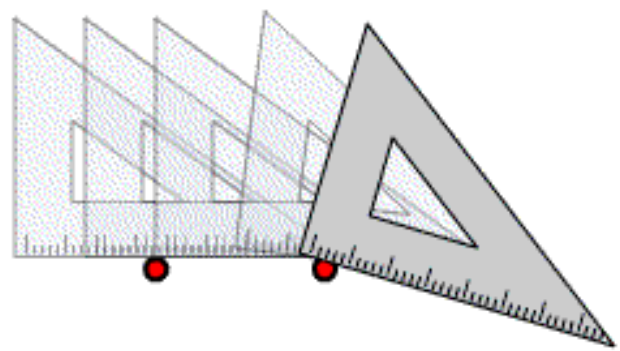

Figura 3.5 - Vínculos para os esquadros. Fonte: (SANTOS et al., 2005)

Obs: em um dos bordos de cada esquadro existe uma graduação que se destaca quando os instrumentos de desenho são encostados nele. Conforme o instrumento 
desliza pelo bordo com a escala, esta se destaca mudando da cor cinza para a cor verde.

\subsubsection{Lupa}

A lupa permite realizar operações de zoom in (ampliar) e zoom out (reduzir) em escala proporcional ao desenho, na tela. A lupa, apresentada na Figura 3.6, pode ser movida para qualquer posição da tela sendo arrastada por sua região correspondente ao cabo. O centro da lente é o ponto de homotetiaße permanece estacionado. Clicando sobre a lente e arrastando-a para cima, a imagem aproxima ou "aumenta" (zoom in) e, caso seja levada para baixo, a imagem afasta ou "diminui" (zoom out). Tal recurso permite executar desenhos com muitos detalhes mantendo alta precisão.

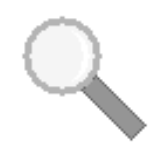

Figura 3.6 - Lupa para ajuste de visualização

Sendo estas as partes funcionais que compõem a interface do Risko.

A interface desenvolvida apresenta somente um lápis/borracha, um compasso, dois esquadros e uma lupa e, segundo o Teorema Fundamental enunciado por KOSTOVSKII (1980):

"É possivel resolver os problemas de construção geométrica que usam compasso e régua usando somente compasso. Teorema Fundamental."

(KOSTOVSKII, 1980, p.9)

No entanto, se este teorema fosse seguido à risca e fosse implementado somente o compasso, algumas tarefas seriam extremamente trabalhosas e cansativas, principalmente aquelas que necessitam de visualização de retas. Por isso, além do

\footnotetext{
${ }^{8}$ Relação entre duas séries de pontos, tal que os de cada uma estão dois a dois em linha reta com um centro comum e separados destes por distâncias de razão constante.
} 
compasso (elementar) foram implementados os esquadros que têm a função de facilitar aquelas construções gráficas que requerem a visualização dos segmentos de retas e, conseqüentemente, faz-se necessário o uso de um instrumento que gere a reta, no caso o lápis que traça a reta a ser visualizada na tela. Finalmente, a borracha foi implementada para excluir figuras da tela.

\subsection{Conclusão do Capítulo}

Neste capítulo foram apresentadas e descritas as funcionalidades encontradas nas partes que compõem as interfaces dos aplicativos $i$ Geom e Risko, bem como as "affordances" dos instrumentos reais de desenho implementados na interface do Risko. 


\section{CAPÍTULO 4}

\section{PERFIL DO USUÁRIO E ANÁLISES DE USABILIDADE}

Neste capítulo é apresentado o perfil dos usuários a quem se destinam as interfaces gráficas em estudo. $\mathrm{Na}$ seqüência, são mostrados os resultados de um conjunto de análises de usabilidade (heurística, funcional e de tarefas) realizadas com as interfaces dos aplicativos $i$ Geom e Risko.

\subsection{Perfil do Usuário}

É importante, antes de iniciar qualquer avaliação de GUI, estabelecer ou identificar o perfil dos usuários-alvo para que suas necessidades específicas sejam consideradas. O perfil do usuário a que se destina o produto exerce influência direta não só no método de avaliação das GUI, mas em todo o ciclo de vida do aplicativo computacional que está sendo desenvolvido e que será testado.

Antes de definir o grupo de usuários a quem se destinam as interfaces gráficas, é necessário saber como estes são classificados enquanto usuários e programas computacionais. Neste trabalho, é utilizada a classificação proposta por DIX (1998) que traz as seguintes categorias:

- "Primary - those who use the system."

- "Secondary - those who don't directly use the system but receive output from it or provide input to it (for example, someone who receives a report produced by the system)." 
- "Tertiary - those who do not fall into 1 or 2 but who are affected by the success or failure of the system (for example, a director whose profits increase or decrease depending on the success of the system)."

- "Facilitating - those who are involved with design, development and maintenance of the system."

(DIX et al., 1998, p.224)

Pelo fato das interfaces serem destinadas à Geometria Gráfica servindo como ferramenta para a capacitação de profissionais, a gama de usuários potenciais que possam compor o perfil que foi postulado é significativamente reduzida. Nele se enquadram os jovens de ambos os sexos, com idade entre 17 e 22 anos, com ensino superior incompleto, cursando ou que cursará alguma disciplina que envolva o assunto Geometria Gráfica. Os usuários pertencentes ao perfil postulado têm conhecimentos básicos de informática, ou já utilizaram o computador para alguma atividade anteriormente, apresentando também noções de desenho auxiliado pelos instrumentos reais (compasso, esquadros, lápis e borracha), obtidas em cursos anteriores (OLIVEIRA e SANTOS, 2003). Seguindo a classificação proposta por DIX (1998), para este caso, somente os usuários primários ("primary") são considerados para o presente estudo.

Uma outra característica, inerente aos usuários que se enquadram no perfil postulado, é a disparidade referente ao grau de conhecimento sobre o tema Geometria entre os alunos de uma mesma turma, que pode variar de aluno para aluno. Estas são as características mais relevantes para o perfil postulado dos usuários das interfaces e que são considerados neste trabalho.

Neste caso específico, não há a necessidade de determinar ou estudar os demais perfis apresentados por DIX (1998). Entretanto, deve-se relatar a existência dos pseudo-usuários, que são aqueles que estão diretamente envolvidos com o produto que são os programadores, professores e pesquisadores que trabalham no desenvolvimento do aplicativo. Estes não serão estudados neste trabalho, por serem considerados especialistas nas diversas tarefas e na manipulação tanto dos programas em questão quanto das suas interfaces. No entanto, parte do método de avaliação das 
interfaces é realizado pelo autor do trabalho que é especialista em ambos os aplicativos.

\subsection{Análises de Usabilidade Realizadas}

A escolhas e a aplicação das Analises de Usabilidade foram feitas somente pelo autor do trabalho. Neste caso, as 3 Análises de Usabilidade escolhidas foram (Heurística, Funcional e de Tarefas), pois estas podem apontar os problemas e virtudes das interfaces em questão. A seguir, são descritos os critérios considerados em cada uma das análises realizadas.

Análise Heurística: consiste em avaliar os princípios gerais de usabilidade de um "software", neste caso as GUI, segundo os critérios pré-estabelecidos para avaliação. Para o presente trabalho serão consideradas as 10 heurísticas fundamentais que foram propostas por Nielsen (1993):

1. visibilidade do estado do sistema: o programa deve manter o usuário informado sobre o que está acontecendo, por meio de realimentação apropriada, ou seja, mantendo o diálogo de maneira simples e clara;

2. concordância entre o sistema e o mundo real: a linguagem utilizada no programa deve ser a do usuário-alvo, com o emprego de palavras, frases, conceitos e convenções que sejam familiares ao mesmo;

3. controle do usuário e liberdade: usuários pouco experientes, freqüentemente escolhem funções por engano e devem poder desistir das mesmas com facilidade, caso queiram. O sistema deve prover mecanismos de ajuda apresentando suporte, como as funções desfazer ("undo") e refazer ("redo");

4. consistência e padrões: aos usuários não compete a tarefa de descobrir se diferentes palavras, situações ou ações significam a mesma coisa, em um sistema como um todo. O sistema deve seguir 
as convenções da plataforma em uso a fim de manter a consistência geral bem como nas partes;

5. prevenção de erros: melhor do que boas mensagens de erro é um projeto cuidadoso que previna ou diminua a ocorrência dos erros;

6. reconhecimento ao invés de lembrança: objetos, ações e opções devem ser visíveis. Os usuários não têm que lembrar de informações vistas em partes anteriores do diálogo corrente. As instruções sobre uso do sistema devem ser visíveis ou facilmente acessíveis quando necessárias, evitando o uso de linguagens generalizadas;

7. flexibilidade e eficiência de uso: aceleradores, de difícil percepção para os usuários iniciantes, podem melhorar o desempenho na interação dos usuários experientes com o sistema, e assim considerar grupos distintos de usuários. Então o sistema deve permitir que o usuário configure as ações de seu uso mais freqüentes, onde o padrão inicial deve ser destinado aos usuários iniciantes;

8. estética e “design” minimalista: no diálogo não devem existir informações irrelevantes ou que raramente são necessárias. Cada unidade extra de informação contida em um diálogo compete diretamente com as unidades de informação relevantes e diminui a sua visibilidade relativa, aumentando a carga cognitiva;

9. ajudar usuário a reconhecer, diagnosticar e recuperar erros: as mensagens de erros devem ser expressas em linguagem direta, ou seja, sem códigos, sempre indicando precisamente a solução para o problema e deve ser apresentada numa linguagem educativa para solucionar o problema, e nunca coibir o usuário;

10. ajuda e documentação: o recomendável é que o sistema possa ser usado sem documentação, caso isso não seja possível, pode ser necessário o fornecimento de ajuda e de documentação auxiliar. Tais informações devem ser facilmente consultadas, focadas na tarefa do usuário, listando os passos exatos a serem executados e não devem ser muito amplas. 
Análise Funcional: é usada para determinadas questões como, quais recursos os aplicativos devem oferecer e como eles serão utilizados. No caso específico dos aplicativos em análise, as funcionalidades estão diretamente relacionadas às necessidades do perfil de usuário postulado e considera suas capacidades técnicas bem como as limitações do ferramental. Embasada nestes princípios, a Análise Funcional deve apontar quais são os recursos oferecidos pelos aplicativos e como eles são utilizados, quando empregados ao ensino de Desenho Gráfico.

Análise de Tarefas: é fundamentada no levantamento dos requisitos de usabilidade, segundo as características do perfil de usuário postulado. A Análise de Tarefas foi dividida em duas etapas: a) obtenção das informações sobre as atividades, ou seja, as tarefas que serão realizadas em teste e, b) levantamento dos dados juntamente com a modelagem das tarefas. Neste caso, as tarefas selecionadas serão testadas com ambas as interfaces a fim de confirmar se elas permitem ou não a conclusão de cada uma das tarefas.

\subsubsection{Análises Heurísticas}

Com base nestas 10 heurísticas estabelecidas, os problemas de usabilidade detectados nas interfaces foram:

Referente à interface do $i$ Geom:

- Nas construções gráficas correlacionadas, ou seja, que dependem uma das outras, ao apagar uma delas as demais figuras dependentes são excluídas automaticamente pelo programa. Em muitos casos, esta pode não ser a opção desejada pelo usuário e que ocorre sem qualquer notificação prévia sobre o resultado final da operação "deletar objeto" (violação da primeira heurística);

- Os comandos desfazer e refazer atuam apenas em situações que excluem objetos ou retornam objetos excluídos. Não existem avisos a respeito do que irá acontecer após o uso dos referidos comandos (violação da terceira heurística); 
- A simbologia apresentada por alguns ícones como, por exemplo, isometria, limpar a tela, etc. é de difícil reconhecimento para o usuário iniciante. Neste caso, o ideal seria utilizar ícones padronizados e que são disponibilizados em outras interfaces semelhantes para facilitar o reconhecimento da função. Caso no mundo real não existam figuras ou objetos que correspondam diretamente a estas ações, o mais usual é optar pelo uso de ícones criados somente para o mundo virtual, mas que estejam culturalmente incorporados ao meio, ao invés de criar novos símbolos sem qualquer expressão (violação da quarta heurística);

- O programa disponibiliza uma calculadora auxiliar que é vista em uma janela secundária sobreposta à interface principal. A interface desta calculadora é completamente diferente de qualquer outro padrão encontrado, tanto para as calculadoras reais como as virtuais. Por mais simples que seja usar uma calculadora, o ideal é que a sua interface acompanhe algum padrão culturalmente conhecido para facilitar o uso (violação da quarta heurística);

- A maioria dos comandos do $i$ Geom são acionados seguindo a seqüência ação-seleção, mas os comandos: esconder objetos, "script", etc. são acionados de maneira inversa, ou seja, seleção-ação. Apesar da escolha de tal seqüência ser assunto controverso (BRAVIANO, 2001), é notória a inconsistência que, conseqüentemente, aumenta a carga cognitiva para os novos usuários (violação da quarta heurística);

- A documentação do $i$ Geom é escassa e ainda não cobre todas as funções oferecidas pela interface (violação da décima heurística).

Referente à interface do Risko:

- Na versão analisada (v0.8), ainda não estava implementada a função "highlight" para linhas, que facilita o alinhamento ou posicionamento sobre linhas. Há também uma inconsistência nesta função no compasso pois, ao aproximar a ponta seca do instrumento a um ponto, este assume a 
cor verde e, quando o botão do mouse é solto e o vínculo entre a ponta do instrumento e o ponto fica estabelecido, o mesmo ponto retorna a sua cor padrão, cinza escuro. As funções "snap" e "highlight" são de grande valia numa interface de manipulação direta pura para auxiliar e facilitar as construções gráficas. Idealmente tais funções deveriam existir para todas as figuras e também para as demais interações possíveis entre os próprios instrumentos, como por exemplo, lápis com esquadros, esquadro com esquadro, compasso com esquadro, etc., (violação da quarta heurística);

- Na versão avaliada, ainda não estava implementada a função de "highlight" de hot-areas dos instrumentos ou o mecanismo previsto na especificação inicial (mudança do formato do cursor, ao passar o apontador sobre elas). Para que fique clara a existência das hot-areas, evitando-se confusões por parte dos iniciantes, deveria existir um mecanismo, como por exemplo "tooltips", para indicar como se utiliza cada uma das partes dos instrumentos citados, (violação da sexta heurística);

- Apresentar uma interface simples e intuitiva é o objetivo central no desenvolvimento do Risko, o que não implica no descarte de um mecanismo de ajuda ou material explicativo para esclarecer como se usa a interface. A existência de um "help" ou manual de uso deveria existir para os casos em que o usuário não consegue utilizar ou entender a funcionalidade de alguma parte da interface, (violação da décima heurística).

\subsubsection{Análise Funcional}

Referente à interface do $i$ Geom:

- Em alguns casos, onde dois ou mais elementos gráficos se sobrepõem, não é possível selecionar um deles;

- O programa não traz uma opção para criar arcos ou para cortá-los, portanto só é possível fazer arcos com 360 graus; 
- O tamanho da área de trabalho deveria ser reconfigurável ("resize") para a realização de problemas complexos e que necessitam de muito espaço para as construções gráficas;

- Todas as figuras criadas são vistas na cor azul, com uma mesma espessura e em linha contínua, exceto os pontos. Idealmente deveria existir uma paleta de atribuições para alterar: cor, tipo e espessura dos traçados. Estas ações facilitariam o entendimento de partes isoladas em construções com muitas figuras, é comum ocorrerem situações de poluição visual.

Referente à interface do Risko:

- Na versão analisada, o tamanho da área de trabalho era ilimitada e, em alguns casos, os instrumentos podiam se perder fora da área da tela em foco. A área de trabalho deveria ser limitada ou seria adequada a presença de um comando para enquadrar todos os instrumentos de desenho e as figuras existentes;

- O aplicativo poderia disponibilizar uma paleta para alterar e atribuir propriedades das figuras criadas como, por exemplo, cor, modelo de traçado, espessura do traçado, etc. (recurso previsto em projeto mas ainda não implementado). Isso facilitaria destacar construções gráficas e o entendimento de figuras complexas. As figuras criadas são vistas na cor cinza escuro com mesma espessura e em linha contínua, com exceção dos traçados à mão livre;

- A cor apresentada pela maioria dos instrumentos de desenho segue tons de cinza e os traçados são apresentados na cor cinza escuro, portanto, quase tudo é visto em tons de cinza dificultando o trabalho e a visualização. Por exemplo, os esquadros possuem uma borda cinza que é pouco mais clara que o cinza dos traçados criados, e a espessura desta borda é igual à espessura do traçado. Dificilmente as retas executadas com o auxílio do compasso são vistas sem que o instrumento seja removido do local; 
- Na versão avaliada, a área sensitiva de detecção da função “snap” estava demasiadamente pequena quando se trabalha com tela em alta resolução, dificultando a interação dos instrumentos com as figuras que apresentam tal função. Conseqüentemente, alinhar o bordo do esquadro com uma reta ou a ponta do lápis com o bordo do esquadro ficavam muito trabalhosas;

Os pontos criados na versão analisada eram pequenos, dificultando a visualização dos mesmos e, conseqüentemente, a interação. Considerando que no ensino desenho os pontos são parte fundamental para as construções gráficas, eles deveriam ser tratados e apresentados com alta qualidade e rigor funcional;

- Para construir uma reta com precisão é necessário utilizar um dos esquadros como apoio para o lápis e, caso o traçado seja prolongado além do apoio, surgirá um rabisco na cor azul claro, sem precisão, como ocorre com instrumentos reais. O ideal seria que o "snap" dos esquadros não permitisse traçar além do apoio. Neste caso, o aplicativo deveria prever a limitação do ferramental e do próprio usuário, pois ele está se baseando em algo visualmente limitado. Deve-se considerar ainda que a sensibilidade inerente ao cursor, acionado pelo mouse, dificulta a ação de parar o lápis exatamente numa das extremidades dos esquadros. Portanto, o aplicativo deveria auxiliar o usuário a manusear os instrumentos. Não é intuitivo, didático ou prático permitir que o lápis construa uma reta ligada seguida por um rabisco num aplicativo educacional. Impedir que o lápis ultrapasse o instrumento facilitaria significativamente o uso de ambos e aumentaria a precisão das construções;

- É difícil enxergar os valores da escala apresentada em um dos bordos dos esquadros, pois os números são muito pequenos e a cor não proporciona contraste. Caso o lápis seja encostado no bordo do esquadro com a referida escala, a "highlight" é ativada e o número mais próximo, originalmente visto na cor cinza escuro, passa para a cor verde claro. Porém, a tonalidade do verde claro não contrasta com o cinza claro usado como fundo para o instrumento e muito menos com a cor branca da área de trabalho, dificultando a leitura da escala dos esquadros. 


\subsubsection{Análise de Tarefas}

Para determinar quais tarefas seriam consideradas nesta análise foi realizado um levantamento de quais ações são mais freqüentes para o usuário. As tarefas testadas estão relacionadas diretamente com a finalidade de uso dos aplicativos e de acordo com o perfil do usuário postulado. Utilizou-se uma amostra composta por 15 exercícios, extraídas de uma apostila didática de desenho (KAWANO et al., 2005), cujas soluções foram analisadas para o levantamento das tarefas elementares às interfaces. Os enunciados e as respectivas resoluções dos 15 exercícios considerados estão disponíveis no Anexo A.

Uma lista composta por 13 tarefas foi montada para a avaliação pretendida. Estas tarefas receberam na avaliação a respectiva interface.

As 13 tarefas e as classificações para as interfaces obtidas com a avaliação realizada são apresentadas na Tabela 4.1. Na primeira coluna da Tabela 4.2 encontram-se as 13 tarefas avaliadas.

Tabela 4.1 - Classificação atribuída para as tarefas avaliadas

\begin{tabular}{|l|c|c|}
\hline \multicolumn{1}{|c|}{ Tarefas avaliadas } & \multicolumn{2}{c|}{ Classificação atribuída } \\
\hline \hline & iGeom & Risko \\
\hline 1- Desenhar ponto em posição arbitrária & possível & possível \\
\hline 2- Desenhar ponto sobre uma construção gráfica qualquer & possível & possível \\
\hline 3- Desenhar ponto em intersecção de outras construções & possível & possível \\
\hline 4- Desenhar circunferência com raio qualquer & possível & possível \\
\hline 5- Desenhar uma circunferência com raio igual ao comprimento de & possível & possível \\
& & \\
\hline 6- Desenhar arco com menos de 360 graus & impossível & possível \\
\hline 7- Desenhar segmento em posição arbitrária & possível & possível \\
\hline 8- Desenhar segmento de reta por dois pontos & possível & possível \\
\hline 9- Desenhar segmento paralelo & possível & possível \\
\hline 10- Desenhar segmento perpendicular & possível & possível \\
\hline 11- Prolongar um segmento de reta & possível & possível \\
\hline 12- Desenhar um segmento de reta com medida numérica dada & impossível & possível \\
\hline 13- Apagar construções & possível & possível \\
\hline
\end{tabular}

Segue resumidamente a apresentação dos resultados dispostos na Tabela 4.1:

Referente à interface do $i \mathrm{Geom}$, das 13 tarefas avaliadas, 2 delas não são passivas de serem realizadas com a interface do aplicativo: "6-Desenhar arco com menos de 360 graus" e "12- Desenhar um segmento de reta com medida numérica 
dada”, para o caso da tarefa 6 é possível somente criar circunferências. Entretanto, esta característica do $i$ Geom não pode ser considerada como um grave problema de usabilidade se visto isoladamente para a construção com poucos arcos. Mas caso sejam necessários vários arcos, como por exemplo, em exercícios complexos, as muitas construções podem gerar a poluição visual, problema consideravelmente grave em termos de avaliação de usabilidade para uma interface educacional.

Referente ao Risko, pelo fato de sua interface disponibilizar os objetos do mundo real, as 13 tarefas listadas puderam ser realizadas.

\subsection{Conclusão do Capítulo}

As Análises de Usabilidade realizadas pelo autor apontam os principais problemas encontrados nos distintos padrões de interfaces. Referente ao padrão “WIMP” apresentado pelo $i$ Geom, pode-se dizer que em geral o modelo é favorável quando utilizado em circunstâncias específicas. Porém, o modelo não atende completamente às necessidades do ensino de desenho. Segue um resumo das análises do $i \mathrm{Geom}$.

A Análise Heurística possibilitou detectar problemas consideravelmente relevantes em termos de usabilidade. São eles: ícones não intuitivos, remoção de elementos sem notificação prévia, comando desfazer ("undo") limitado e a inexistência do comando refazer ("redo"). Na Análise Funcional, os principais problemas estão relacionados a falta de comandos como, por exemplo, "resize", "pan" ou "zoom" para solucionar às questões ligadas a seleção de figuras sobrepostas e à falta de controle da área de trabalho para facilitar a visualização das construções. Finalmente, a Análise de Tarefas apontou que os recursos atualmente disponíveis na interface do $i$ Geom atendem boa parte das necessidades impostas pelo tema Geometria Gráfica.

É necessário ressaltar que os problemas detectados nas análises para interface do $i$ Geom podem não existir em outros programas de Geometria que usam interfaces seguindo o padrão "WIMP” avaliado e que o aplicativo traz outros recursos que não entraram na avaliação. 
Os problemas encontrados no padrão "WIMP" foram considerados no projeto da interface do aplicativo Risko, mesmo este não seguido o mesmo padrão e a interface projetada ser embasada no levantamento das ações e "affordances" dos instrumentos reais mostrados no item 3.2.

As análises realizadas com a interface de Manipulação Direta pura do aplicativo Risko apontaram que o modelo é promissor, entretanto são necessários alguns ajustes para que ela atenda com excelência e por completo às necessidades do ensino de desenho.

A Análise Heurística apontou os seguintes problemas: inconsistência funcional das ferramentas "snap" e "highlight" e a falta de esclarecimentos para os instrumentos com várias "hot-areas". Na Análise Funcional, os problemas são: falta destaque nas cores em uso pelos instrumentos com relação às demais partes e funções da interface; necessidade de um mecanismo de enquadramento; a região sensitiva do "snap" é demasiadamente pequena; referente ao "snap" para o bordo dos esquadros, estes deveriam impedir que o lápis uma vez apoiado, não desencoste do mesmo durante o período em que o traçado é realizado. A Análise de Tarefas mostrou que os recursos implementados na interface do Risko atendem por completo às necessidades impostas a um aplicativo destinado ao ensino de Geometria Gráfica. 


\section{CAPÍTULO 5}

\section{AVALIAÇÃO COMPARATIVA}

Objetivando gerar os dados necessários para a avaliação comparativa das GUI dos programas $i$ Geom e Risko, um método baseado nas normas que regulamentam a construção e avaliação de produtos de "software" foi desenvolvido. Este método consiste em checar dois grupos de atributos: 1- Usabilidade e 2-Eficiência. Para isso, são utilizados: um teste prático, onde usuários executam um mesmo conjunto de ações com o auxílio das interfaces, e um questionário pós-teste a ser respondido somente pelos participantes dos testes após utilizarem ambos os aplicativos.

\subsection{Método de Avaliação Desenvolvido}

O método arquitetado foi constituído a partir da fusão de várias técnicas de análise e desenvolvimento não só de "softwares" mas que é usado no desenvolvimento de vários outros produtos comercias.

Do ponto de vista do autor, testar efetivamente o produto não só pelo construtor, mas principalmente pelos usuários a que se destina é a maneira mais eficiente e justa de avaliar a sua qualidade. No presente trabalho, o produto a ser avaliado é apresentado na forma de interfaces gráficas computacionais (GUI) e os usuários a que se destinam são os alunos e professores de Geometria Gráfica, conforme foi apresentado no capítulo 1. Para isso, um método comparativo fundamentado em testes empíricos é utilizado para avaliar a usabilidade das GUI. 
"Os testes empíricos consistem em observar os usuários utilizando o sistema. Estas observações podem ser realizadas de diversas maneiras e são insubstituiveis por proporcionarem informações diretas sobre a forma de utilização do sistema, por identificarem as dificuldades no uso da interface e por reproduzirem uma situação próxima da realidade."

(ARGOLLO et al., 1997, p.10)

Os testes empíricos com usuários reais também podem ser chamados de "user-tests" e são os mais recomendados para este caso, pois podem ser construídos de maneira a atender os objetivos específicos almejados, ou seja, são projetados para atender a uma determinada situação gerando os dados para uma avaliação que busca responder a questões pré-estabelecidas. Neste caso, é objetivo central do trabalho estabelecer um método capaz de comparar, por meio de análises, distintos modelos de GUI. E adicionalmente, após aplicar o método, se possível apontar qual dos modelos de interface é o mais adequado para o ensino de Geometria Gráfica.

Os dois "objetos" a serem avaliados comparativamente, são representados na forma de interfaces gráficas computacionais que apresentam diferentes linguagens. Uma delas apresenta o padrão “WIMP” e a outra é de Manipulação Direta Pura. Porém, ambas as interfaces são destinadas a uma única finalidade que é auxiliar o aprendizado de Desenho a um grupo específico de usuários.

Para o teste prático criado, somente 9 tarefas das 13 tarefas levantadas e apresentadas na Tabela 4.1, somente 9 delas foram mantidas . Pois, as tarefas 6 e 11 são impossíveis de serem realizadas com o $i$ Geom e a tarefa 3 é realizada automaticamente pelo Risko. Para executar a tarefa 5 e 11 são necessárias outras construções auxiliares, conseqüentemente, a conclusão destas tarefas depende diretamente da tarefas anterior. é composto por 9 tarefas, consideradas elementares, de desenho que serão realizadas com as duas interfaces.

Pelo fato das tarefas serem as mesmas e, serão realizadas seguindo uma ordem cronológica, a seqüência do uso dos aplicativos é definida por meio de sorteio aleatório para cada participante, a fim de não comprometer o resultado da avaliação pretendida. Tal procedimento é apenas cautelar, pois as tarefas solicitadas são básicas e o conhecimento necessário para a resolução das mesmas não é cumulativo. 
A fase dos testes práticos realizados pelos participantes é documentada em vídeo e serão conduzidos pelo autor do trabalho, que simultaneamente anota as informações relevantes que ocorrem durante cada teste. Esta documentação em vídeo permite não só rever cada teste o quanto for necessário, mas possibilita uma análise minuciosa a fim de obter os dados e as informações necessárias para a avaliação. Tais vídeos serão disponibilizados para consulta ao termino do trabalho.

Escolhido o "user-test" como método formal para avaliar as interfaces, é necessário determinar quais são os dados a serem colhidos com ele e que posteriormente receberão um tratamento estatístico.

"Formally, we define measurement as a mapping from the empirical world to the formal, relational world. Consequently, a measure is the number or symbol assigned to an entity by this mapping in order to characterize an attribute."

(FENTON, 1997, p.28)

A literatura que trata o assunto é vasta se considerarmos como objeto de análise um "software". Ocorre que os objetos a serem avaliados não constituem "softwares", mas apenas uma determinada parte deles que são as suas GUI. Diante do resultado obtido na pesquisa realizada sobre o específico assunto, avaliação de GUI, o material encontrado é bem reduzido, e que mais se aproxima das necessidades impostas pelo trabalho aqui em desenvolvimento está no texto da normativa ISO/IEC 9126 de 1991, que é destinada à avaliação do ciclo de vida de produtos de "software". A ISO 9126 estabelece, de maneira generalizada, quais as características e requisitos são associados ao processo de avaliação da qualidade um produto de "software", considerando o seu ciclo de vida. Nela, seis grupos pré-definidos, funcionalidade, confiabilidade, usabilidade, eficiência, manutenabilidade e portabilidade, são avaliados e devem ser atendidos para que um produto de "software" seja considerado de boa qualidade em seu ciclo de vida. Prevendo as diferentes finalidades, e grande variedade possível de aplicativos e seus derivados, a ISO/IEC 9126 de 1991 recomenda para alguns casos a criação ou adequação dos grupos acima citados bem como dos atributos que os compõem. Esta recomendação tem o objetivo de abranger ao máximo as particularidades do objeto em avaliação. Que é o caso da avaliação pretendida neste trabalho. Portanto, esta recomendação é válida e será 
aplicada, pois os objetos a serem avaliados não constituem "softwares", mas sim parte deles, ou seja, suas GUI.

Após verificar a função de cada um dos seis grupos apresentados pela normativa, concluiu-se que somente dois deles se enquadram na avaliação pretendida para as interfaces, que são: 1- Usabilidade e 2- Eficiência. Os demais grupos foram desconsiderados para esta avaliação. Definidos os dois grupos, o próximo passo é estabelecer os atributos que os compõem e que serão verificados com os testes.

\subsubsection{Grupo Usabilidade}

Definições para o termo usabilidade:

"The effectiveness, efficiency and satisfaction with which specified users achieve specified goals in particular environments."

(DIX, et al., 1998, p.192)

Segundo a NBR 9241:

"Conjunto de atributos que evidenciam o esforço necessário para se poder utilizar o software, bem como o julgamento individual desse uso, por um conjunto explícito ou implícito de usuários."

(ISO 9241, 1998, apud NBR 9241-11, 2002, p.19)

Ou simplesmente, facilidade de uso, como prefere o autor.

Os atributos propostos neste trabalho para compor o grupo usabilidade são:

a) Intuitividade: refere-se ao reconhecimento espontâneo, que ocorre de maneira clara e incontestável, dispensando alto grau de raciocínio ou esclarecimentos para o uso das interfaces.

A intuitividade está relacionada ao treinamento ou quantidade de explicações necessárias sobre a interface para que um usuário iniciante, pertencente ao perfil postulado, possa dominá-la e realizar com facilidade as tarefas desejadas.

b) Facilidade de interpretar e utilizar corretamente as funcionalidades: trata da compreensão de como são operadas as funções oferecidas por cada uma das interfaces, sejam ícones, menus 
ou instrumentos virtuais. Deve-se considerar a competência necessária para que os usuários iniciantes possam manipular as ferramentas oferecidas pelas interfaces com o objetivo de executar corretamente as tarefas programadas para o teste prático.

"As habilidades estão associadas ao saber fazer: ação fisica ou mental que indica a capacidade adquirida. Assim, identificar variáveis, compreender fenômenos, relacionar informações, analisar situaçõesproblema, sintetizar, julgar, correlacionar e manipular são exemplos de habilidades."

"Já as competências são um conjunto de habilidades harmonicamente desenvolvidas e que caracterizam, por exemplo, uma função/profissão específica: ser arquiteto, médico ou professor de química. As habilidades devem ser desenvolvidas na busca das competências."

(MORETTO apud MAFALDA,2004, p.12).

c) Satisfação do usuário: posterior ao entendimento de como se utiliza uma interface, a satisfação está relacionada ao sentimento de contentamento expresso pelo usuário. Este sentimento deve ser manifestado de maneira convincente e, se possível, declarada pelo usuário.

A satisfação neste caso é definida como:

"The comfort and acceptability of the work system to its users and other people affected by its use."

(DIX, et al., 1998, p.192)

Para garantir a completa satisfação por parte do usuário das interfaces, nenhuma das funções oferecidas por elas deve deixar a desejar no que diz respeito à finalidade a que se destina ou que é almejada pelo próprio usuário. E para mensurar o sentimento de satisfação ou descontentamento do usuário, o procedimento mais eficaz é coletar a opinião do mesmo por meio de um questionário imparcial que deve, preferencialmente, ser preenchido pelo próprio após o uso das interfaces. Tal questionário é parte do método de avaliação aqui proposto e será apresentado mais adiante. 


\subsubsection{Grupo Eficiência}

Definições para o termo eficiência:

"The resources expended in relation to the accuracy and completeness of goals achieved."

(DIX, et al., 1998, p.192)

"Conjunto de atributos que evidenciam o relacionamento entre o nível de desempenho do software e a quantidade de recursos usados, sob condições estabelecidas."

(KOSCIANSKI, 1999, p.50)

a) Eficiência: é relacionada à ação, força, virtude ou capacidade de produzir um efeito, que é expresso como rendimento final, ou seja, a velocidade com que o usuário experiente executa determinadas tarefas.

Neste caso, o mesmo teste prático estabelecido para os participantes será realizado somente pelo autor que é experiente no uso de ambos os aplicativos.

\subsection{Procedimentos Experimentais}

Os testes experimentais realizados com os participantes serão documentados e para isso foi montado um sistema composto por dois microcomputadores ligados em rede, ambos providos com o Sistema Operacional "MS-WindowsXP Professional versão 2002”. No entanto, as demais configurações são distintas para as máquinas. No micro designado para que o participante execute as tarefas do teste, foram instalados os aplicativos testados: $i$ Geom (versão 2.4.5 "stand-alone" de 17 de junho de 2003) e o Risko (versão 0.8 "stand-alone" de 28 de março de 2005). Para que os aplicativos funcionem perfeitamente é preciso instalar duas plataformas distintas e suas bibliotecas: "JavaTM" (versão JRE 1.1.8_010 ou JDK 1.1.8_0109] e “JavaTM" (versão J2RE 1.4.2_08 ou J2SDK 1.4.2_0810 (DEITEL, 2003) respectivamente compatíveis com os aplicativos $i$ Geom e Risko nas versões

\footnotetext{
9 Disponível gratuitamente em http://java.sun.com/products/archive/jdk/1.1.8_010/jre/index.html

${ }^{10}$ Disponível gratuitamente em http://java.sun.com/j2se/1.4.2/download.html
} 
analisadas, além de uma video-câmera digital. No segundo micro, destinado ao avaliador e que tem a função de gravar os vídeos, foi instalado o aplicativo “Camtasia StudioTML1" (versão 1.0.1) para captura sincronizada da tela do micro do usuário junto a imagem da face do participante gerada pela vídeo-câmera. Adicionalmente o "Camtasia StudioTM" fornece algumas informações técnicas do vídeo gravado como, tempo decorrido, número de quadros, resolução, etc. Todo o processo de controle do teste é feito remotamente, via rede, valendo-se do aplicativo "NetMeeting” da Microsoft (também de uso gratuito).

Com o objetivo de padronizar os testes com os participantes, eles foram aplicados e conduzidos pelo próprio criador e autor deste trabalho que adotou os passos relatados a seguir. Inicialmente o participante é informado verbalmente de todos os procedimentos e da finalidade a que se destina o experimento. Ciente das etapas e finalidades do teste, o participante assina uma declaração que autoriza a filmagem e uso da sua imagem onde é explicitamente mencionado que ela será utilizada somente para fins acadêmicos (o modelo do formulário utilizado está disponível nos Anexos). Somente após o participante autorizar a sua filmagem o experimento é iniciado, e a lista impressa contendo as 9 tarefas a serem feitas com ambas interfaces é entregue a ele, tarefas estas que serão apresentadas mais adiante. Complementando a documentação, além do teste gravado para arquivo, o avaliador, paralelamente, realiza as anotações mais relevantes decorrentes do teste numa planilha chamada como "Planilha de monitoramento do teste" (modelo disponível nos Anexos). Nesta planilha são anotados os tempos de início e término de uso de cada interface bem como os fatos mais relevantes que aconteceram durante os experimentos, como por exemplo, os questionamentos e as colocações feitas pelos participantes. O uso da Planilha de monitoramento do teste facilita consultar as imagens arquivadas.

Somente após o término do teste prático, o participante recebe o questionário denominado Pós-teste, cujo modelo utilizado é apresentado no item 5.3.2 a seguir. No questionário existem campos onde o participante é incentivado expor a sua

\footnotetext{
11 Utilizada a versão gratuita para 30 dias de uso, disponível em http://www.techsmith.com/download/studiodefault.asp
} 
opinião como: sugestões, elogios, dificuldades, observações, reclamações, etc. Estas ficam relatadas formalmente em um documento que está guardado com o autor.

O método proposto gera, para cada participante do teste, os seguintes documentos: formulário de autorização de uso da imagem, um vídeo com as ações de uso das interfaces sincronizado associado com as expressões faciais, questionário pós-teste e a planilha de monitoramento. Exceto o formulário de autorização de uso da imagem, os demais arquivos compõem a documentação que será utilizada na avaliação das GUI. Estas informações servem para avaliar os atributos que compõem o Grupo Usabilidade.

Para avaliar o Grupo Eficiência o mesmo conjunto de 9 tarefas será realizado, diversas vezes, com ambas as interfaces. Neste caso quem executará as tarefas é um usuário experiente (o autor do trabalho). O tempo de execução de cada tarefa será mensurado, separadamente, a fim de se obter a média de tempo gasto para executar cada uma das 9 tarefas. Esta média será multiplicada pela freqüência relativa de ocorrência das mesmas tarefas na resolução do conjunto de 15 exercícios que foi utilizado na Análise de Tarefas (Anexo). Com isso é determinado o tempo médio de execução de um exercício genérico. A Tabela 5.1 mostra na primeira coluna as 9 tarefas consideradas para o teste prático, na segunda e terceira colunas estão as freqüências e médias, respectivamente, para este grupo de tarefa que permitem realizar o conjunto de exercícios em questão.

Tabela 5.1 - Total de ocorrências e freqüência relativa das tarefas na resolução do conjunto de exercícios

\begin{tabular}{lcc}
\hline \multicolumn{1}{c}{ Tarefas } & $\begin{array}{c}\text { Total de } \\
\text { ocorrências }\end{array}$ & $\begin{array}{c}\text { Freqüência } \\
\text { Relativa (\%) }\end{array}$ \\
\hline \hline 1- desenhar ponto & 41 & 10,0 \\
2- desenhar uma reta & 10 & 2,4 \\
3- desenhar um arco & 3 & 0,7 \\
4- desenhar um ponto sobre uma reta & 60 & 14,6 \\
5- desenhar uma reta passando por dois pontos & 100 & 24,4 \\
6- desenhar um arco centrado em um ponto & 36 & 8,8 \\
7- desenhar uma reta paralela & 77 & 18,8 \\
8- desenhar uma reta perpendicular & 83 & 20,2 \\
9- apagar uma figura & 0 & 0,0 \\
Total & $\mathbf{4 1 0}$ & $\mathbf{1 0 0 , 0}$ \\
\hline
\end{tabular}


No Apêndice A é apresentada a Tabela A.1 que traz detalhadamente os valores obtidos na contagem de freqüências para cada tarefas por exercício avaliado.

\subsection{Mecanismos de Coleta dos Dados}

O primeiro mecanismo é apresentado como um teste prático a ser realizado com o uso das interfaces ("user-test"). O segundo mecanismo é um questionário que deve ser preenchido somente pelos colaboradores que acabaram de participar do teste prático.

\subsubsection{Teste Prático}

O teste criado é composto pelo mesmo grupo de tarefas elementares para resolução de exercícios, ou seja, as 9 tarefas da Tabela 5.1. O objetivo de usar estas tarefas elementares é estimular o participante a contribuir com o experimento e também diminuir a pressão psicológica circunstancial envolvida, por isso as tarefas propostas requerem conhecimentos mínimos, tanto no que diz respeito ao tema geometria quanto ao uso do computador. Considerando que as primeiras tarefas não exigem precisão e são independentes de figuras auxiliares, elas são consideradas mais simples quando comparadas as questões seguintes e, fato este determinante na ordem de apresentação e execução do teste.

Conforme mencionado anteriormente, a seqüência de uso de uma interface ou da outra é definida por sorteio aleatório realizado na frente de cada participante valendo-se de uma simples moeda, "cara" indica que o primeiro aplicativo a ser utilizado para a execução das tarefas é o Risko. Segue para cada interface a ser testada, uma das soluções possíveis de serem realizada com o auxilio dos aplicativos $i$ Geom e do Risko que são apresentados nas Figuras 5.1 e 5.2 respectivamente. 


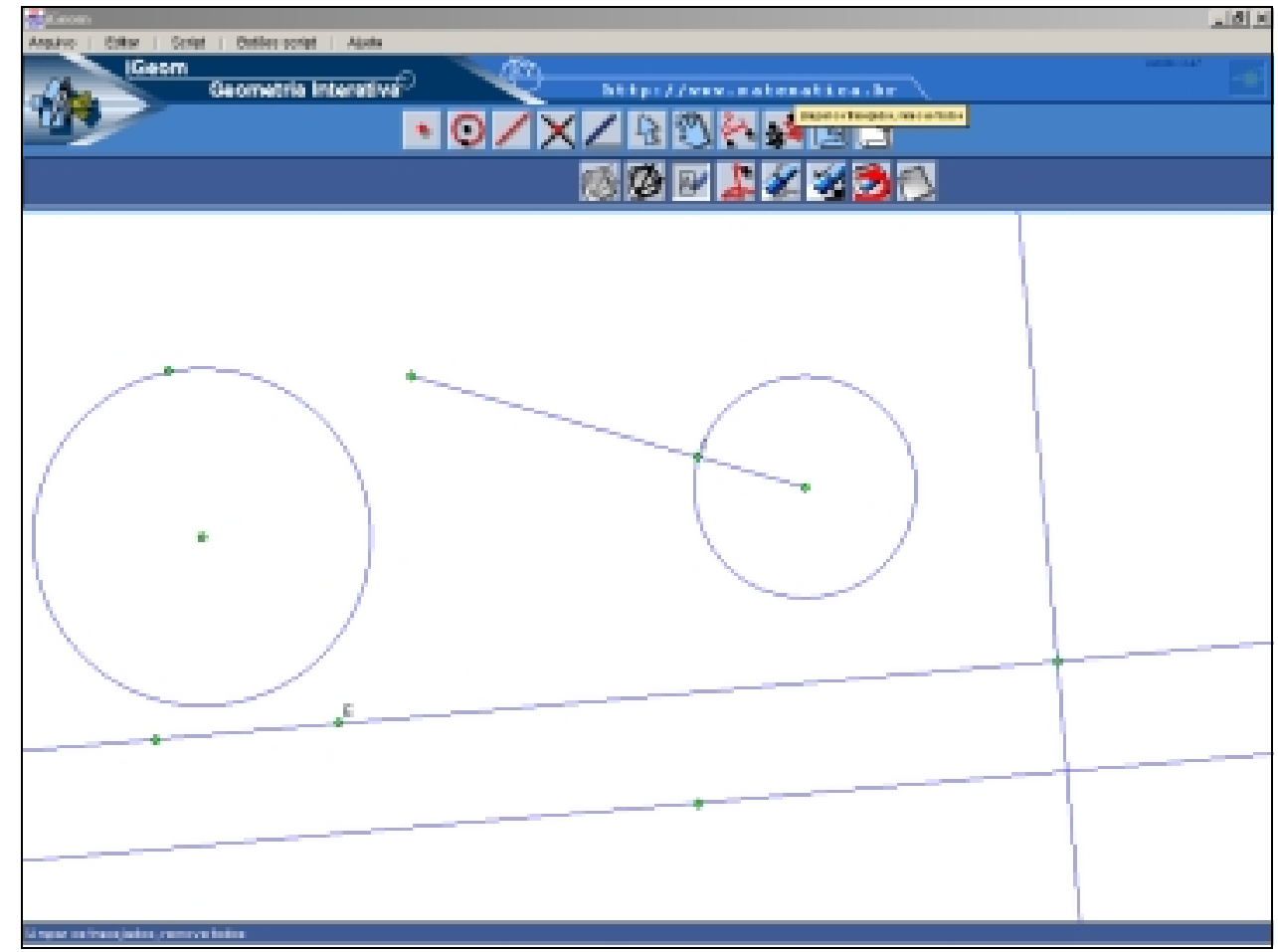

Figura 5.1 - Resolução das tarefas feita com a interface do $i$ Geom

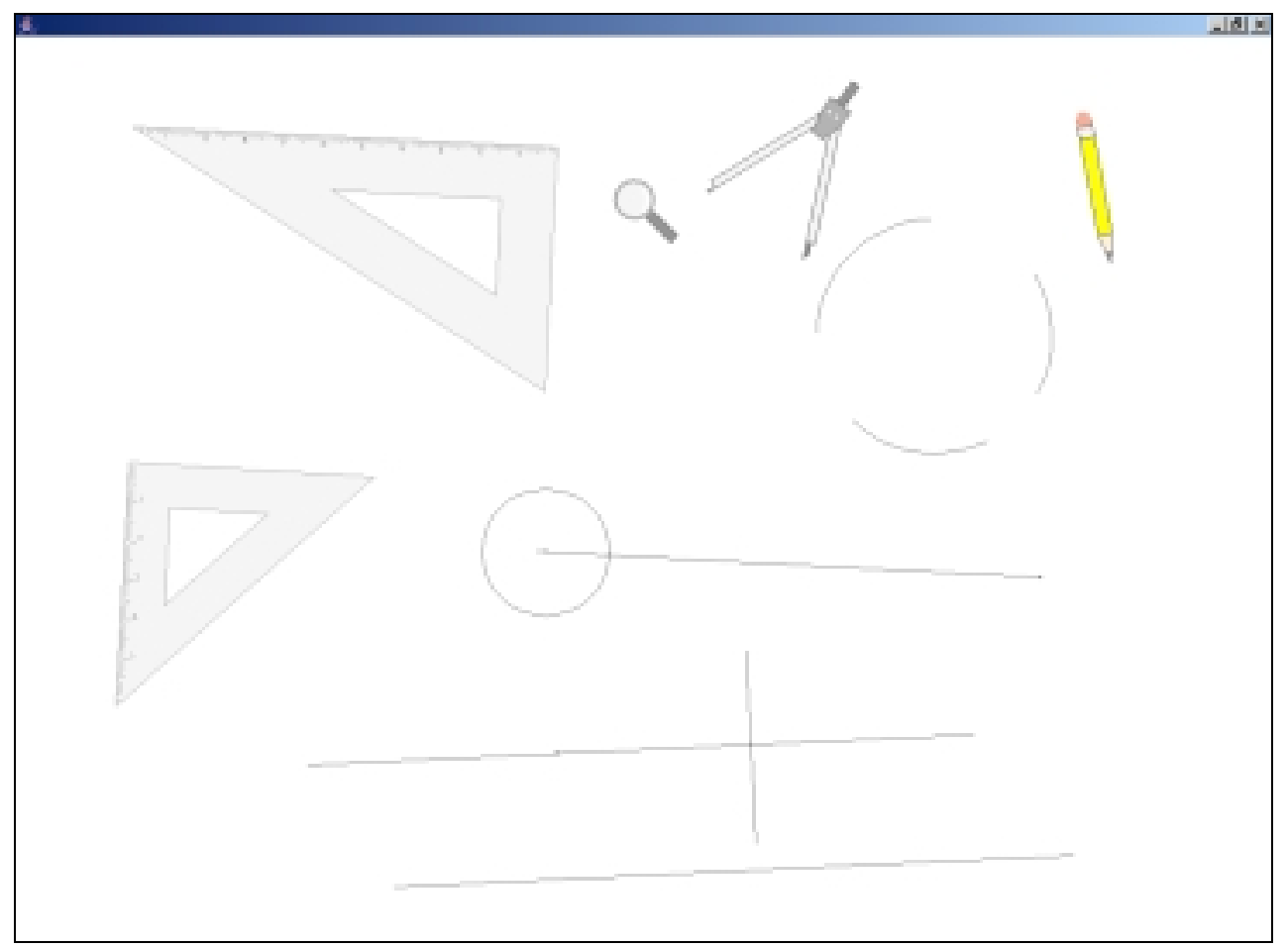

Figura 5.2 - Resolução das tarefas feita com a interface do Risko 
A Tabela 5.2 mostra a correlação das "affordances" dos instrumentos de desenho com as tarefas que são propostas no teste prático.

Tabela 5.2 - Correlação das tarefas com as ("affordances")

\begin{tabular}{l|l}
\multicolumn{1}{c}{ Utilizando os instrumentos individualmente } \\
\hline \hline \multicolumn{1}{c}{ Instrumento } & \multicolumn{1}{c}{ Tarefa } \\
\hline Lápis & $1,2,4,5,7$ e 8 \\
\hline Borracha & 9 \\
\hline Esquadro $30^{\circ} / 60^{\circ}$ ou $45^{\circ}$ & $2,5,7$ e 8 \\
\hline Compasso Instrumento & 3 e 6 \\
\hline \multicolumn{2}{c}{ Tarefa } \\
\hline \hline \multicolumn{2}{c}{ Lápis e Borracha $\quad$ não há interação } \\
\hline Lápis e um dos Esquadros $30^{\circ} / 60^{\circ}$ ou $45^{\circ}$ & $2,5,7$ e 8 \\
\hline Esquadros $30^{\circ} / 60^{\circ}$ e/ou esquadro $45^{\circ}$ e Lápis & 7 e 8 \\
\hline
\end{tabular}

No método proposto é extremamente relevante a postura e a experiência do condutor do teste. Neste caso é o próprio autor do trabalho que atuou como membro da equipe de desenvolvimento e implantação do Laboratório de Usabilidade instalado no posto de atendimento (e-poupatempo) da cidade de Guarulhos - SP. Pois, a ele compete a função de expor de maneira clara e objetiva o propósito do teste, deixando claro ao participante que o objetivo é avaliar somente as interfaces gráficas e não a sua capacidade bem como conduzir o teste prático, fornecendo as informações, os materiais necessários e principalmente estabelecer um ambiente produtivo para o sucesso do experimento.

\subsubsection{Questionário Pós-teste}

O questionário pós-teste é destinado a coletar os dados para a avaliação do atributo "satisfação do usuário" e, somente os participantes que utilizaram ambas as interfaces responderão ao questionário. O questionário desenvolvido também pode contribuir, parcialmente na avaliação dos outros atributos, pois nele o participante pode fazer importantes anotações a respeito do uso das ferramentas, exprimindo uma ótica diferente a dos que estão envolvidos com o projeto. As questões elaboradas e que devem ser respondidas são de múltipla escolha para minimizar a subjetividade 
inerente a uma questão com resposta aberta, além de facilitar a tabulação dos dados e agilizar o processo de preenchimento.

Para o levantamento das preferências dos participantes é utilizada a escala proposta no método desenvolvido por Renis Likert12 (1932 apud MACNAUGHTON, 1996, p.1099), que consiste em disponibilizar 5 conceitos de múltipla escolha como opção ao respondente. Porém, para que o tratamento estatístico seja realizado, os conceitos serão convertidos em valores numéricos (inteiros), como mostra a Figura 5.3.

\begin{tabular}{|l|l|l|l|l|}
\hline Péssimo $=-2$ & Ruim $=-1$ & Regular $=0$ & Bom $=1$ & Ótimo $=2$ \\
\hline
\end{tabular}

Figura 5.3 - Conversão para a escala de Likert

${ }^{12}$ Likert, R. A technique for the measurement of attitudes. Arch Psychol 140, p. 1-55, 1932. 
Seguem as questões propostas:

a) Com qual freqüência você usa o computador? (não importa para qual atividade!)

\begin{tabular}{|c|c|c|c|c|}
\hline $\begin{array}{l}\text { Nunca } \\
\text { usei }\end{array}$ & $\begin{array}{c}\text { Raramente } \\
\text { uso }\end{array}$ & Uma vez por mês & $\begin{array}{c}\text { Uma vez } \\
\text { por semana }\end{array}$ & $\begin{array}{l}\text { Todos } \\
\text { os dias }\end{array}$ \\
\hline
\end{tabular}

b) Após usar o programa Risko para resolver as tarefas, quais avaliações você faz?

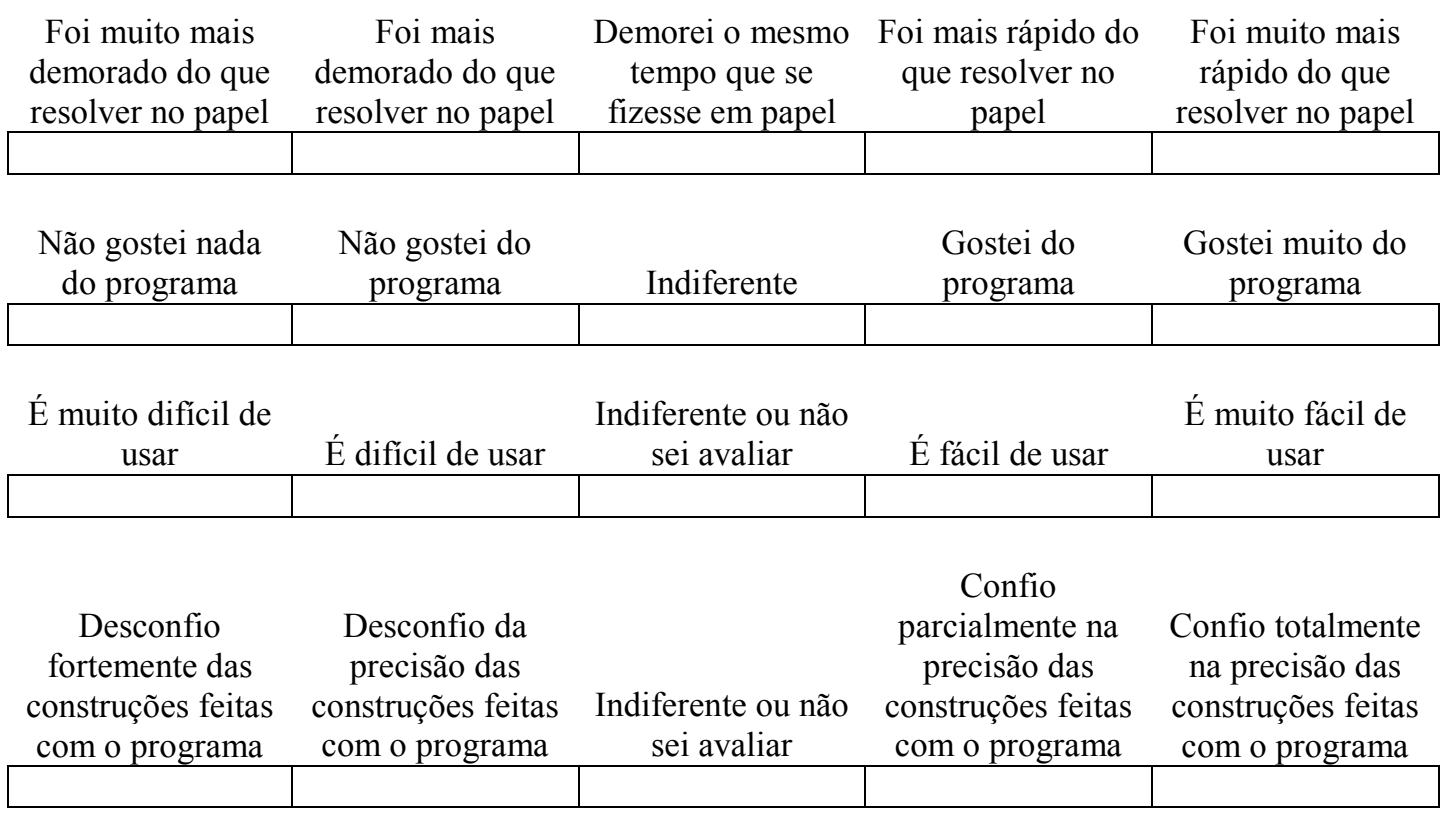

c) Você teve dificuldades ao usar o programa Risko? Caso sim, quais os prováveis motivos? (marque quantas quiser)!

\begin{tabular}{|l|l}
\hline & Encontrar os comandos desejados; \\
\hline & Entender o funcionamento dos comandos e instrumentos de desenho; \\
Houve erros do programa; & \\
Faltam explicações na tela; & \\
\hline & Outras dificuldades. Quais?
\end{tabular}

Caso queira descrever ou comentar algo mais sobre o que gostou e o que não gostou no programa Risko, use o verso da folha! 
d) Após usar o programa $i$ Geom para realizar as tarefas, quais avaliações você pode fazer?

\begin{tabular}{|c|c|c|c|c|}
\hline $\begin{array}{l}\text { Foi muito mais } \\
\text { demorado do que } \\
\text { resolver no papel }\end{array}$ & $\begin{array}{c}\text { Foi mais } \\
\text { demorado do que } \\
\text { resolver no papel }\end{array}$ & $\begin{array}{c}\text { Demorei o mesmo } \\
\text { tempo que se } \\
\text { fizesse em papel }\end{array}$ & $\begin{array}{c}\text { Foi mais rápido do } \\
\text { que resolver no } \\
\text { papel }\end{array}$ & $\begin{array}{l}\text { Foi muito mais } \\
\text { rápido do que } \\
\text { resolver no papel }\end{array}$ \\
\hline $\begin{array}{l}\text { Não gostei nada } \\
\text { do programa }\end{array}$ & $\begin{array}{l}\text { Não gostei do } \\
\text { programa }\end{array}$ & Indiferente & $\begin{array}{l}\text { Gostei do } \\
\text { programa }\end{array}$ & $\begin{array}{c}\text { Gostei muito do } \\
\text { programa }\end{array}$ \\
\hline $\begin{array}{c}\text { É muito difícil de } \\
\text { usar }\end{array}$ & É difícil de usar & $\begin{array}{c}\text { Indiferente ou não } \\
\text { sei avaliar }\end{array}$ & É fácil de usar & $\begin{array}{c}\text { È muito fácil de } \\
\text { usar }\end{array}$ \\
\hline $\begin{array}{c}\text { Desconfio } \\
\text { fortemente das } \\
\text { construções feitas } \\
\text { com o programa }\end{array}$ & $\begin{array}{c}\text { Desconfio da } \\
\text { precisão das } \\
\text { construções feitas } \\
\text { com o programa }\end{array}$ & $\begin{array}{c}\text { Indiferente ou não } \\
\text { sei avaliar }\end{array}$ & $\begin{array}{c}\text { Confio } \\
\text { parcialmente na } \\
\text { precisão das } \\
\text { construções feitas } \\
\text { com o programa }\end{array}$ & $\begin{array}{l}\text { Confio totalmente } \\
\text { na precisão das } \\
\text { construções feitas } \\
\text { com o programa }\end{array}$ \\
\hline
\end{tabular}

e) Você teve dificuldades ao usar o programa iGeom? Caso sim, quais os prováveis motivos? (marque quantas quiser)!

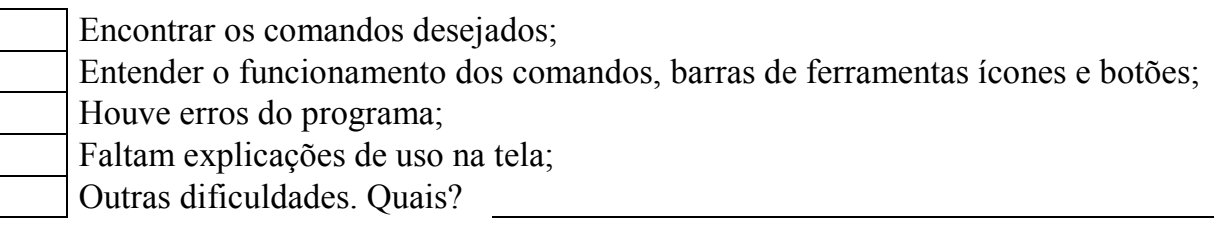

Caso queira descrever ou comentar algo mais sobre o que gostou e o que não gostou no programa iGeom, use o verso da folha! 
f) Caso tenha que usar um destes programas durante todo o curso de desenho, qual você gostaria de usar para as seguintes atividades:

Uso em sala de aula?

RISKO - interface com os instrumentos de desenho, ou $i \mathrm{Geom}$ - interface com ícones e botões.

Uso em casa para estudar ou fazer os trabalhos e exercícios? RISKO - interface com os instrumentos de desenho, ou
$i \mathrm{Geom}-$ interface com ícones e botões.

Uso para fazer as provas?

RISKO - interface com os instrumentos de desenho, ou $i \mathrm{Geom}$ - interface com ícones e botões.

g) Você teve dificuldades para realizar as tarefas propostas no teste? Caso sim, quais os prováveis motivos? (marque quantas quiser e, se quiser)!

As tarefas foram difíceis de resolver;
A seqüência das tarefas foi complicada;
Não entendi o que foi pedido para fazer;
Outras dificuldades. Quais?

Espera-se obter por meio das respostas extraídas com o questionário pós-teste:

Questão "a": refinar o perfil postulado para o usuário a que se destinam as interfaces e avaliar se o mesmo está apto ou não a utilizar um computador como ferramenta de auxílio ao aprendizado. Deve-se ressaltar que nenhuma das duas interfaces foi criada com objetivo de promover a inclusão digital.

Questões "b" e "d": avaliar comparativamente, segundo a opinião dos participantes, os seguintes itens: o tempo gasto para realizar as tarefas com o auxilio dos aplicativos é maior ou menor que o tempo gasto para realizar as mesmas tarefas valendo-se dos instrumentos reais de desenho, o quanto gostaram ou não gostaram dos programas e finalmente, se a precisão de desenho dos aplicativos é confiável ou não.

Questões "c" e "e": encontrar as prováveis barreiras de uso, podendo ainda dar indicativos sobre a preferência por uma das interfaces. 
Questão “f”: apresenta, segundo a opinião do participante, qual das interfaces é a melhor em três situações diferentes. Deve-se ressaltar que o participante não sabe das outras finalidades e benefícios que existem por trás de cada modelo perante o projeto, como um todo, a que estão vinculadas.

Questão "g": avaliar o grau de dificuldade do grupo de 9 tarefas que foram propostas no teste prático ou eventuais incapacidades do participante no ato de executar as tarefas solicitadas.

Regra para aplicação do questionário:

É disponibilizado para o participante somente após o término do teste prático com as duas interfaces e deve ser preenchido pelo próprio participante. Caso haja desistência no decorrer do teste, não será fornecido o questionário ao respectivo desistente. $\mathrm{O}$ avaliador não pode interferir ou ajudar o participante a responder o questionário fornecendo mais explicações, após a entrega do mesmo, portanto caso seja necessário elas serão apresentadas antes da entrega para o preenchimento. $\mathrm{O}$ participante será informado que ele não é obrigado a responder a todas as questões, deixando-o à vontade para participar ou não da pesquisa. Entretanto, o teste prático daquele que não responder o questionário será descartado.

\subsection{Conclusão do Capítulo}

Neste capítulo foi apresentado um método empírico para a avaliação de usabilidade de duas GUI distintas, porém destinadas a uma única finalidade bem como os procedimentos experimentais para uso do mesmo. O método consiste em determinar os grupos de análise, os atributos que os compõem e os mecanismos para coletar os dados que fundamentam a análise. Os dados registrados pelos mecanismos criados subsidiam as informações que serão utilizadas na avaliação de cada um dos dois grupos estabelecidos. Todos os procedimentos foram elaborados visando minimizar a subjetividade dos testes e conseqüentemente da mensuração dos dados coletados. 


\section{CAPÍTULO 6}

\section{RESULTADOS E TRATAMENTO ESTATÍSTICO}

Neste capítulo são apresentados os critérios e os métodos matemáticos aplicados no tratamento das amostras de dados coletados com os mecanismos criados. Na seqüência são apresentados e comentados, separadamente, os resultados das avaliações feitas com as amostras, tanto para o teste prático quanto para o questionário pós-teste sincronizado com o tratamento em uso. Finalizando o capítulo, os principais trechos dos vídeos gerados durante os testes práticos foram editados e são comentados para ilustrar os acontecimentos mais relevantes que ocorreram nos testes.

\subsection{Critérios e Métodos para as Avaliações}

Visivelmente as GUI têm diferenças não só por seguirem diferentes linguagens, mas sim pela interação do usuário que opera as funcionalidades de cada uma delas. Surge então a premissa de que estes fatores podem exercer influência no processo cognitivo do usuário iniciante em função do aplicativo, principalmente nos casos em que ele é utilizado como ferramenta de auxílio ao ensino desenho.

Pelo fato da interface do aplicativo Risko ser inovadora, não existem estudos contendo informações suficientes para que se possa compará-la com a interface do aplicativo $i$ Geom, que segue o padrão “WIMP”, já estudado em outras circunstâncias. Avaliar comparativamente os distintos modelos de GUI com o objetivo de comprovar ou não as prováveis diferenças existentes entre elas é de 
grande valia tanto para o ensino de desenho quanto para o segmento que lida com desenvolvimento de aplicativos. Se possível, espera-se após as análises obter informações suficientes para determinar qual das GUI melhor atende às necessidades impostas a uma ferramenta enquanto utilizada para auxiliar o ensino de Geometria Gráfica.

Conforme apresentado no capítulo 5, os dados gerados com os mecanismos de coleta estabelecidos são empregados para avaliar os atributos. No caso do teste prático com os usuários iniciantes, os dados servirão para avaliar o Grupo Usabilidade é composto pelos atributos: 1.1- Intuitividade e 1.2 - Facilidade para interpretar e utilizar as funcionalidades enquanto o mesmo teste executado pelo usuário experiente gera os dados para avaliar o Grupo Eficiência que é composto somente pelo atributo 2.1 Eficiência. Os dados obtidos com o questionário pós-teste são destinados à avaliação do atributo 1.3 Satisfação do usuário e, neste caso, o usuário experiente não participa da composição da amostra. A Tabela 6.1 apresenta o resumo do método estabelecido para a avaliação comparativa de GUI. Na primeira coluna da Tabela 6.1 são alocados os dois grupos de usabilidade conforme a ISO 9126. A coluna seguinte apresenta os atributos que compõem cada grupo apresentado na primeira coluna e que serão avaliados com os mecanismos criados e, finalmente, na terceira coluna desta mesma tabela estão associados aos atributos os mecanismos usados como fonte de coleta de dados para a avaliação do mesmo.

Tabela 6.1 - Resumo do método em uso para avaliação das GUI

\begin{tabular}{|c|l|l|}
\hline \multicolumn{1}{|c|}{ Grupos } & \multicolumn{1}{c|}{ Atributos a serem avaliados } & \multicolumn{1}{c|}{ Parâmetros } \\
\hline \hline \multirow{4}{*}{ 1 - Usabilidade } & 1.1 - Intuitividade & $\begin{array}{l}\text { Tempo médio (usuário } \\
\text { iniciante) menos o tempo } \\
\text { médio (usuário experiente) para } \\
\text { execução de tarefas. }\end{array}$ \\
\cline { 2 - 3 } & $1.2-\begin{array}{l}\text { Facilidade para interpretar e } \\
\text { utilizar as funcionalidades }\end{array}$ & $\begin{array}{l}\text { Número de erros e desistências } \\
\text { para cada tarefa. }\end{array}$ \\
\cline { 2 - 3 } Notas do questionário. \\
\hline \multirow{2}{*}{ - Eficiência } & 2.3 - Satisfação do usuário & $\begin{array}{l}\text { Tempo médio para execução do } \\
\text { exercício médio. }\end{array}$ \\
\hline
\end{tabular}




\subsubsection{Obtenção da Amostra}

Durante o período de 12 a 20 de abril de 2005 foram realizados 17 testes com as interfaces que geraram os dados para a avaliação. O material é composto pelos vídeos, planilhas de monitoramento dos testes e os questionários pós-teste. Neste trabalho serão apresentados, resumidamente, os principais dados e os resultados extraídos e a documentação completa encontra-se com o autor.

A amostra composta pelos 17 participantes dos testes são alunos regularmente matriculados na Escola Politécnica da Universidade de São Paulo - EPUSP, atendendo fielmente às características impostas pelo perfil de usuários que foi postulado. Os participantes dos testes foram captados a partir de cartazes afixados nos murais da Escola Politécnica. Portanto, a amostra foi obtida a esmo ou sem norma.

"É a amostragem em que o amostrador, para simplificar o processo, procura ser aleatório sem, no entanto, realizar propriamente o sorteio usando algum dispositivo aleatório confiável."

(COSTA NETO, 1977, p.44)

Costa Neto (1977) classifica a amostragem a esmo ou sem norma como uma amostra "não-probabilística", por considerar que a população é infinita e não está totalmente accessível, e foi obtida por meios que não são bem definidos como, por exemplo, sorteios ou com a aplicação criteriosa de uma regra para a sua composição. Tais fatores estão presentes na amostragem em uso neste trabalho, por isso, a amostra foi classificada como sendo não-probabilística.

\subsubsection{Classificação das Variáveis}

Costa Neto (1977) e Pereira (2004) chamam de "variável" aquilo que neste trabalho é denominado como dado, ou seja, as informações obtidas com os mecanismos de coleta de dados (teste prático e questionário pós-teste). Independentemente da terminologia em uso, os dados devem ser classificados antes de receberem um tratamento estatístico. 
"A variável será qualitativa quando resultar de uma classificação por tipos ou atributos. A variável será quantitativa quando seus valores forem expressos em números."

(COSTA NETO, 1977, p.6)

O critério utilizado para classificar os dados obtidos com os mecanismos de coleta segue a Classificação de Variáveis apresentada por Pereira (2004). Temos duas situações distintas, para os dados obtidos com o teste prático, expressos como números inteiros que não podem ser fracionados, são classificados como dados quantitativos. Os dados do questionário pós-teste, obtidos das respostas de múltipla escolha, seguem categorias ordinais que estão correlacionadas mantendo uma ordenação entre si, são classificados como dados qualitativos.

Não é possível aplicar um único método de tratamento estatístico para os dados qualitativos ou quantitativos, portanto, serão utilizados métodos distintos para avaliar os dados.

\subsection{Análise dos Dados Obtidos com o Teste Prático}

Pediu-se, para cada um dos 17 participantes dos testes, que realizassem um grupo de 9 tarefas duas vezes, ou seja, as mesmas tarefas feitas com os dois aplicativos. Tem-se 17 (testes) x 9 (tarefas) x 2 (aplicativos), o que representa 306 tarefas avaliadas. Separando por aplicativo, temos 153 tarefas para cada interface analisada. Destas 153 tarefas, 20 delas não foram concluídas com o uso do Risko, (o que equivale a $13 \%$ do total da amostra), e 2 delas não foram concluídas com o uso do $i$ Geom, (o que equivale a $1,3 \%$ do total da amostra). Seguem os resultados referentes aos erros e desistências verificadas nos 17 testes para cada uma das 9 tarefas separadas e comentadas para cada aplicativo:

- tarefa “1-desenhar dois pontos quaisquer”. Utilizando o Risko, 8 dos 17 participantes não realizaram corretamente a tarefa 1 , (o que representa $47 \%$ de erro sobre a amostra). Todos participantes concluíram corretamente a referida tarefa utilizando o $i \mathrm{Geom}$. 
- tarefa “4- desenhar um ponto sobre a reta criada”. Utilizando o Risko, 2 participantes não realizaram esta tarefa corretamente, (o que equivale a $12 \%$ de erro) e 1 participante desistiu de fazer a mesma, (representando $6 \%$ de desistência sobre o total da amostra). Somando os erros e a desistência, temos que 3 participantes não concluíram a tarefa 4, (o que representa $18 \%$ da amostra total). Todos participantes concluíram corretamente a referida tarefa utilizando o $i$ Geom.

- tarefa "5- desenhar uma reta passando pelos dois pontos criados". Utilizando o Risko, 3 participantes não realizaram corretamente esta tarefa, (o que equivale a $18 \%$ de erro), e 1 participante desistiu de fazê-la (o que representa $6 \%$ de desistência sobre o total da amostra). Somados os erros e a desistência, temos que 4 participantes não concluíram a tarefa 5 , (o que representa $24 \%$ do total da amostra) para o Risko. Todos participantes concluíram corretamente a referida tarefa utilizando o $i$ Geom.

- tarefa "6- desenhar um arco centrado em um dos pontos criados". Utilizando o Risko, 2 participantes não realizaram esta tarefa corretamente, (o que representa $12 \%$ da amostra) e utilizando o $i$ Geom, 1 participante desistiu de fazer a sexta tarefa, (o que equivale $6 \%$ da amostra).

- tarefa "7- desenhar uma reta paralela a uma das retas criadas". Utilizando o Risko, 2 participantes não realizaram a tarefa 7 corretamente, (o que equivale a $12 \%$ da amostra). Todos participantes concluíram corretamente a referida tarefa utilizando o $i \mathrm{Geom}$.

- tarefa "8- desenhar uma reta perpendicular a uma das retas criadas". Utilizando o Risko, 1 participante não realizou corretamente a referida tarefa, (representando $6 \%$ da amostra). Utilizando o $i$ Geom, 1 participante desistiu de fazer a tarefa 8 , (o que equivale a $6 \%$ da amostra).

Para as tarefas "2- desenhar uma reta qualquer", "3- desenhar um arco qualquer" e "9- apagar uma das figuras que acabou de criar", não houve erros ou desistências, (o que representa $0 \%$ da amostra). 
A Tabela 6.2 apresenta os valores e respectivos percentuais para os dados obtidos com os testes, separadamente, por aplicativo.

Tabela 6.2 - Resumo dos valores obtidos sobre os erros e as desistências

\begin{tabular}{c|cccccc|cccccc}
\hline Tarefa & \multicolumn{7}{|c|}{ Risko } & \multicolumn{7}{c}{ iGeom } \\
\hline \hline & erro & $\%$ & desist. & $\%$ & total & $\%$ & erro & $\%$ & desist. & $\%$ & total & $\%$ \\
\cline { 2 - 13 } $\boldsymbol{1}$ & 8 & 47,0 & 0 & 0,0 & 8 & 47,0 & 0 & 0,0 & 0 & 0,0 & 0 & 0,0 \\
$\mathbf{2}$ & 0 & 0,0 & 0 & 0,0 & 0 & 0,0 & 0 & 0,0 & 0 & 0,0 & 0 & 0,0 \\
$\mathbf{3}$ & 0 & 0,0 & 0 & 0,0 & 0 & 0,0 & 0 & 0,0 & 0 & 0,0 & 0 & 0,0 \\
$\mathbf{4}$ & 2 & 12,0 & 1 & 6,0 & 3 & 18,0 & 0 & 0,0 & 0 & 0,0 & 0 & 0,0 \\
$\mathbf{5}$ & 3 & 18,0 & 1 & 6,0 & 4 & 24,0 & 0 & 0,0 & 0 & 0,0 & 0 & 0,0 \\
$\mathbf{6}$ & 2 & 12,0 & 0 & 0,0 & 2 & 12,0 & 0 & 0,0 & 1 & 6,0 & 1 & 6,0 \\
7 & 2 & 12,0 & 0 & 0,0 & 2 & 12,0 & 0 & 0,0 & 0 & 0,0 & 0 & 0,0 \\
$\mathbf{8}$ & 1 & 6,0 & 0 & 0,0 & 1 & 6,0 & 0 & 0,0 & 1 & 6,0 & 1 & 6,0 \\
$\mathbf{9}$ & 0 & 0,0 & 0 & 0,0 & 0 & 0,0 & 0 & 0,0 & 0 & 0,0 & 0 & 0,0 \\
\hline Soma & $\mathbf{1 8}$ & \multicolumn{18}{c}{$\mathbf{2}$} & $\mathbf{2 0}$ & & $\mathbf{0}$ & & $\mathbf{2}$ & & $\mathbf{2}$ & \\
\hline
\end{tabular}

\subsubsection{Avaliação do atributo "1.1 Intuitividade"}

Este atributo foi avaliado pelo tempo que o usuário inexperiente consome para entender como se executa cada tarefa com os aplicativos. Este tempo é estimado subtraindo-se do tempo total gasto pelo usuário inexperiente (Tabelas B.1 e B.2 disponíveis no Apêndice B) para executar cada tarefa o tempo médio que foi gasto pelo usuário experiente na execução da mesma tarefa 13 apresentados na Tabela 6.3. Os tempos reais para a execução de cada tarefa, pelos usuários iniciantes são apresentados nas Tabelas B.3 e B.4 do Apêndice B. Para este caso são consideradas somente as tarefas realizadas corretamente, descartando-se as demais. Os tempos médios de execução das tarefas pelo usuário experiente foram obtidos conforme descrito na secção 6.2.3 e estão reproduzidos na Tabela 6.3.

\footnotetext{
${ }^{13}$ Para a tarefa 1, em que são desenhados dois pontos, o tempo de execução é subtraído em dobro.
} 
Tabela 6.3 - Tempo médio para executar cada tarefa

\begin{tabular}{lcc}
\hline \multicolumn{1}{c}{ Tarefas } & \multicolumn{2}{c}{ Tempo Médio } \\
\hline \hline & Risko & iGeom \\
\cline { 2 - 3 } 1. desenhar ponto & 03,83 & 02,57 \\
2. desenhar uma reta & 07,20 & 03,29 \\
3. desenhar um arco & 04,63 & 02,81 \\
4. desenhar um ponto sobre uma reta & 05,04 & 02,58 \\
5. desenhar uma reta passando por 2 pontos & 13,76 & 05,14 \\
6. desenhar um arco centrado em um ponto & 06,57 & 05,41 \\
7. desenhar uma reta paralela & 25,36 & 03,90 \\
8. desenhar uma reta perpendicular & 15,84 & 04,09 \\
9. apagar uma figura & 04,00 & 03,63 \\
\hline
\end{tabular}

Tempos apresentados em segundos e centésimos (ss,00).

Para verificar estatisticamente a significância dos dados obtidos é utilizado um teste de hipóteses. O teste em questão consiste em formular duas hipóteses. Uma delas é a "hipótese nula" $(H 0)$ e a outra é a "hipótese alternativa" $(H 1)$. O teste de hipóteses permite aceitar, a um determinado nível de significância, a hipótese alternativa quando a hipótese nula é rejeitada. Assim a hipótese que é colocada à prova é a hipótese nula e que no geral indica a igualdade a ser contestada. As hipóteses formuladas e que serão testadas neste caso são as seguintes:

$$
\begin{aligned}
\boldsymbol{H O}= & \text { não existe diferença no tempo médio para o usuário iniciante } \\
& \text { entender como executar a tarefa nas duas interfaces; } \\
\boldsymbol{H 1}= & \text { existe diferença no tempo médio para o usuário iniciante entender } \\
& \text { como executar a tarefa nas duas interfaces. }
\end{aligned}
$$

Para o teste das hipóteses foi empregado o teste de "Wilcoxon-MannWhitney” (Costa Neto, 1977 p.145), obtendo-se os resultados apresentados na Tabela 6.4, adotando-se nível de significância $\alpha=0,05$. 
Tabela 6.4 - Tempo gasto para o entender o funcionamento

\begin{tabular}{|c|c|c|c|c|}
\hline Tarefas & \multicolumn{2}{|c|}{ Tempos médios } & p-valores & Resultado \\
\hline & Risko & iGeom & & \\
\hline 1. desenhar ponto & 49,90 & 06,39 & 0,002 & rejeita $H 0$ \\
\hline 2. desenhar uma reta & 17,92 & 11,71 & 0,003 & rejeita $H O$ \\
\hline 3. desenhar um arco & 11,78 & 18,43 & 0,801 & não rejeita $H 0$ \\
\hline 4. desenhar ponto sobre uma reta & 23,67 & 17,07 & 0,506 & não rejeita $H O$ \\
\hline 5. desenhar reta por 2 pontos & 29,86 & 15,68 & 0,219 & não rejeita $H 0$ \\
\hline 6. desenhar arco centrado em ponto & 19,36 & 08,99 & 0,452 & não rejeita $H 0$ \\
\hline 7. desenhar uma reta paralela & 37,28 & 18,10 & 0,000 & rejeita $H 0$ \\
\hline 8. desenhar uma reta perpendicular & 26,80 & 12,29 & 0,037 & rejeita $H 0$ \\
\hline 9. apagar uma figura & 18,76 & 38,43 & 0,085 & rejeita $H O$ \\
\hline
\end{tabular}

Tempos apresentados em segundos e centésimos (ss,00).

Os resultados permitem concluir que desenhar pontos, retas, perpendiculares e paralelas com o Risko é menos intuitivo que com o $i$ Geom. Já, apagar figuras é mais intuitivo com o Risko. Para as demais tarefas o p-valor obtido não permitiu uma conclusão ao nível de significância adotada.

\subsubsection{Avaliação do atributo "1.2 Facilidade para interpretar as funcionalidades"}

Este atributo será avaliado comparando-se o desempenho (acerto ou erro) que cada usuário obtém executando as tarefas em cada uma das interfaces. Assim, tratase de duas amostras pareadas, já que será verificados o desempenho do mesmo usuário com os dois aplicativos.

A avaliação comparativa das amostras pareadas consiste em checar, por meio de um teste de hipóteses, as seguintes hipóteses formuladas:

$$
\begin{aligned}
\boldsymbol{H O}= & \text { não existe diferença na taxa de erros na execução da tarefa } \\
& \text { com as duas interfaces; } \\
\boldsymbol{H 1}= & \text { existe diferença na taxa de erros ao executar a tarefa } \\
& \text { utilizando cada uma das interfaces. }
\end{aligned}
$$

As hipóteses formuladas são válidas para a comparação de cada um dos pares amostrais para as 9 tarefas. Rosner (1999) recomenda, para testar hipóteses com amostras pareadas e com distribuição binomial, o teste de "McNemar". Pois, o teste de "McNemar" possibilita a comparação de pares amostrais, sendo ele realizado 
após a separação dos dados amostrais a fim de formar pares concordantes ou discordantes:

"A concordant pair is a matched pair in the which the outcome is the same for each member of the pair."

"A discordant pair is a matched pair in which the outcomes are different for each member of the pair."

(ROSNER, 1999, p. 378)

Neste caso, para o teste de "McNemar" serão considerados somente os pares discordantes. Para facilitar a visualização dos pares formados por tarefa, foram utilizadas tabelas que seguem o modelo da Tabela 6.5, que apresenta o somatório dos dados obtidos para a tarefa 1 do teste prático.

Tabela 6.5 - Somatório dos dados pareados para a tarefa 1

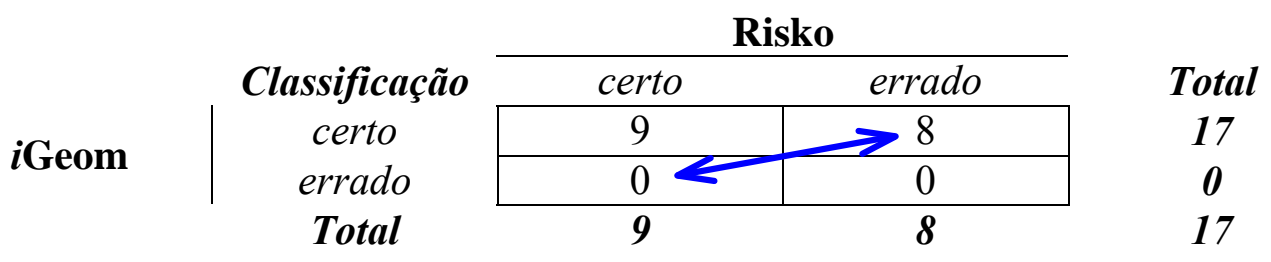

A Tabela 6.5 possibilita visualizar facilmente a seguinte informação: os pares concordantes são as tarefas classificadas como "certo/certo" ou "errado/errado" (na diagonal 9 e 0 ) e, os pares discordantes referem-se às tarefas classificadas como "certo/errado" e "errado/certo" (na diagonal 8 e 0), para a tarefa 1. No Apêndice B as Tabelas B.5 à B.13 mostram os dados completos que foram utilizados e no teste.

Antes de validar ou não uma hipótese, é necessário checar o "nível de significância” ou "p-valor” ( $p$-value) para controlar erro do tipo I14

"All statistical tests produce a p-value and this is equal to the probability of obtaining the observed difference, or one more extreme, if the null hypothesis is true. To put it another way - if the null hypothesis is true, the p-value is the probability of obtaining a difference at least as large as that observed due to sampling variation.

\footnotetext{
${ }^{14}$ erro tipo I: rejeitar $\mathrm{H}_{0}$, sendo $\mathrm{H}_{0}$ verdadeira/erro tipo II: aceitar $\mathrm{H}_{0}$, sendo $\mathrm{H}_{0}$ falsa.
} 
Consequently, if the p-value is small the data support the alternative hypothesis. If the p-value is large the data support the null hypothesis. But how small is 'small' and how large is (large)?! Conventionally (and arbitrarily) a p-value of $0.05(5 \%)$ is generally regarded as sufficiently small to reject the null hypothesis. If the p-value is larger than 0.05 we fail to reject the null hypothesis. The 5\% value is called the significance level of the test."

(LEARNING TECHNOLOGIES DEPARTMENT OF THE UNIVERSITY

OF THE WEST OF ENGLAND, 2002)

Usualmente adota-se um nível de significância de 5\% ( $\alpha$ ) para testar a hipótese. É possível calcular o "nível de significância” ou " $p$-valor exato”, partindo dos dados amostrais. Rosner (1999) recomenda as seguintes equações para a obtenção do p-valor exato, especialmente se o número de pares discordantes for menor que 20:

$$
\begin{gathered}
p=2 \times \sum_{k=0}^{n_{A}}\left(\begin{array}{c}
n_{D} \\
k
\end{array}\right)\left(\frac{1}{2}\right)^{n_{D}} \text { se } n_{A}<n_{D} / 2 \\
p=2 \times \sum_{k=n_{A}}^{n_{D}}\left(\begin{array}{c}
n_{D} \\
k
\end{array}\right)\left(\frac{1}{2}\right)^{n_{D}} \text { se } n_{A}>n_{D} / 2 \\
p=1 \text { se } n_{A}=n_{D} / 2
\end{gathered}
$$

onde:

$n A=$ número de pares onde houve acerto com $i$ Geom e erro com Risko; $n D=$ total de pares discordantes;

A validade de um teste de hipóteses está relacionada diretamente com o "nível de significância" ou valor do nível " $p$ ” considerado para a amostra.

"A significância estatística de um resultado é uma medida estimada do grau em que este resultado é 'verdadeiro' (no sentido de que seja realmente o que ocorre na população, ou seja, no sentido de 'representatividade da população'). Mais tecnicamente, o valor do nivel-p representa um indice decrescente da confiabilidade de um 
resultado. Quanto mais alto o nivel-p, menos se pode acreditar que a relação observada entre as variáveis na amostra é um indicador confiável da relação entre as respectivas variáveis na população."

(REIS, 2005)

A Tabela 6.6 mostra os p-valores calculados para cada uma das 9 tarefas com o objetivo de checar as amostras considerando um $\alpha=0,05$ de significância.

Tabela 6.6 - Análise da significância pelo p-valor

\begin{tabular}{cccc}
\hline Tarefas & p-valores & Análise para $\boldsymbol{\alpha}=\mathbf{0 , 0 5}$ & Resultados \\
\hline $\mathbf{1}$ & 0,008 & significativo & rejeita $\boldsymbol{H O}$ \\
$\mathbf{2}$ & 1,000 & não significativo & inconclusivo \\
$\mathbf{3}$ & 1,000 & não significativo & inconclusivo \\
$\mathbf{4}$ & 0,250 & não significativo & não rejeita $\boldsymbol{H 0}$ \\
$\mathbf{5}$ & 0,125 & não significativo & não rejeita $\boldsymbol{H 0}$ \\
$\mathbf{6}$ & 1,000 & não significativo & não rejeita $\boldsymbol{H O}$ \\
$\mathbf{7}$ & 0,500 & não significativo & não rejeita $\boldsymbol{H O}$ \\
$\mathbf{8}$ & 1,000 & não significativo & inconclusivo \\
$\mathbf{9}$ & 1,000 & não significativo & inconclusivo \\
\hline
\end{tabular}

Analisando os resultados apresentados na última coluna da Tabela 6.6, conclui-se que somente para a tarefa 1 "HO" é rejeitada segundo o nível de significância adotado. Para as tarefas 2, 3, 8 e 9, que apresentaram pares discordantes com valores idênticos (veja Apêndice B), não foi possível detectar nenhuma tendência que favoreça uma ou outra hipótese formulada, portanto são inconclusivas. Para as tarefas 4, 5, 6 e 7 que apresentaram o p-valor superior ao “ $\alpha$ ” estabelecido não se pode rejeitar " $H O$ ”.

As tarefas 4, 5, 6 e 7 apresentaram o número de pares discordantes muito pequeno. Isso se deve ao fato do tamanho da amostra também ser reduzida. Para esses casos (em que $\mathrm{nA} \neq \mathrm{nD} / 2$ ), é possível estimar o tamanho da amostra mínima $n$ necessária para rejeitar a hipótese nula com o nível de significância adotado, valendo-se da seguinte fórmula: 


$$
n=\frac{\left(z_{1-\alpha / 2}+2 z_{1-\beta} \sqrt{P_{A} q_{A}}\right)^{2}}{4\left(P_{A}-0,5\right)^{2} P_{D}}
$$

onde:

$n$ = número total de pares da amostra;

$P D=$ proporção estimada de pares discordantes dentre todos os pares;

$P A=$ proporção estimada de pares com acerto usando o $i$ Geom e erro usando

o Risko, dentre todos os pares discordantes;

$q A=1-P A$ ou proporção estimada de pares com erro usando o $i$ Geom e acerto usando o Risko, dentre todos os pares discordantes.

A Tabela 6.7 apresenta o resultado do cálculo feito para obter o número total de pares amostrais necessário para validar uma das hipóteses formuladas, considerando as tarefas $4,5,6$ e 7 .

Tabela 6.7 - Cálculo da amostra necessária $n$

\begin{tabular}{cc}
\hline Tarefas & $\boldsymbol{n}$ \\
\hline $\mathbf{4}$ & 22 \\
$\mathbf{5}$ & 16 \\
$\mathbf{6}$ & 511 \\
7 & 33 \\
\hline
\end{tabular}

Considerados $\alpha=0,05$ que é associado ao erro do tipo I e $\beta=0,10$ que é associado ao erro do tipo II

Para o atributo 1.2- Facilidade para interpretar e utilizar as funcionalidades pode-se concluir que a funcionalidade de desenhar pontos quaisquer (tarefa 1) é mais facilmente interpretada no $i$ Geom que no Risko.

\subsubsection{Avaliação do atributo "2.1 Eficiência"}

Para avaliar o atributo 2.1 Eficiência, é utilizado um teste prático com as mesmas 9 tarefas apresentas anteriormente, mas agora sendo executadas várias vezes por um único usuário experiente nos dois aplicativos. 
Para a execução deste teste, as áreas de desenho dos aplicativos foram divididas em 9 partes como mostra a Figura 6.1, e em cada área foram executadas as tarefas propostas no teste. Assim, a tarefa 1 foi realizada uma vez em cada área da tela e o tempo total foi cronometrado. Em seguida, foi repetido o procedimento para a tarefa 2 e assim por diante. A Figura 6.1 ilustra o resultado final do procedimento descrito, com a interface do Risko.

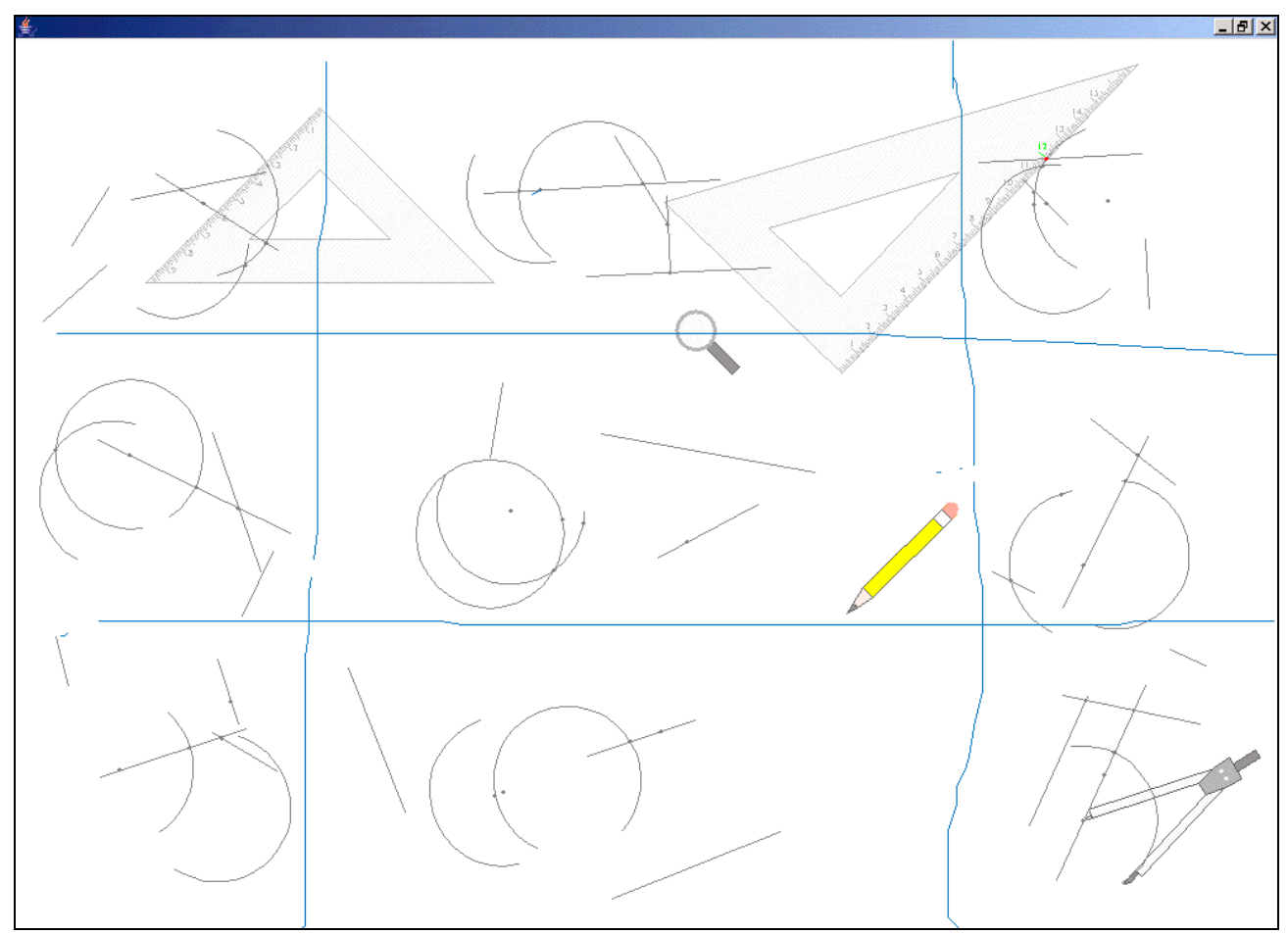

Figura 6.1 - Interface com a resolução das tarefas pelo usuário experiente

Os tempos médios para a execução de cada uma das tarefas foram calculados e estão apresentados na Tabela 6.3, para os dois aplicativos.

Para avaliar a eficiência, estimou-se o tempo de execução de um exercício cuja resolução demanda a construção do número médio de elementos de cada tipo, conforme a freqüência relativa por tarefa indicada na Tabela 5.1.

Os cálculos realizados mostram que são necessários, em média, 1:50,01s para executar o exercício médio com o auxílio do $i$ Geom e 6:01,68s para executar o mesmo exercício valendo-se do Risko, ou seja, 3,3 vezes mais. 
Estes são os principais dados obtidos com os testes práticos e que serviram para comparar as interfaces dos aplicativos na avaliação dos grupos: 1- Usabilidade (1.1- Intuitividade, 1.2- Facilidade para interpretar e utilizar as funcionalidades) e 2- Eficiência (2.1-Eficiência).

\subsection{Análise dos Dados Obtidos com o Questionário Pós-teste}

Partindo-se do pressuposto que as interfaces têm diferenças, segundo a opinião dos participantes, e que os mesmos preferem uma delas, mas não se sabe qual, o questionário pós-teste foi aplicado com a finalidade de gerar os dados para avaliar o atributo 1.3- Satisfação do usuário e, se possível, apontar qual das interfaces é a preferida pelos participantes.

Inicialmente, é preciso classificar as questões a fim de aplicar o tratamento adequado aos dados gerados. Para isso, os resultados extraídos dos questionários foram separados em dois grupos para análise: o primeiro grupo é formado pelas respostas obtidas para as 5 questões de múltipla escolha “A, C, E, F e G” e o segundo grupo é formado pelas 2 questões cujas respostas foram obtidas com a aplicação da escala Likert "B x D". Tal divisão faz-se necessária, pelo fato do tratamento estatístico ser diferente para os grupos. Pois, as questões “A, C, E, F e G”, destinadas a comparações diretas entre as interfaces, são classificadas como unidimensionais e os dados serão apenas apresentados. No entanto, as questões comparativas "B x D composta por (4 sub-itens - a, b, c, d)" são classificadas como bidimensionais independentes e devem ser tratadas estatisticamente.

Os comentários e resultados observados a respeito dos dados obtidos para as questões unidimensionais “ $\mathrm{A}, \mathrm{C}, \mathrm{E}, \mathrm{F}$ e $\mathrm{G}$ ” foram: 
- Objetivando verificar a familiaridade dos participantes do teste com o computador, perguntou-se na primeira questão " $A$ - Com qual freqüência você usa o computador?". Os 17 participantes responderam "todos os dias", (o que representa 100\% da amostra). A Figura 6.2 apresenta os resultados da questão.

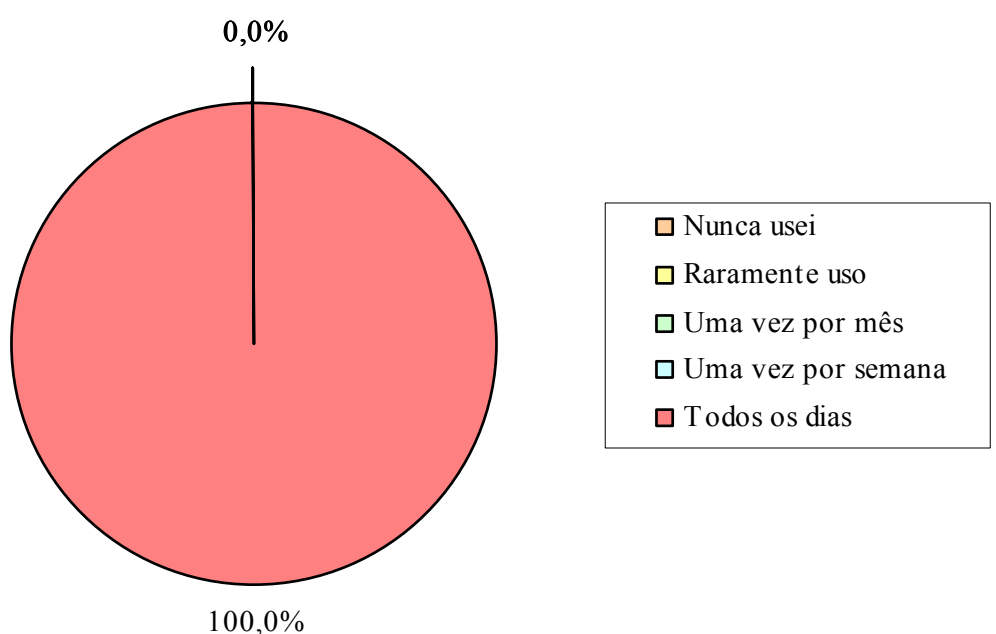

Figura 6.2 - Gráfico referente à freqüência de uso do computador

Os dados apresentados anteriormente comprovam que o uso do computador, considerando a amostra de participantes, não constitui uma barreira para a realização do mesmo e que o perfil postulado é capaz de manipular a ferramenta computador. 
- $\mathrm{Na}$ segunda questão, perguntou-se aos participantes " $C / E$ - Você teve dificuldades ao usar o programa Risko/iGeom? Caso sim, quais os prováveis motivos? (marque quantas quiser)!”.

A pergunta buscou identificar alguns problemas nas interfaces que geram dificuldades de uso das mesmas. O resultado observado foi: 9 e 7 participantes responderam ter dificuldades para "Entender o funcionamento dos comandos $e$ instrumentos de desenho" ou que "Faltam explicações na tela" ao utilizar a interface do Risko. Para o uso da interface do $i$ Geom, 9 participantes responderam ter dificuldades para "Encontrar os comandos desejados" e 5 responderam não "Entender o funcionamento dos comandos e instrumentos de desenho". A Figura 6.3 mostra o gráfico de barras referente aos percentuais de respostas.

\section{Dis tribuição das respostas (\%)}

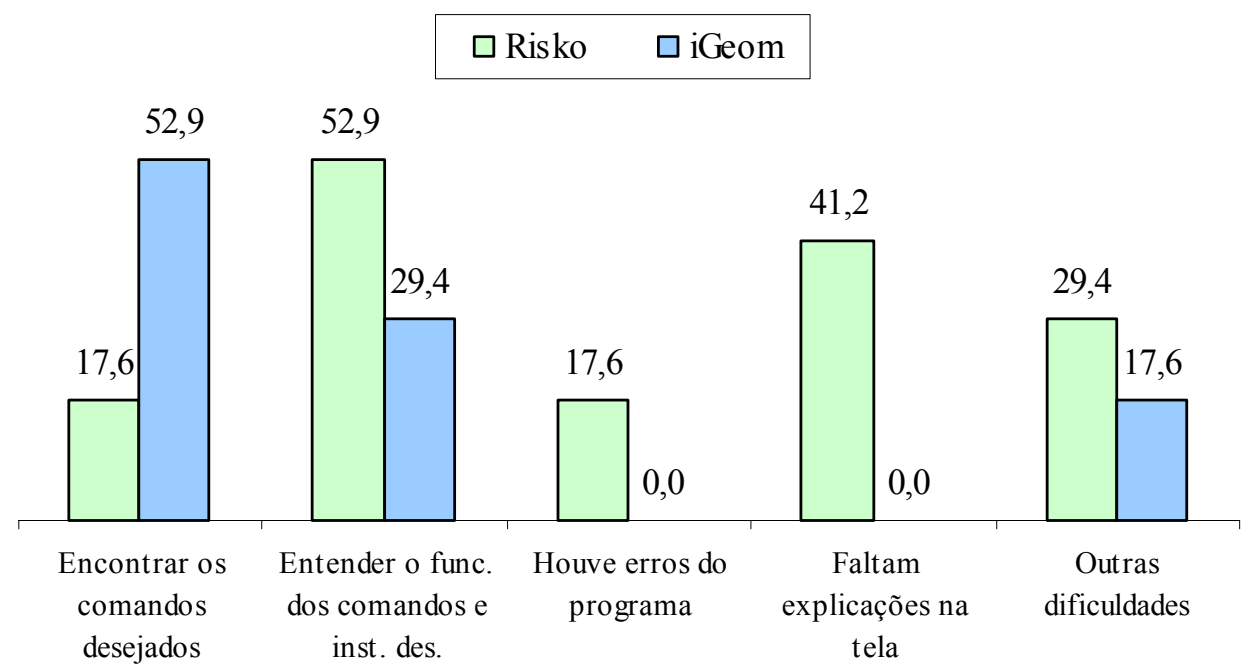

Figura 6.3 - Gráfico comparativo sobre a credibilidade dos programas

É perceptível que houve uma distribuição das respostas, nas 5 opções apresentadas, considerando a interface do Risko. Para o $i$ Geom, os participantes concentraram suas respostas na primeira, segunda e última opções e as demais não foram mencionadas. 
- A questão sobre a preferência de uso de um dos aplicativos para ocasiões específicas, inicialmente perguntou " $F$ - Caso você tenha que usar um dos programas durante todo o curso de desenho, qual você gostaria de usar para as seguintes atividades?". A questão "F" é sub-dividida em três partes para melhor representar as distintas situações de uso, normalmente encontradas num curso de desenho.

Como relação ao uso "em sala de aula", 15 participantes optaram pelo Risko e 2 pelo $i$ Geom, (respectivamente $88,2 \%$ e $11,8 \%$ da amostra). A segunda questão tratou o uso "em casa para estudar ou fazer os trabalhos e exercícios", 6 participantes preferem o Risko e os outros 11 preferem o $i$ Geom, (respectivamente 35,3\% e 64,7\% da amostra). Com relação ao uso "para fazer as provas", 9 participantes escolheram o Risko e 8 optaram pelo $i$ Geom, (respectivamente 52,9\% e 47,1\% da amostra). A Figura 6.4 com o gráfico de barras referente aos percentuais de respostas.

\section{Dis tribuição das respostas (\%)}

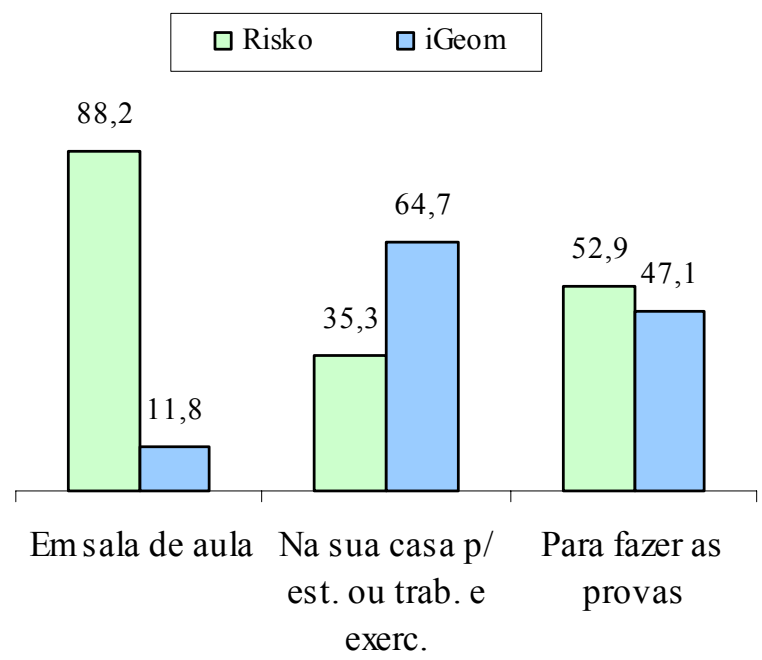

Figura 6.4 - Gráfico comparativo de preferência de uso em um curso 
- Na última questão perguntou-se "G-Você teve dificuldades para realizar as tarefas propostas no teste?”. O objetivo é identificar se os participantes tiveram dificuldades para realizar as tarefas que foram propostas no teste. Como resposta, somente 1 (um) dentre os 17 participantes escolheu o item "as tarefas foram dificeis de resolver". No entanto, o mesmo participante realizou todas as tarefas com sucesso. Outros 4 participantes responderam "outras dificuldades" e os demais, 12 participantes, não se manifestaram. A Figura 6.5 mostra o gráfico de barras referente aos percentuais de respostas.

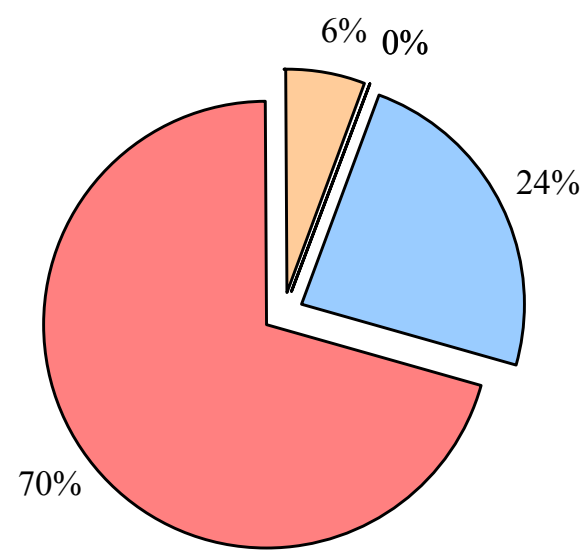

$\square$ As tarefas foram difíceis de resolver

$\square$ A seqüência das tarefas foi complicada

$\square$ Não entendi o que foi pedido para fazer

$\square$ Outras dificuldades

$\square$ Nada respondeu

Figura 6.5 - Gráfico referente às dificuldades em realizar as tarefas

A questão "G" comprovou que, na opinião dos participantes, as tarefas propostas no teste não constituíam barreiras para a conclusão das mesmas. Portanto, as tarefas incorretas e as desistências não são justificadas pelo grau de dificuldade inerente a execução das tarefas propostas no teste.

Às questões unidimensionais “A, C, E, F e G”, não cabe qualquer tratamento estatístico e têm como finalidade mostrar algumas características dos participantes do teste. 
Na questão comparativa "B x D", bidimensionais independentes, perguntouse aos participantes “ $B \times D$-Após usar os programas Risko e iGeom para resolver os exercícios, quais avaliações você faz?”. Esta questão é sub-dividida em 4 itens (a, b, c, d) que foram respondidos pelos participantes numa escala tipo Likert a fim de comparar diretamente as respostas obtidas para os aplicativos. Cada um dos 4 itens é tratado separadamente para facilitar a visualização dos dados coletados. Os dados são apresentados em tabelas que trazem primeiro os dados referentes ao Risko e depois os dados referentes ao $i$ Geom. Seguem os 4 itens avaliados e respectivos dados amostrais e respectivos gráficos de barras.

O item "a" é destinado à comparar o tempo gasto para executar cada uma das 9 tarefas com o auxílio de uma das ferramentas computacionais frente a execução das mesmas tarefas valendo-se das ferramentas físicas. Como resultado, 35,3\% dos participantes respondeu que "Foi mais demorado do que no papel" utilizando o Risko e, 41,2\% respondeu que "Foi muito mais rápido que resolver no papel" utilizando o $i$ Geom. A Figura 6.6 mostra a distribuição das respostas em um gráfico de barras.

\section{Distribuição das respostas (\%)}

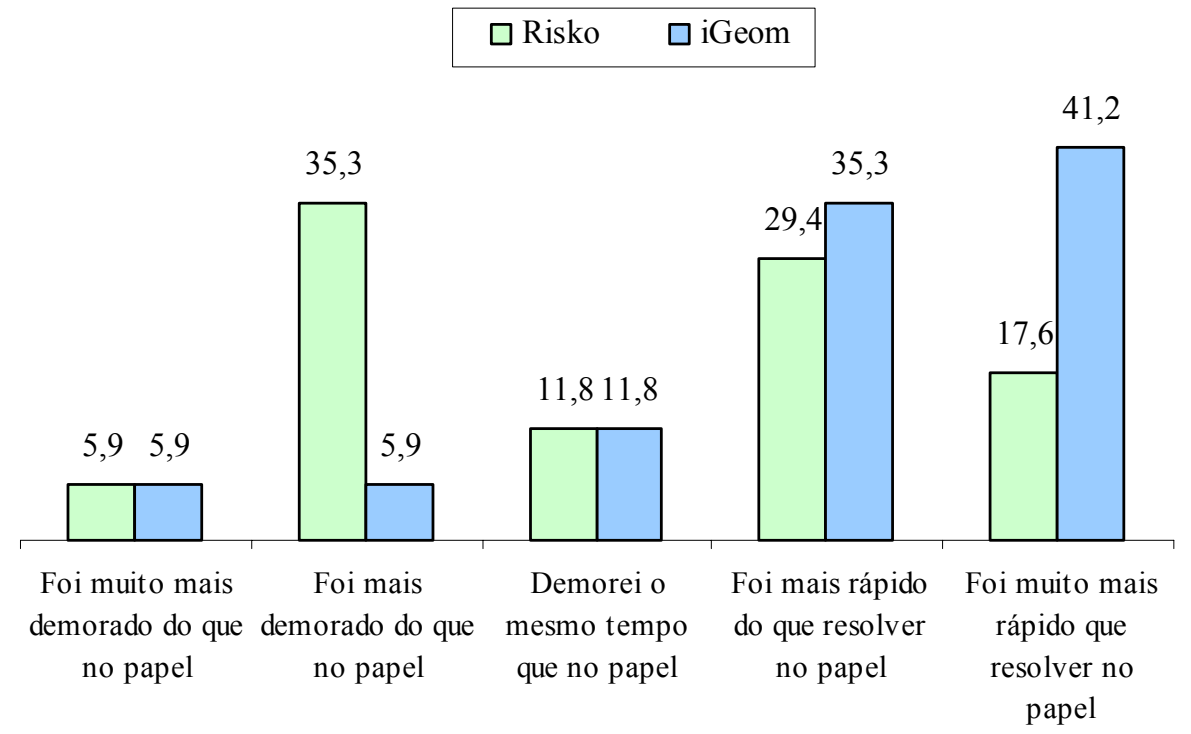

Figura 6.6 - Gráfico comparativo de tempo consumido 
O item "b" é destinado a mapear o gosto ou afeição dos participantes por um dos dois aplicativos. As respostas se concentraram na opção "Gostei do programa” onde $47,1 \%$ optaram pelo Risko contra $41,2 \%$ que escolheram a mesma resposta para o $i$ Geom. A Figura 6.7 mostra a distribuição das respostas em um gráfico de barras.

\section{Distribuição das respostas $(\%)$}

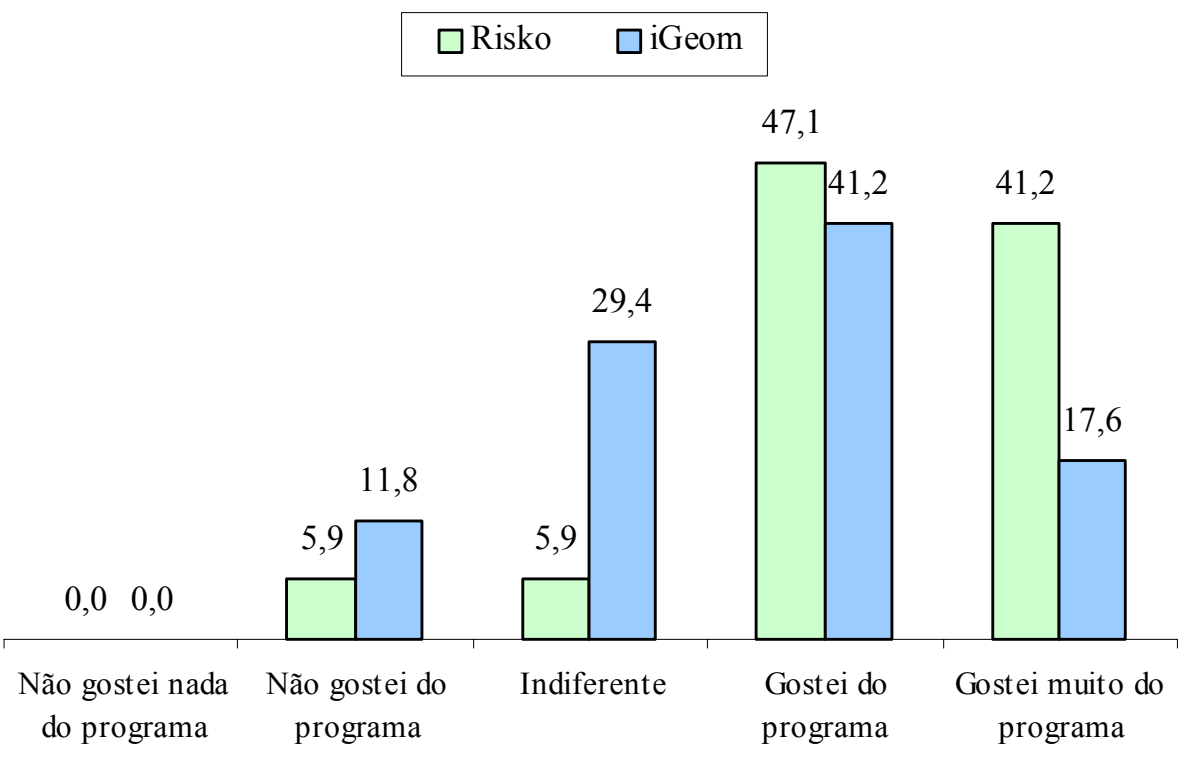

Figura 6.7 - Gráfico comparativo de preferências por aplicativo 
O item "c" trata da dificuldade dos participantes em utilizar os aplicativos. Onde 82,4\% dos participantes responderam "É fácil de usar" com relação ao Risko enquanto 52,9\% escolheu a mesma opção como resposta para o $i$ Geom. A Figura 6.8 apresenta a distribuição das respostas em um gráfico de barras.

\section{Dis tribuição das respostas (\%)}

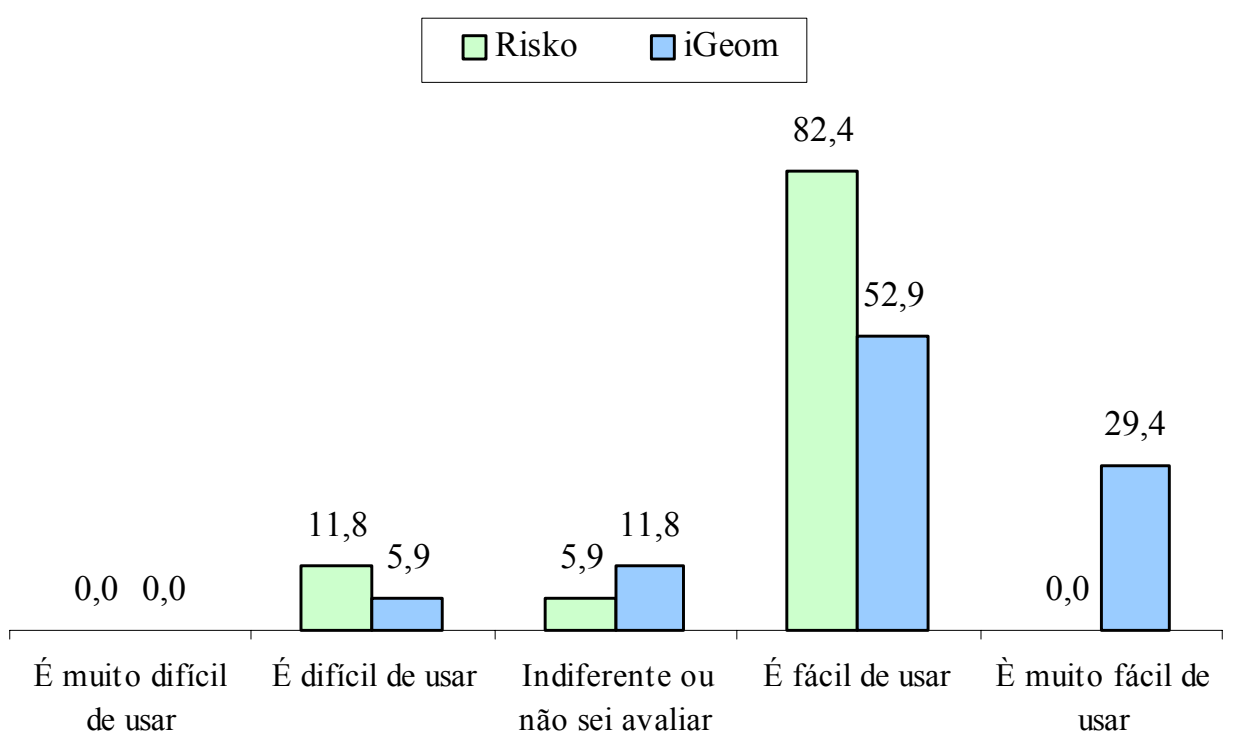

Figura 6.8 - Gráfico comparativo referente as dificuldades de uso

Finalmente o item "d", destinado a avaliar o grau de confiabilidade transmitida pelos aplicativos aos usuários revelou que 76,5\% escolheram como resposta "Confio parcialmente na precisão das construções feitas com o programa" com relação ao Risko, e 64,7\% respondeu "Confio totalmente na precisão das construções feitas com o programa" utilizando o $i$ Geom. A Figura 6.9 mostra a distribuição das respostas em um gráfico de barras. 
Distribuição das respostas (\%)

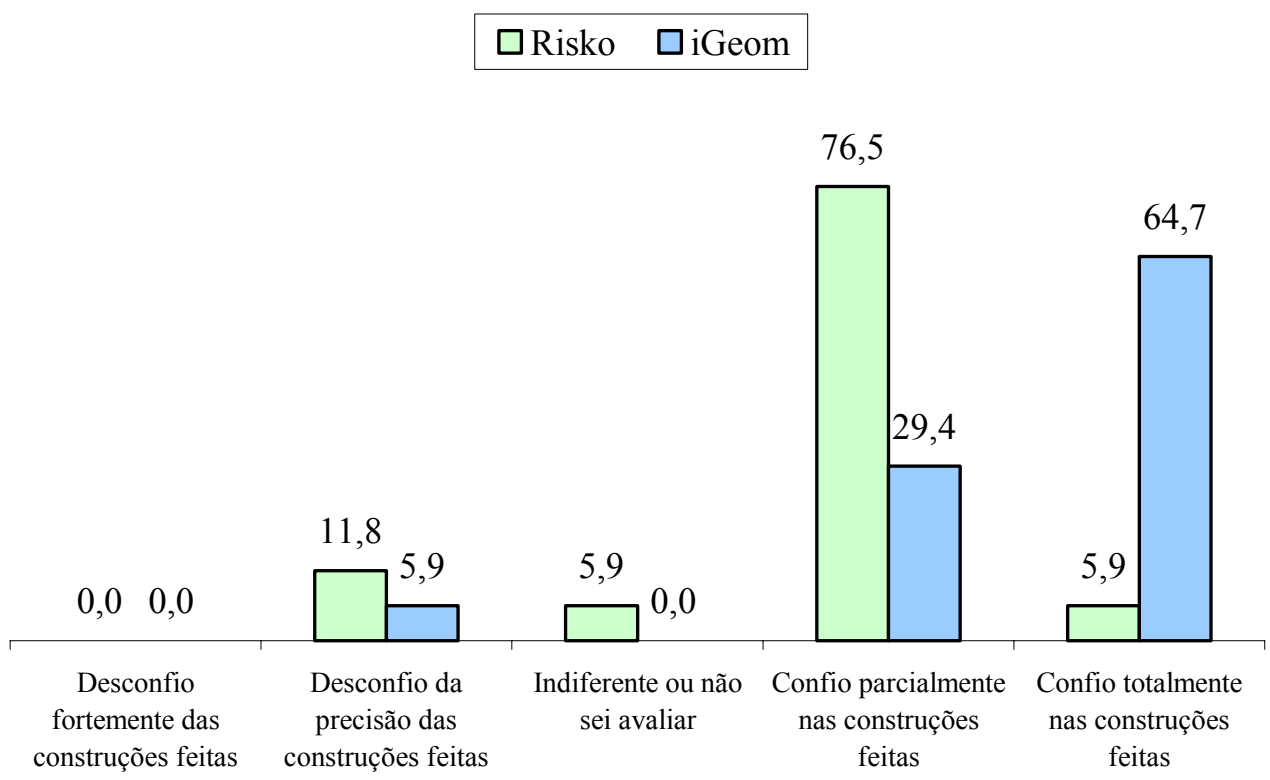

Figura 6.9 - Gráfico comparativo sobre a confiabilidade transmitida

A Figura 6.10 mostra um gráfico de barras horizontais que possibilita visualizar cada nota obtida com relação aos valores, máximo (2) e mínimo (-2).

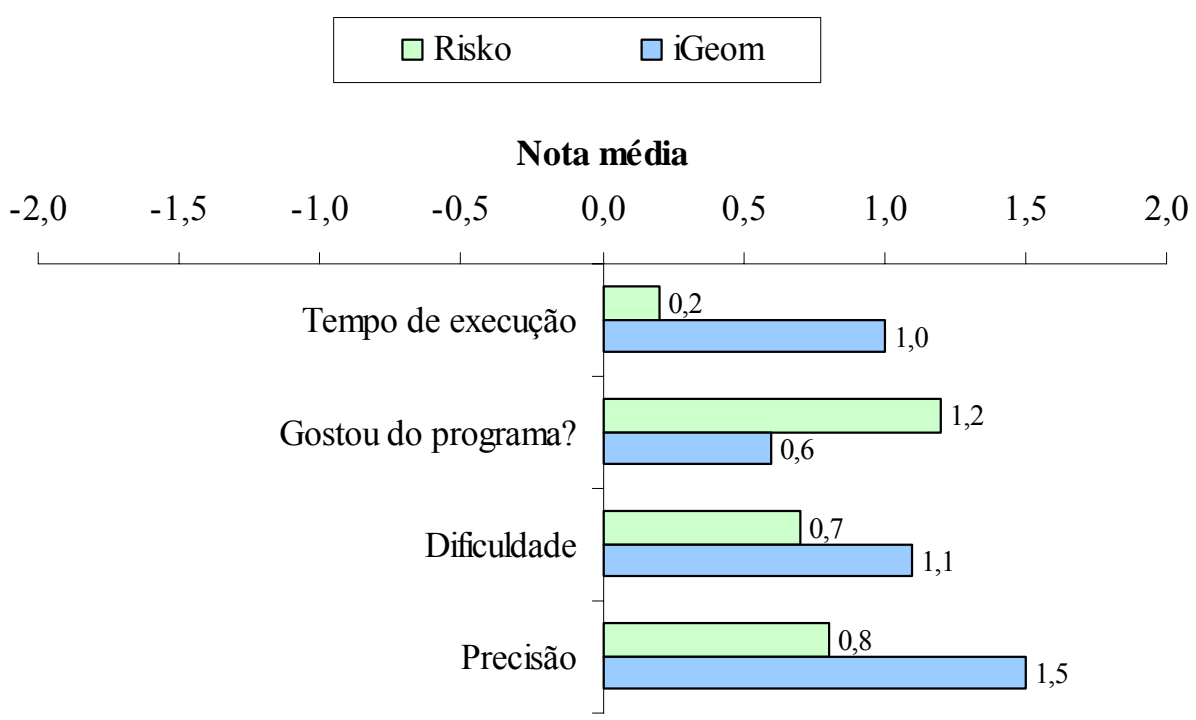

Figura 6.10 - Gráfico comparativo das notas médias por sub-item 
É possível notar que no gráfico apresentado as médias obtidas foram positivas, isso indica que ambas as interfaces foram bem aceitas pelos participantes do teste. Visivelmente as médias obtidas em 3 dos 4 itens avaliados favorecem o $i$ Geom, e somente em 1 dos itens o Risco obteve média superior ao $i$ Geom. As tabelas que geraram os gráfico apresentadas estão disponíveis no Apêndice C.

Apresentados e comentadas as amostras obtidas com o questionário para a questão comparativa “B x D”, bidimensionais independentes, as seguintes hipóteses foram formuladas para os itens " $a, b, c, d$ " a fim de serem testadas:

$$
\begin{aligned}
H 0 \boldsymbol{a}= & \text { não há diferença percebida pelo usuário no tempo de } \\
& \text { execução das construções com os aplicativos; } \\
\boldsymbol{H 1 \boldsymbol { a }}= & \text { há diferença percebida pelo usuário no tempo de } \\
& \text { execução das construções com os aplicativos. } \\
\boldsymbol{H 0 b}= & \text { o usuário gosta igualmente de ambos os aplicativos; } \\
\boldsymbol{H 1 \boldsymbol { b } =} & \text { o usuário não gosta igualmente de ambos os aplicativos. } \\
\boldsymbol{H 0 c}= & \text { não há diferença percebida pelo usuário na dificuldade } \\
& \text { de execução das construções com os aplicativos; } \\
\boldsymbol{H 1 c}= & \text { há diferença percebida pelo usuário na dificuldade de } \\
& \text { execução das construções com os aplicativos. } \\
\boldsymbol{H 0 d}= & \text { não há diferença percebida pelo usuário na precisão } \\
& \text { para a execução das construções com os aplicativos; } \\
\boldsymbol{H 1 d =} & \text { há diferença percebida pelo usuário na precisão para a execução } \\
& \text { das construções com os aplicativos. }
\end{aligned}
$$

Para checar as hipóteses formuladas, foi escolhido o Teste de Wilcoxon que permite comparar dois grupos amostrais relacionados ou emparelhados.

$$
\begin{aligned}
& \text { "O teste de Wilcoxon pode ser usado na comparação de dados } \\
& \text { pareados, medidos nas escalas ordinal, intervalar ou de razão. Não há } \\
& \text { a exigência de que as amostras tenham distribuição normal. Tem 95\% } \\
& \text { do poder do teste t pareado e sua indicação restringe-se às situações em } \\
& \text { que este último não pode ser utilizado." } \\
& \text { (MARCILLO, 2005, p.1) }
\end{aligned}
$$


Cada participante do teste utilizou as duas interfaces e, em seguida respondeu a um questionário com questões destinadas a comparar e apontar a preferência dos mesmos por uma delas. As questões eram idênticas tanto para o Risko quanto para o $i$ Geom, portanto foram obtidas duas amostras emparelhadas.

As amostras foram originalmente geradas por meio de uma escala conceitual (Likert), tais conceitos podem representar grandezas distintas conforme a opinião de cada participante como, por exemplo, em uma determinada questão, o que é "bom" para um pode ser "muito bom" para outro, e assim por diante. No Teste de Wilcoxon, a magnitude da diferença para cada par amostral não sofre grandes distorções, além dele considerar pequenas as diferenças intervalares existentes entre cada um dos postos da escala em uso, seja ela subjetiva ou ordinal.

Os procedimentos descritos a seguir foram extraídos e adaptados de Marcillo, (2005) e serão seguidos na aplicação do Teste de Wilcoxon:

1. Enunciar as hipóteses a serem testadas;

2. Converter a escala conceitual (Likert) em valores numéricos. Neste estudo os valores numéricos vão de 1 até 5 , respectivamente do pior até o melhor dos conceitos apresentados pela escala;

3. Determinar para cada par amostral a diferença " $d j$ " referente aos escores numéricos anotados para cada questionário " $A j$ e $B j$ ”. A ordem para o cálculo das diferenças " $d j$ ” não é relevante, seja primeiro o valor " $A j$ ” menos o segundo valor " $B j$ ”, ou vice-versa, o que importa é manter a mesma ordem para o cálculo de todos os pares amostrais a serem considerados no teste. Para este estudo foi considerada a seguinte ordem, primeiro o valor referente aos dados do Risko "Aj", menos o segundo valor referente aos dados do $i$ Geom “Bj”, então temos “ $d j=A j-B j$ ”;

4. Montar o ranking, em ordem crescente, usando os valores absolutos obtidos com o cálculo das diferenças " $d j$ ” excluindo as diferenças que apresentar valor zero “ $d j=0$ ”. Caso haja empates, atribuir a média dos pontos para definir o posto a ser ocupado no ranking; 
5. Somar, separadamente, as diferenças positivas " $d j+$ " das negativas “ $d j$-". A soma de menor valor em módulo, representa o " $T$ ”;

6. Calcular o $n$ subtraindo do total da amostra os empates " $d j=0$ ”;

7. Fixar um nível de significância “ $\alpha$ ”. Usar a tabela de Wilcoxon (ZAR, 1974, p.488) para determinar o "T critico". Se " $T$ ” $\leq$ " $T$ critico" rejeitar " $H O$ ".

Adotou-se $\alpha=0,05$ e os procedimentos descritos foram aplicados para os 4 itens da questão " $B x D$ ”. As Tabelas C.4, C.6, C.8 e C.10 apresentadas na íntegra no Apêndice $\mathrm{C}$ mostram o ranking para cada um dos 4 sub-itens da questão comparativa “ $B x D$ ”. A Tabela 6.8 mostra resumidamente os resultados do Teste de Wilcoxon:

Tabela 6.8 - Resumo do Teste de Wilcoxon para os itens da questão "B x D"

\begin{tabular}{lcccc}
\hline \multicolumn{1}{c}{ itens } & $\boldsymbol{n}$ & $\boldsymbol{T}$ & T critico & Resultados \\
\hline \hline a - tempo de execução & 10 & 3,5 & 8 & rejeita $H 0$ \\
b - gostou do programa? & 14 & 22 & 21 & não rejeitar $H O$ \\
c - dificuldade & 9 & 11,5 & 5 & não rejeitar $H O$ \\
d - precisão & 12 & 10 & 13 & rejeita $H O$ \\
\hline
\end{tabular}

As análises obtidas com o Teste de Wilcoxon nos permitem concluir que os participantes consideram gastar menos tempo para executar as construções gráficas com o auxílio do $i$ Geom e que o mesmo aplicativo é mais preciso quando comparado com o Risko. Referente aos itens gosto e dificuldade não se pode rejeitar a hipótese "HO”, como mostra a última linha da Tabela 6.8.

\subsection{Análise dos Vídeos}

Os 17 testes realizados foram monitorados e, para cada um deles, foi gerado um vídeo. Pelo fato dos arquivos em vídeo serem extensos, somente os principais trechos são apresentados para ilustrar os erros e problemas que ocorreram no decorrer dos testes práticos. Os vídeos editados são referenciados no texto junto ao respectivo texto explicativo. $\mathrm{O}$ texto a seguir trata primeiro dos comentários referentes ao Risko e dos respectivos 29 vídeos, na seqüência seguem os comentários 
dos 15 vídeos referentes ao iGeom. Os 44 vídeos estão disponíveis no DVD que acompanha este trabalho. Para visualizar os vídeos é necessário um player que leia arquivos no formato *.avi e, para melhor qualidade visual dos detalhes, recomendase uma resolução de vídeo de 1280 x 1024 pixels. Seguem os comentários referentes ao Risko:

- Para realizar as tarefas seguintes: "1- desenhar dois pontos quaisquer" e "4- desenhar um ponto sobre a reta criada”, é necessário usar o lápis clicando em sua ponta com grafite. A diferença entre as tarefas é com relação à precisão exigida para concluir a tarefa 4 . Em nenhum dos testes essa diferença foi barreira para os participantes não realizarem corretamente as referidas tarefas. O problema detectado, e que gerou os erros, está relacionado ao entendimento de como manipular a ponta do instrumento para criar os pontos. O correto é: primeiro posicionar o lápis movendo-o para o local desejado com o instrumento preso pelo seu corpo (região na cor amarela). Posicionado no local desejado, a segunda ação é clicar e soltar o botão do mouse com o cursor sobre a parte marrom da ponta com grafite e sem movimentá-lo para que o ponto seja criado. Os vídeos V-01, V-02 e V-03 mostram alguns erros cometidos por usuários que não entenderam como se usa o lápis e criaram figuras, como por exemplo, pequenos rabiscos que são parecidos com pontos ou então moveram o cursor com o botão pressionado desenhando rabiscos além dos pontos. Outro erro cometido pelos participantes que não entenderam o funcionamento do lápis foi em criar figuras à mão livre, ou seja, sem precisão, como exemplo, rabiscos que se cruzam ou "circunferências" sem o uso do compasso. Os vídeos V-04 e V-05 ilustram estes erros. O vídeo V-06 mostra um usuário que não entende como se cria pontos somente com o lápis, entretanto ele usa retas auxiliares feitas com o lápis apoiado num dos esquadros para que nas intersecções das retas o aplicativo gere automaticamente os pontos. Neste caso, o participante construiu três retas, onde uma delas é interceptada por outras duas, em locais distintos, e no cruzamento das retas os pontos foram criados. A maioria dos participantes que não entenderam o funcionamento do lápis para criar os pontos 
requeridos na tarefa 1 cometeram os mesmos erros na tarefa 4 . O vídeo V07 mostra os rabiscos feitos à mão livre sobre uma reta, como tentativa de construir um ponto na intersecção das figuras.

- Para a tarefa "5-desenhar uma reta passando pelos dois pontos criados", o vídeo V-08 mostra uma reta que passa por um ponto e próximo a um pequeno rabisco feito à mão livre, que é entendido pelo participante como sendo o segundo ponto de referência. Visivelmente no V-08, no instante que o participante tenta criar os vínculos para o bordo do esquadro, ele tenta usar as duas figuras (ponto e rabisco) como referência. Entretanto, somente o ponto assume a cor vermelha indicando o estabelecimento do vínculo com precisão.

- Nas tarefas: "5- desenhar uma reta passando pelos dois pontos criados" e "6- desenhar um arco centrado em um dos pontos criados", necessariamente o participante deve ter concluído a primeira tarefa de maneira correta, pois os pontos serão usados como referência para as construções requeridas nas tarefas 5 e 6 . Conseqüentemente, aqueles participantes que não executaram corretamente os pontos, não construíram as figuras (reta e o arco) com precisão. Os vídeos V-09 e V-10 mostram as construções incorretamente por conta das referências usadas como base.

- Para realizar a tarefa "2- desenhar uma reta qualquer", houve casos em que os participantes prenderam o lápis pela ponta com a grafite, a fim de posicioná-lo, e rabiscaram na cor azul o caminho percorrido com o cursor. Os vídeos V-11 e V-12 ilustram o uso incorreto para movimentar o lápis. Especificamente no vídeo V-12 note a expressão facial da participante que executa algo inesperado e que imediatamente é visto e reconhecido como sendo um erro de interpretação de uso do instrumento. Em outra ocasião o lápis é preso pela "hot-areas" referente ao seu corpo, região esta que é apresentada na cor amarela. O usuário move por várias vezes o instrumento, que se encontra com sua ponta próximo ao bordo do esquadro, na tentativa de traçar uma reta como é mostrado no vídeo V-13. 
- Para as tarefas onde são pedidas as construções de retas, o uso do esquadro é indispensável para conclusão das mesmas corretamente. Percebendo que não é possível construir retas à mão livre, alguns participantes ao executarem as retas valendo-se dos esquadros como apoio, traçaram além do limite do esquadro surgindo os rabiscos à mão livre na cor azul. Os vídeos V-14 e V-15 mostram casos em que o traço ultrapassa o limite do apoio. Especificamente no vídeo V-15 o usuário percebeu o erro e apaga o rabisco excedente.

- Uma das maneiras possíveis de se fazer a tarefa "8-desenhar uma reta perpendicular a uma das retas criadas" é apoiar os bordos dos esquadros para que um deles forme um ângulo de 90 graus com relação à reta de referência. Na execução desta tarefa, o problema detectado foi por conta dos traços feitos entre os bordos dos esquadros apoiados. Os vídeos V-16 e V-17 mostram usuários traçando entre os apoios dos esquadros. Nestes mesmos vídeos é possível perceber um segundo problema que ocorre após a conclusão do traço. $\mathrm{O}$ problema está relacionado à difícil visualização do mesmo pelo fato das cores dos instrumentos e do traçado seguirem tons de cinza muito parecidos. Os demais vídeos que mostram o uso do esquadro, também apresentam esta mesma dificuldade, vista nos vídeos V-16 e V17.

- Referente à precisão, na tarefa "4- desenhar um ponto sobre a reta criada" em alguns casos, após o participante criar o ponto sobre a reta ele usa a lupa na tentativa de ampliar a figura com o objetivo de verificar se realmente o ponto realmente estava sobre a reta. O vídeo $\mathrm{V}-18$ mostra o uso da lupa na tentativa de ampliar as figuras.

- Para criar um vínculo, ao aproximar o esquadro de um ponto qualquer automaticamente ele se destaca mudando da cor cinza para a cor verde (durante o período em que o botão estiver pressionado). Quando ele é solto o vínculo é criado com o ponto em questão, que assume então a cor vermelha. No caso do compasso, ao aproximar a sua ponta seca do ponto ele assume inicialmente a cor verde, mas depois do compasso ser fixado, o 
ponto retorna a cor original cinza ao invés de assumir a cor vermelha usada como padrão de indicação de precisão. O vídeo V-19 mostra o caso descrito. Tratando ainda da questão de estabelecimento dos vínculos, em duas circunstâncias o aplicativo apresentou o mesmo problema referente à mudança de cor do ponto vinculado. Nestes dois casos, o participante vincula o bordo do esquadro em dois pontos, mas somente um deles assumiu a cor vermelha, indicando que o vínculo foi feito com precisão, enquanto o outro ponto vinculado mantém a sua cor original cinza. O vídeo V-20 mostra a inconsistência das cores dos vínculos. Como confirmação de que o bordo estava realmente vinculado aos pontos, após a reta ter sido traçada o esquadro foi removido e, visivelmente, a reta passa sobre os pontos de referência que apresentaram o problema. No vídeo V21 o participante tem o trabalho extra de criar um segundo ponto para alinhar o bordo. Novamente após alinhar o bordo do instrumento nos pontos vinculados que estão sobre a reta somente um deles assume a cor vermelha, e o outro não muda de cor, como era esperado.

- No vídeo V-22 o participante aproxima a ponta do lápis de uma reta com o objetivo de construir um ponto sobre a mesma. Pelo fato de não existir qualquer indicação de precisão para as retas, como existe para a interação do compasso e dos esquadros com os pontos, o usuário utiliza a lupa para aproximar a imagem na tentativa de visualizar o que havia feito. Entretanto, neste caso de interação de um instrumento com uma figura a lupa altera a escala referencial somente para as figuras enquanto o instrumento que está vinculado com mesma fica estático. Pelo fato do aplicativo alterar escala somente das figuras elas são afastadas do instrumento e perdem o vínculo (caso ele tenha sido feito corretamente). Para ilustrar esta situação, o vídeo V-23 mostra um caso em que a lupa foi utilizada demasiadamente e sem controle, onde o usuário afastou a imagem muitas vezes, diminuindo a área de detecção da figura. $\mathrm{Na}$ seqüência, ele teve dificuldade para alinhar o bordo do esquadro com a reta em questão. 
- Alguns testes permitiram detectar problemas relacionados ao aplicativo, e os vídeos V-24, V-25 e V-26 mostram o surgimento de retas aleatoriamente durante alguns testes. No vídeo V-26 o usuário ao perceber o aparecimento da reta entende que é um erro gerado pelo aplicativo, que neste caso ocorreu pela segunda vez com o mesmo participante, e o usuário apaga a figura. Em um outro teste, auxiliado pelos instrumentos de desenho, o participante constrói duas retas que se cruzam e, no cruzamento das retas, deveria aparecer automaticamente um ponto. $\mathrm{O}$ vídeo V-27 mostra a falha do aplicativo. O vídeo V-28 mostra um outro teste com a mesma construção e o aplicativo cuida de gerar o ponto na intersecção. Outra falha detectada é referente à sobreposição dos esquadros que pode ser visto no vídeo V-29.

Comentários e vídeos referentes ao $i \mathrm{Geom:}$

- Realizada a tarefa "2-desenhar uma reta qualquer" onde é utilizado o ícone para construção de retas, o usuário passa pelas tarefas seqüentes 3 e 4 usando outros ícones até o momento de fazer a tarefa "5-desenhar uma reta passando pelos dois pontos criados”, a qual pode ser realizada usando o mesmo ícone usado na tarefa 2. Neste caso, o participante não lembra a localização do ícone e realiza a busca pelo mesmo passando por diversos outros ícones, como mostra o vídeo V-30.

- A maioria dos participantes encontrou dificuldades para executar a tarefa "9- apagar uma das figuras que acabou de criar". Dentre os problemas que foram detectados, os que ocorreram com mais freqüência foram: uso da tecla "delete" para apagar uma figura, como mostram os vídeos V-31 e V-32. Note nos vídeos a expressão facial do participante no momento que percebe a ação sem efeito. O vídeo V-32 mostra um participante que usa a tecla "delete" várias vezes na tentativa de excluir uma figura e, na seqüência, ele procura entre os ícones o comando correto que gera a ação de apagar. Freqüentemente, na tentativa de excluir um objeto, os participantes usando o comando "Marcar ou desmarcar objetos", que 
altera a cor azul da figura passando para a cor amarela, pressionando na seqüência a tecla "delete". Ao perceberem que a ação não propicia o resultado desejado os usuários procuram pelo ícone correto para excluir objetos, como mostram os vídeos V-33 e V-34. Especificamente no vídeo V-35, é possível notar um outro erro de interpretação pelos usuários que confundem os ícones "Limpar os tracejados, remover todos" e "Remover objetos, clique sobre os mesmos", que apresentam símbolos muito parecidos, mas têm funções distintas. Em um outro caso, o participante que busca pelo comando para apagar figuras acaba desenhando várias outras figuras indesejavelmente. O vídeo V-36 mostra o ocorrido bem como a poluição visual criada na tela.

- Para realizar a tarefa "6-desenhar uma arco centrado em um dos pontos criados" é necessário utilizar o mesmo comando "ícone" que foi usado para fazer a tarefa "3- desenhar um arco qualquer". Pelo fato dos participantes utilizarem outros grupos de comandos para fazer as tarefas 4 e 5 intermediárias às tarefas 3 e 6 eles não se recordam onde está o comando anteriormente usado e que possibilita a criação de arcos. Para ilustrar este caso, em um dos testes o participante desiste de realizar a tarefa após procurar o comando que cria arcos, como mostra o vídeo V-37. Neste mesmo vídeo, o usuário desconfia que o problema está na seleção dos pontos, selecionando um e depois o outro.

- As "tooltips" são ativadas pelo cursor quando o mouse é parado sobre cada um dos ícones, aparecendo por alguns instantes as tarjas em amarelo contendo textos que indicam a funcionalidade do mesmo. O vídeo V-38 mostra o participante se aproximando da tela na tentativa de visualizar as "tooltips" a fim de ler e entender o que o comando permite realizar, visando criar um ponto. Esta mesma dificuldade foi percebida em vários outros testes. Ainda referente ao caso comentado anteriormente, o participante já tinha utilizado o comando, e faz uma nova busca e confunde as imagens apresentadas pelos dois ícones que permitem criar pontos. 
- A difícil interpretação dos símbolos ocorre também para os ícones que permitem criar arcos e o vídeo V-39 mostra a indecisão e uso errado do comando na tentativa de realizar a tarefa " 6 - desenhar um arco centrado em um dos pontos criados".

- Na tentativa de executar a tarefa "4- desenhar um ponto sobre a reta criada”, o usuário também confunde os símbolos e usa o segundo ícone da barra, que serve para criar um ponto médio. Ao perceber o erro, usa o primeiro ícone para executar corretamente a tarefa, como mostra o vídeo V-40. No vídeo V-41 é apresentada uma situação mais grave, onde o ícone destinado à criação de um ponto médio é utilizado para realizar a tarefa $4 \mathrm{e}$ o ponto gerado pelo aplicativo surge após o segundo ponto de referência e não no meio como era esperado.

- Na tarefa "8-desenhar uma reta perpendicular a uma das retas criadas" os participantes também tiveram dificuldades para encontrar o ícone correto pela similaridade simbólica apresentada pelos três últimos ícones da barra que possibilita desenhar reta: "Traçar uma perpendicular à uma reta dada passando por algum ponto”, “Criar eixos cartesianos (com unidade)" e "Criar reta perpendicular a eixo selecionado, com distância fixada por medida (marque primeiro medida)". Para esta mesma tarefa, os vídeos V-42 e V-43 mostram alguns participantes usando os ícones "Criar eixos cartesianos (com unidade)" e "Criar reta perpendicular a eixo selecionado, com distância fixada por medida (marque primeiro medida)", na tentativa de criar a reta perpendicular, no entanto acabaram desenhando retas paralelas. Note nos vídeos V-42 e V-43 que os participantes tentam ler as "tooltips" destes três comandos.

- Outro problema detectado durante os testes realizados está relacionado as legendas geradas automaticamente pelo aplicativo e que em alguns casos se sobrepõem, como mostra o vídeo V-44.

Os vídeos gerados ilustram e documentam os comentários apresentados e servem como matérial de consulta para avaliações extras. É válido o ditado popular de autor desconhecido "as imagens falam mais do que muitas palavras". 
Complementando os dados obtidos com os questionários pós-teste, a maioria dos participantes acrescentou, no verso do mesmo, valiosas observações a respeito da experiência vivenciada, estas anotações foram transcritas integralmente e são apresentadas no Apêndice D.

A neutralidade e a imparcialidade dos participantes que comentaram sobre as virtudes, problemas, sugestionaram, etc. engrandeceu o trabalho e possibilitou a visualização do uso dos aplicativos educacionais com maior sensibilidade para questões pessoais. Nem sempre o participante, no caso aluno, quer simplesmente interagir com uma máquina, é visível a carência da interação entre os homens. Pois deixar campos em aberto no questionário para os participantes exprimirem suas opiniões, possibilitou o inicio de conversas informais entre o participante e o avaliador sobre o evento, isso não só contribuiu para o método de avaliação criado, mas principalmente para o amadurecimento do avaliador para conduzir os testes seguintes.

\subsection{Conclusão do Capítulo}

Neste capítulo foi apresentado o método de avaliação utilizado para validar os dados coletados bem como os critérios de seleção dos dados gerados. Finalizando o capítulo são comentados os vídeos editados que mostram as situações mais relevantes registradas nos testes práticos para ilustrar os erros e problemas vivenciados pelos participantes durante a execução dos testes com as GUI. 


\section{CAPÍTULO 7}

\section{CONCLUSÕES}

\subsection{Conclusão Final}

A gratificante oportunidade de desenvolver este trabalho possibilitou a obtenção de resultados significativos e que serão apresentados neste capítulo como conclusões do trabalho. No entanto, é conveniente realizar uma breve recapitulação dos motivos que justificam e originaram este estudo.

Tradicionalmente o ensino presencial do tema Geometria Gráfica apresenta desafios tanto para os professores como para os alunos. A solução para tais desafios vai além do uso dos recursos tradicionais empregados ao ensino do tema, fato este que motivou alguns educadores a utilizarem recursos auxiliares, como os aplicativos computacionais, a fim de atingir a excelência no ensino. Ocorre que boa parte dos aplicativos usados com essa finalidade são programas genéricos que não foram desenvolvidos exclusivamente para fins didáticos e, conseqüentemente, não suprem as necessidades inerentes ao ensino/aprendizado. A maioria destes aplicativos foram criados para fins comerciais e por isso trazem em suas interfaces o padrão "WIMP", que, comprovadamente, privilegia a produtividade. Por conseqüência do modelo de GUI em uso, surgem os seguintes problemas no emprego da ferramenta para o ensino: baixa intuitividade, longos períodos de treinamento para o domínio da ferramenta, excesso/falta de recursos e a possibilidade de realização de construções imediatas. 
Visando sanar alguns destes problemas, uma nova interface foi implementada e traz os instrumentos virtuais para que os usuários possam adquirir o conhecimento do tema logo no ato da realização das construções gráficas.

Criada a nova interface, surgiu então a necessidade de desenvolver um método para avaliar, comparativamente, a usabilidade dos diferentes modelos de GUI destinados ao auxílio do ensino de Geometria Gráfica e, conseqüentemente, testar na prática o método criado.

Como parte inicial da aplicação do método de avaliação das GUI, foi realizado um conjunto de análises clássicas de usabilidade, com ambos os modelos, por um especialista. As primeiras conclusões obtidas destas análises foram: para a interface do $i$ Geom que segue o padrão "WIMP", a Análise Heurística apontou problemas como: ícones não intuitivos, remoção de elementos sem notificação prévia, comando desfazer ("undo") limitado e a inexistência do comando refazer ("redo”). $\mathrm{Na}$ Análise Funcional, os principais problemas notados foram com relação à falta de comandos como, por exemplo, "resize", "pan" ou "zoom" e a falta de controle da área de trabalho. Finalmente, a Análise de Tarefas mostrou que o aplicativo não permite realizar a construção de arcos com menos de 360 graus e não permite especificar medidas numericamente. Estes problemas de usabilidade são consideravelmente graves para um aplicativo destinado ao ensino de Geometria Gráfica, principalmente quando ele é empregado para a resolução de exercícios de Geometria Cotada e de Geometria Descritiva.

Para a interface do Risko, que segue o padrão da Manipulação Direta Pura, a Análise Heurística apontou a inconsistência funcional das ferramentas "snap" e "highlight" e a falta de esclarecimentos para o uso dos instrumentos com várias "hot-areas". Com a Análise Funcional foi possível detectar a falta do contraste referente às cores utilizadas pelos instrumentos de desenho com relação às demais cores das outras partes da interface; a necessidade de um mecanismo para enquadrar a área de trabalho; uma região sensitiva para a função "snap" demasiadamente pequena e; que o "snap" do bordo dos esquadros deveria impedir o lápis de continuar a traçar após o limite do instrumento. Finalmente, a Análise de Tarefas comprovou que os recursos implementados na interface do Risko atendem por 
completo às necessidades impostas para um aplicativo destinado ao ensino de Geometria Gráfica. Entretanto é notória a necessidade de alguns ajustes, para as versões futuras, a fim de que o aplicativo atenda com excelência às necessidades a que se destina.

Valendo-se de uma amostra reduzida, o método de avaliação de usabilidade das GUI criado foi testado. Os resultados obtidos são válidos internamente, ou seja, apenas para a amostra considerada e permitem as seguintes conclusões:

Os testes realizados pelos 17 participantes mostraram que, das 153 tarefas solicitadas por aplicativo, 20 delas não foram concluídas com o uso do Risko, (13,0\% do total da amostra), e 2 delas não foram concluídas com o uso do $i \mathrm{Geom}$, ( $1,3 \%$ do total da amostra). Estes dados permitem concluir que o padrão "WIMP" contribui significativamente para que o usuário conclua as tarefas, entretanto, concluir tarefas não é o objetivo primário em um curso de capacitação.

Os mesmos dados foram submetidos a um teste de hipóteses, a fim de validar os resultados para cada uma das 9 tarefas. Dos testes foi possível somente a rejeição da hipótese nula para a tarefa 1 . Para as tarefas $2,3,8$ e 9 , não foi possível comprovar qualquer tendência que favorecesse a uma ou outra interface, pois os pares discordantes apresentados foram formados por valores idênticos. Referente às tarefas 4, 5, 6 e 7, o p-valor obtido foi superior ao “ $\alpha$ ” estabelecido, indicando que as amostras não foram significativas. Nestes casos, o método permite estimar o tamanho da amostra mínima necessária para que uma das hipóteses formuladas possa ser validada a fim de atingir o nível de significância pré-estabelecido.

As mesmas tarefas realizadas pelos usuários iniciantes foram realizadas pelo usuário especialista para comprovar o Grupo Eficiência que considera o tempo de execução. Os resultados mostraram que o tempo médio para se executar as 9 tarefas propostas com o Risko consome em média 6:01,68 e 1:50,01 para executar o mesmo grupo de tarefas com o $i$ Geom. Comparando estes tempos médios conclui-se que fazer o exercício médio com o auxílio do Risko é mais demorado do que fazer o mesmo exercício utilizando o $i$ Geom. Esta constatação já era esperada, pois conforme foi mencionado no início do trabalho, a interface de Manipulação Direta Pura não privilegia a produtividade e, como era de se esperar, comprovou-se que o 
$i$ Geom é mais eficiente que o Risko, finalizando assim, as conclusões extraídas dos testes práticos com as interfaces.

Para o questionário pós-teste é possível apresentar as seguintes conclusões:

Referente a questão sobre a freqüência de uso do computador, conclui-se que os participantes usam freqüentemente a ferramenta e que eles possuem conhecimentos suficientes para utilizá-lo. Portanto, o uso do computador não constitui uma barreira.

$\mathrm{Na}$ questão referente às dificuldades para utilizar os programas, 9 participantes responderam ter dificuldades para "Entender o funcionamento dos comandos e instrumentos de desenho" e 7 disseram que "Faltam explicações na tela" com relação a interface do Risko. Enquanto 9 participantes disseram ter dificuldades para "Encontrar os comandos desejados" e 5 em "Entender o funcionamento dos comandos e instrumentos de desenho" disponibilizados na interface do $i$ Geom. Independentemente da interface, conclui-se que as explicações na tela são extremamente importantes do ponto de vista dos usuários iniciantes, pois eles sempre esperam que o aplicativo forneça informações adicionas para auxiliá-los na interação. Esta expectativa está incorporada culturalmente pelo fato das interfaces tradicionalmente apresentarem textos ou mecanismos de ajuda.

O resultado obtido com a questão destinada a identificar as dificuldades dos participantes para realizar as tarefas propostas no teste, comprovou que as tarefas foram fáceis. Desta maneira, conclui-se que as tarefas não foram barreiras para o bom desenvolvimento do experimento realizado e, conseqüentemente não exerceram influência nos resultados dos testes.

A questão sobre o uso de um dos aplicativos para ocasiões específicas mostrou que a maioria dos participantes prefere utilizar o Risko em sala de aula, talvez pelo fato do professor estar obrigado a executar passo a passo todas as construções no ato da exposição do tema. Com relação ao uso em casa, para estudar ou fazer os trabalhos e exercícios, a maioria optou pelo $i$ Geom. Esta escolha contribui para a confirmação de que a produtividade inerente ao padrão "WIMP" agrada aos usuários, pois otimiza o tempo destinado ao "trabalho". Com relação ao uso dos aplicativos para fazer as provas houve praticamente um empate, onde 9 
participantes optaram pelo Risko e 8 escolheram o $i$ Geom. Para estas questões são necessários estudos mais aprofundados a fim de confirmar as tendências apresentadas com mais precisão. No entanto, é verdadeiro que a escolha de um aplicativo educacional deve ser feita com muito cuidado, pois o objetivo é garantir ao aprendiz a competência para domínio do tema Desenho Gráfico, independentemente do aplicativo e da ocasião em que ele é utilizado.

Com base no teste de hipóteses proposto por Wilcoxom foi possível rejeitar "HOa" e "HOd", ou seja, os participantes consideram o uso do iGeom mais produtivo e preciso do que o Risko. Para os outros dois itens que trataram do gosto e da dificuldade, respectivamente " $H O b$ " $e$ " $H O c$ ", não podem ser rejeitadas, o que impossibilita detectar a preferência por qualquer um dos aplicativos.

A conclusão geral que se faz para o trabalho desenvolvido é que o objetivo estabelecido como meta central foi alcançado com sucesso, pois o método de avaliação criado e testado mostrou-se capaz gerar os dados para comparar distintos modelos de GUI, aplicadas a uma mesma finalidade.

Adicionalmente, os resultados das análises apresentadas no trabalho desenvolvido contribuem para as correções e alterações das futuras versões dos aplicativos $i$ Geom e Risko.

\subsection{Sugestões para Trabalhos Futuros}

O trabalho realizado permitiu vislumbrar outros estudos a serem realizados e que podem contribuir não só para a continuidade do ciclo de vida dos aplicativos analisados, mas também para o desenvolvimento de novas técnicas aplicas ao ensino de Geometria Gráfica. Seguem algumas propostas:

- aplicar o método de avaliação apresentado valendo-se de amostras numericamente significativas, a fim de tentar comprovar estatisticamente as hipóteses formuladas;

- realizar um estudo com diferentes grupos de usuários como, por exemplo, alunos dos diferentes níveis de ensino (infantil, fundamental e médio), ou de diferentes cursos profissionalizantes que também lidam com o Desenho 
Gráfico como, por exemplo, alunos dos cursos de Arquitetura, Matemática, Geologia, etc;

- aplicar em um curso real de desenho os diferentes padrões de interfaces ( "WIMP” e Manipulação Direta Pura) em distintas turmas de alunos afim de comparar e mensurar o grau de aprendizado obtido com cada modelo de interface;

- testar comparativamente o aprendizado adquirido com o uso de ferramentas computacionais frente ao método de ensino clássico, que usa instrumentos reais de desenho, a fim de avaliar qual dos métodos é mais eficiente para aquisição do conhecimento e das técnicas de manipulação dos próprios instrumentos de desenho;

- testar o modelo de interface que segue o conceito da Manipulação Direta Pura frente a outros aplicativos destinados ao ensino de Geometria Gráfica como, por exemplo, a consagrada trinca de aplicativos "Cabri Géomètre, Cinderella e The Geometer's Sketchpad" que trazem interfaces seguindo o padrão “WIMP”. 


\section{REFERÊNCIAS}

Associação Brasileira de Normas Técnicas. ABNT: requisitos ergonômicos para trabalho de escritórios com computadores. parte 11 - orientações sobre usabilidade. Rio de Janeiro, 2002.

AMANT, R.S. A preliminary discussion of tools and tool use. In: NORTH CAROLINA STATE UNIVERSITY, technical report TR-2002-06. April, 2002. Disponível em: < <http://www.csc.ncsu.edu/ faculty/stamant/papers/toolssummary.pdf $>$. Acesso em: 10 jan. 2003.

AMANT, R.S.; HORTON, T. A tool-based interactive drawing environment. In: CONFERENCE ON HUMAN FACTORS IN COMPUTING SYSTEMS, CHI, Minneapolis, 2002. Extended abstracts. New York: Association For Computing Machinery, 2002a. p.762-763.

AMANT, R.S.; HORTON, T. Characterizing tool use in an interactive drawing environment. In: INTERNATIONAL SYMPOSIUM ON SMART GRAPHICS, 2. Hawthorne, 2002b. Abstract. New York: Association For Computing Machinery, 2001.

ARGOLLO, M.J.; et al. Considerando o usuário no processo de desenvolvimento de Aplicações com interfaces gráficas. In: CONFERÊNCIA INTERNACIONAL DE TECNOLOGIA DE SOFTWARE - CITS, 8., Curitiba, 1997. Abstracts. [S.1.]: 1997

BEDERSON, B.B. et al. Local tools: an alternative to tool palettes. In: PROCEEDINGS OF THE SYMPOSIUM ON USER INTERFACE SOFTWARE AND TECHNOLOGY, Seattle, 1996. Abstracts. New York: Association For Computing Machinery, 1996. p.169-170.

BRANDÃO, L.O.; ISOTANI, S. Uma ferramenta para ensino de geometria dinâmica na internet: $i$ Geom. In: WORKSHOP DE INFORMÁTICA NA EDUCAÇÃO, 9., Campinas, 2003, Campinas. Anais. [S.1.]: 2003. p.1476-1487.

BRAVIANO, G. Ação+seleção ou seleção+ação: qual estratégia é a mais intuitiva? In: INTERNATIONAL CONFERENCE ON GRAPHICS ENGINEERING FOR ARTS AND DESIGN, 4., São Paulo, 2001. Proceedings. São Paulo: EPUSP, 2001.1253p.

BROWNE, D. Structured user-interface design for interaction optimisation. [S.1.]: Prentice Hall, 1994.

CARD, S.; MORAN, T.; NEWELL, A. The psychology of human-computer interaction. Hillsdale, N.J: Lawrence Erlbaum, 1983. 469p. 
CAMTASIA STUDIO ${ }^{\circledR}$ (versão 1.0.1). TechSmith. Free software foundation. Disponível em: $<$ http://www.techsmith.com/download/studiodefault.asp $>$. Acesso em set., 2003.

COSTA NETO, P.L.O. Estatística. São Paulo: Edgard Blucher, 1977. 264p.

DAUGHTRY, J.M.; AMANT, R.S. Power tools and composite tools: integrating automation with direct manipulation. In: INTERNATIONAL CONFERENCE ON INTELLIGENT USER INTERFACES, Miami, 2003. Proceedings. New York: Association For Computing Machinery, 2003. p.233-235.

DIB, C.Z. Afinal, o que você efetivamente mede quando sua avaliação é referenciada pela distribuição normal? (Boletim Informativo do Instituto de Física BIFUSP, v. 21, n. 18, jun. 2002).

DIX, A.J. et al. Human-computer interaction. 2. ed. New York: Prentice Hall, 1998. 638p.

DEITEL, H.M.; DEITEL, P.J. Java como programar. 4. ed. Porto Alegre: Bookman., 2003. 1386p.

DOMINGUES, D.G. O uso de metáforas na computação. Dissertação (Mestrado). Universidade de São Paulo. São Paulo, 2001.

DÜRSTELER, J. C. Affordances. Inf@ Vis! The digital magazine of InfoVis.net, n.72. Disponível em $<$ http://www.infovis.net/E-zine/2002/ num 72.htm $>$. Acesso em apr., 2004.

EUCLIDES. Elementos de euclides. Coimbra: Imprensa da Universidade, 1846. $394 p$.

FENTON, N.E. Software metrics: a rigorous and practical approach. 2. ed. London: PWS Pub., 1997. 638p.

FILGUEIRAS, L.V.L. Introdução ao projeto de interfaces homem-computador. São Paulo: EPUSP, 2000. 11p. (Notas de aula da disciplina PCS 5756).

GÒRSKA, R. et al. International comparisons of gender differences in spatial visualization and the effect of graphics instruction on the development of these skills. In: INTERNATIONAL CONFERENCE ON GEOMETRY AND GRAPHICS ICECGDG, 8., Austin, 1998. Proceedings. [S.1.]: 1998. p.261-266.

HARTSON, H.R.; SIOCHI, A.C.; HIX, D. The UAN: a user-oriented representation for direct manipulation interface designs. Transactions on Information Systems, New York: Association For Computing Machinery, v. 8, n. 3, p.181-203, jul. 1990.

HAWK, M.C. Descriptive geometry. New York: McGraw-Hill, 1962. 
HIX, D.; HARTSON, H.R. Developing user interfaces: ensuring usability through product $\&$ process. New York: John Wiley \& Sons, 1993. 381p.

HUTCHINS, E.; HOLLAN, J.; Direct manipulation interfaces. In: NORMAN, D.; DRAPER, S.W. (Ed.). User centered system design: new perspectives on humancomputer interactions. Hillsdale: Lawrence Erlbaum, 1986. 526p.

IGEOM (versão 2.4.5 “stand-alone"). Sistema para ensino/aprendizagem de geometria (geometria dinâmica). Disponível em:

$<$ http://www.matematica.br/igeom $>$. Acesso em 3 jun., 2003.

INTERNATIONAL ORGANIZATION FOR STANDARDIZATION. ISO/IEC 9126. Information technology - Software product evaluation - Software quality characteristics and metrics. 1991.

KAWANO, A. et al. Apostila de PCC 2111. São Paulo: EPUSP, 2005. 136p. (Impresso com exercícios e notas de aula da disciplina Desenho para Engenharia I).

KOSCIANSKI, A. et al. Guia para utilização das normas sobre avaliação de qualidade de peoduto de software - ISO/IEC 9126 e ISO/IEC 14598. Curitiba: Associação Brasileira de Normas Técnicas, ABNT. 1999. 65p.

KOSTOVSKII, A.H. Construcciones geométricas mediante un compás. Moscou: Mir, 1980. 79p.

LEITE, J.C. Modelos de interação, Disponível em $<$ http://www.dimap.ufrn.br/ jair/piu/apostila/cap2.pdf>. Acesso em 12 nov. 2004.

MACNAUGHTON, J. Numbers, scales, and qualitative research, The Lancet, vol. 347, Issue 9008, apr. 1996. p. 1099 - 1100. Disponível em $<\mathrm{http}: / /$ www.sciencedirect.com/science/article/B6T1B-4B8JKBW18W/2/bd7e5b7a5611dfb9edb57c7f759c78c0>. Acesso em: ago. 2005.

MENEZES, P.F.B. Linguagens formais e autômatos. 4. ed. Porto Alegre: Sagra Luzzato, 1998. (Série livros didáticos, n. 3). 165p.

MAFALDA, R. Pesquisa e formação do pesquisador: os temas e as diversas vias de abordagem. Seminário Interno, EPUSP-PCC. São Paulo, 2004.

MARCILLO, A.M. Teste de wilcoxon. Disponível em $<$ http://www.fcm.unicamp.br/centros/ciped/mp639/Teste\%20de\%20Wilcoxon.pdf $>$. Acesso em 15 jun. 2005.

MICHELS, S. Co-writing, look and feel. 1995. Master Thesis. Tilburg University, The Netherlands, 1995. Disponível em $<$ http://infolab.kub.nl/pub/theses/w3thesis/>. Acesso em 17 abr. 2003.

MICROSOFT WINDOWS XP PROFESSIONAL® (versão 2002 service pack 2). Microsoft corporation. Disponível em $<\underline{\mathrm{http}}$ ://www.microsoft.com $/>$. Acesso em set., 2003. 
NIELSEN, J. Usability engineering. Boston: Academic Press Professional, 1993.

OLIVEIRA, L.L.A.; SANTOS, E.T. Estudo de usabilidade da interface gráfica do programa de geometria dinâmica $i$ Geom. In: SIMPÓSIO NACIONAL DE GEOMETRIA DESCRITIVA E DESENHO TÉCNICO/V INTERNATIONAL CONFERENCE ON GRAPHICS ENGINEERING FOR ARTS AND DESIGN, 16. Santa Cruz do Sul, 2003. Anais do Graphica 2003. Santa Cruz do Sul: UNISC, 2003.

PAYNE, S.; GREEN, T.R.G. Task-action grammar: the model and its developments. In: DIAPER, D. (Ed.). Task analysis for human-computer interaction. Chichester: Ellis Horwood, 1989.

PEREIRA, J.C.R. Análise de dados qualitativos estratégias metodológicas para as ciências da saúde, humanas e sociais. 3 ed. São Paulo: EDUSP, 2004. 156p.

PIEGL, L.A. Ten challenges in computer-aided design. In: COMPUTER-AIDED DESIGN, 37., [S.1.]: 2005. Abstract. Elsevier, 2005. p.461-470.

REIS, M.M.; Homepage pessoal. Disponível em $<$ http://www.inf.ufsc.br/ marcelo/index.html $>$. Acesso em jun., 2005.

RISKO (versão 0.8 "stand-alone"). A realistic interface for simulating a kit of objects. Disponível em $<$ http://risko.pcc.usp.br $>$. Acesso em mar., 2005.

RODRIGUES, D.W.L. Uma avaliação comparativa de interfaces homemcomputador em programas de geometria dinâmica. 2000. Dissertação (Mestrado). Universidade Federal, Santa Catarina. Santa Catarina, 2002.

ROSNER, B. Fundamentals of Biostatistics. 5. ed. [S.1.]: Duxbury Press, 1999. 792p.

SANTOS, E.T. Un applet java ${ }^{\mathrm{TM}}$ para hacer disponibles ejercicios de geometría descriptiva en internet. In: ACTAS DEL CONGRESO IBEROAMERICANO DE EXPRESIÓN GRÁFICA EN INGENIERIA Y ARQUITECTURA, 2., Salta, 1999. Proceedings. [S.1.]: 1999. v.1, p.144-149.

SANTOS, E.T.; LOURENZONI, L.; OLIVEIRA, A. L. L. Risko: desenhando com instrumentos virtuais. In: SIMPÓSIO NACIONAL DE GEOMETRIA DESCRITIVA E DESENHO TÉCNICO/V INTERNATIONAL CONFERENCE ON GRAPHICS ENGINEERING FOR ARTS AND DESIGN, 17., Recife, 2005. Anais do Graphica 2005. Recife: UFPE, 2005.

SANTOS, E.T.; OLIVEIRA, A. L. L.; LOURENZONI, L. A real world metaphor interface for an educational geometry drawing software. In: INTERNATIONAL CONFERENCE ON GEOMETRY AND GRAPHICS, 11., Guangzhou, 2004. Proceedings. [S.1.]: 2004.

SANTOS, E.T.; MARTINEZ, M.L. Software para ensino de geometria e desenho técnico. In: SIMPÓSIO NACIONAL DE GEOMETRIA DESCRITIVA E 
DESENHO TÉCNICO/V INTERNATIONAL CONFERENCE ON GRAPHICS ENGINEERING FOR ARTS AND DESIGN, 15., Ouro Preto, 2000. Anais do Graphica 2000. Ouro Preto: 2000.

SHNEIDERMAN, B. Designing the user interface: strategies for effective humancomputer interaction. 2. ed. Reading: Addison-Wesley, 1992. 573p.

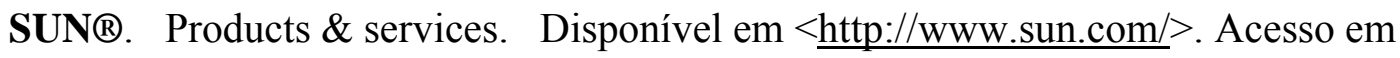
mar., 2005.

SUTHERLAND, I.E. Sketchpad: a man-machine graphical communication system. New York: Garland Publishers, 1980. ISBN 0824044118. Disponível em $<$ http://encyclopedia.thefreedictionary.com/SketchPad $>$. Acesso em: 01 feb. 2005.

VÄÄNÄNEN, K.; SCHMIDT, J. User interfaces for hypermedia: how to find good metaphors. In: CONFERENCE ON HUMAN FACTORS AND COMPUTING SYSTEMS - CHI'94, Boston, 1994. Proceedings. New York: Association For Computing Machinery, 1994. p.263-264.

VALENTE, V.C.P.N. Desenvolvimento de um ambiente computacional interativo e adaptativo para apoiar o aprendizado de geometria descritiva. 2003. Tese (Doutorado), Escola Politécnica - Universidade de São Paulo. São Paulo, 2003.

UNIVERSITY OF THE WEST OF ENGLAND. Coldharbour Lane, Bristol, UK.

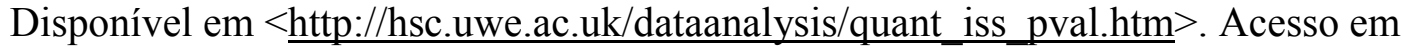
jun., 2005.

WINDOWS® NETMEETING® (versão 3.01 - 5.1 .2600.2180). Microsoft corporation. Disponível em $<\underline{\mathrm{http}}$ ://www.microsoft.com/ $>$. Acesso em set., 2003.

ZAR, J.H. Biostatistical analysis. Englewood Cli ffs: Prentice-Hall, 1974. 620p. 


\section{ANEXOS}

\section{Anexo 1 - Exercícios avaliados}

Seguem as imagens contendo os enunciados e respectivas soluções para a coleção de exercícios extraídos da Apostila da Disciplina de Desenho PCC2111.

\section{Exercícios de Desenho Geométrico}
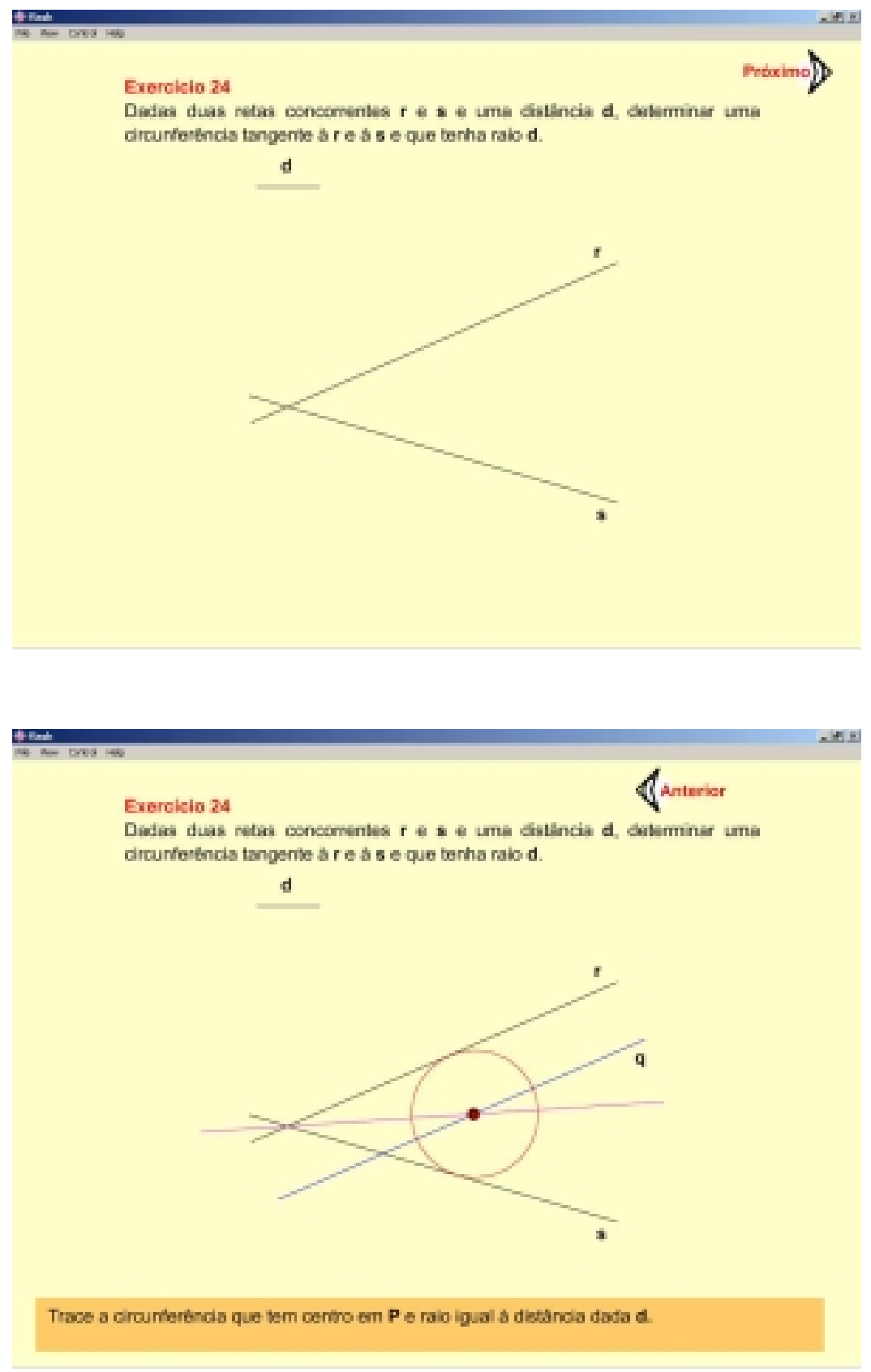


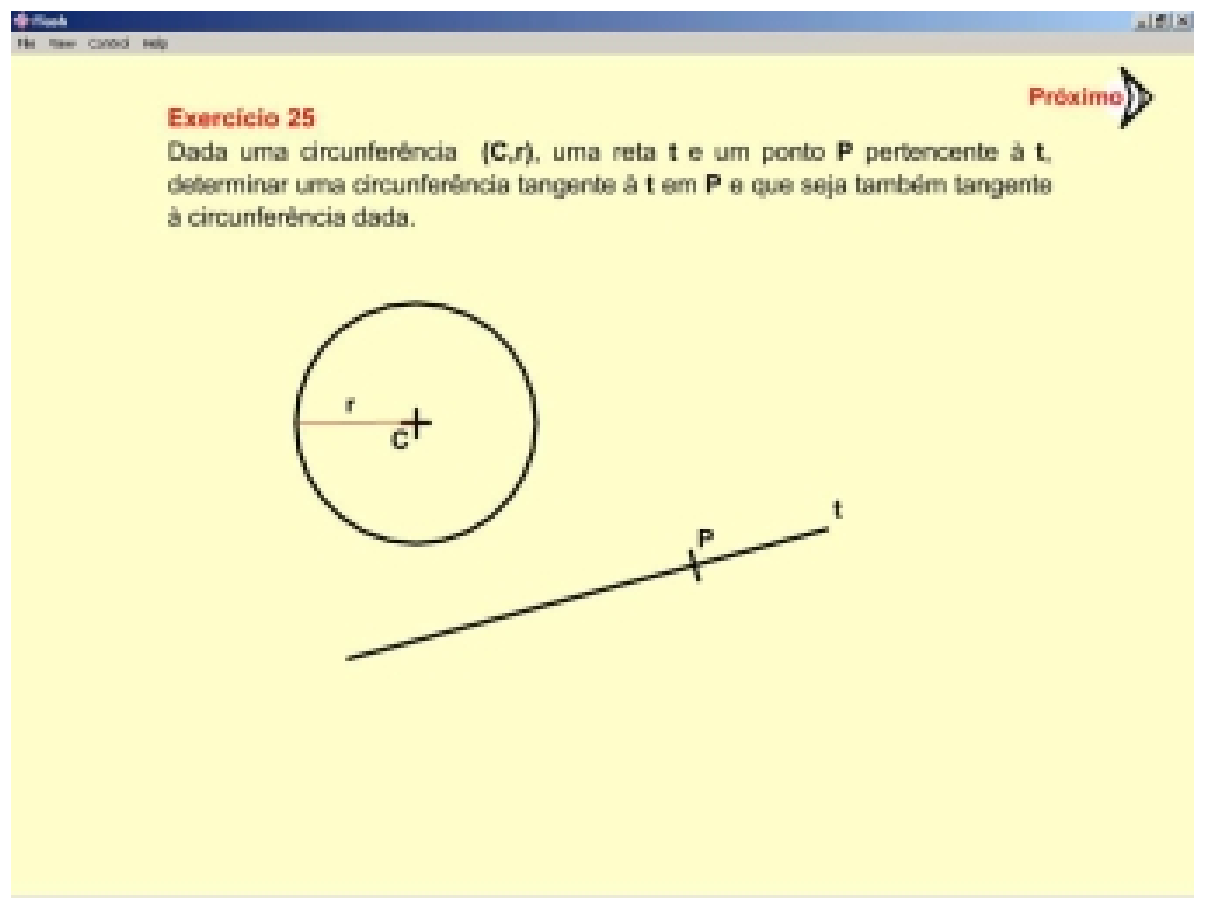

in $\sin$

Exercicio 25

QAnterior

Dada uma dircunferencia $(C, r)$, uma reta $t$ e um ponto $P$ pertencente a $t$. determinar uma circunferencia tancente a $t$ em $P_{\theta}$ eue seja tamberm tangente à circunferència dada.

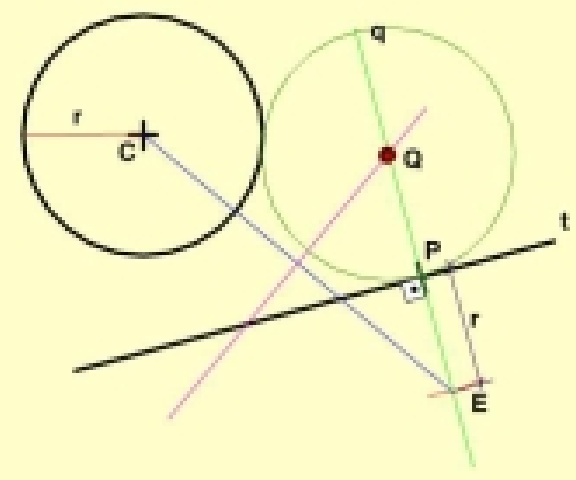

Trace a cirourterència que bem centro em Q e raio QP. 


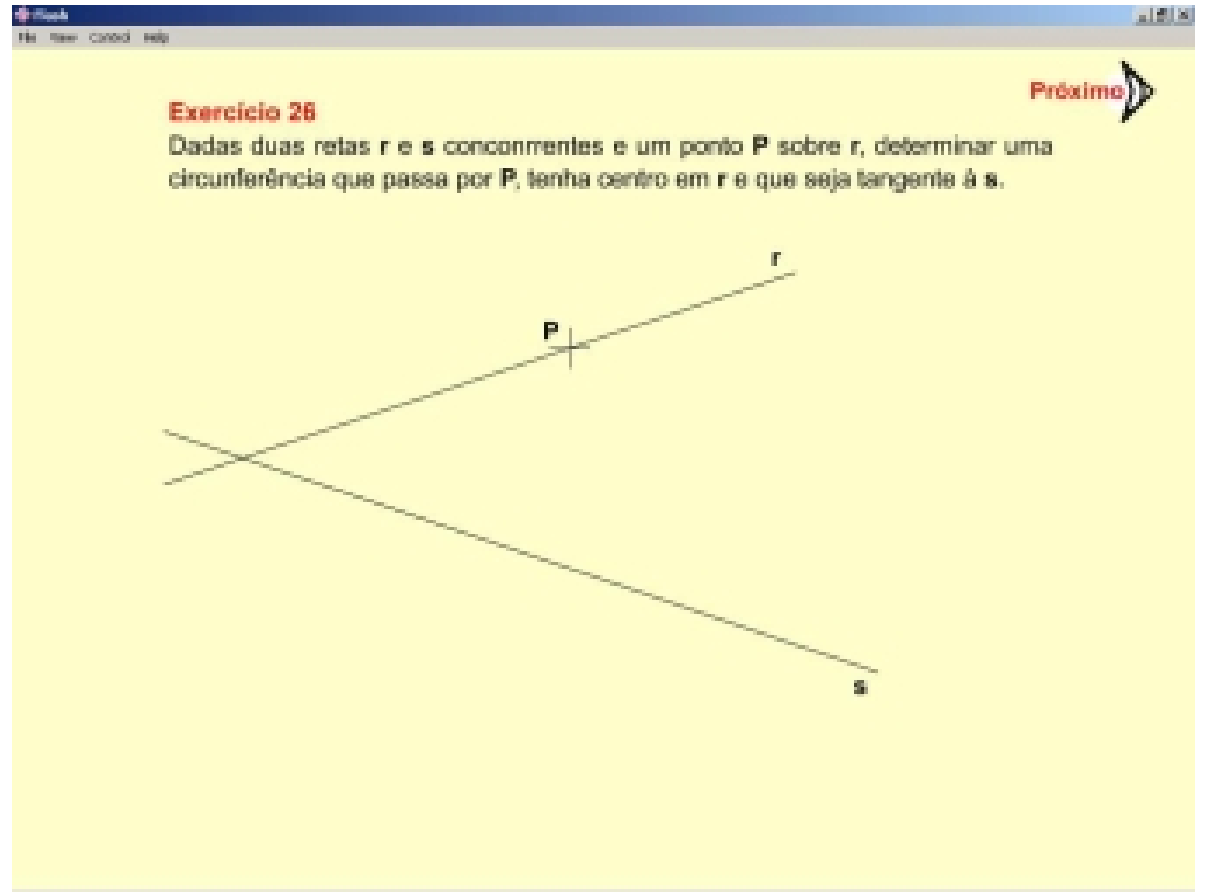

Exercicio 26

QAnterior

Dadas duas retas $r$ e 5 conconrrentes e um ponto $\mathbf{P}$ scbre $r$, deberminar uma circunferincia que passa por $\mathbf{P}$. venha centro em r e que seja tangame a s.

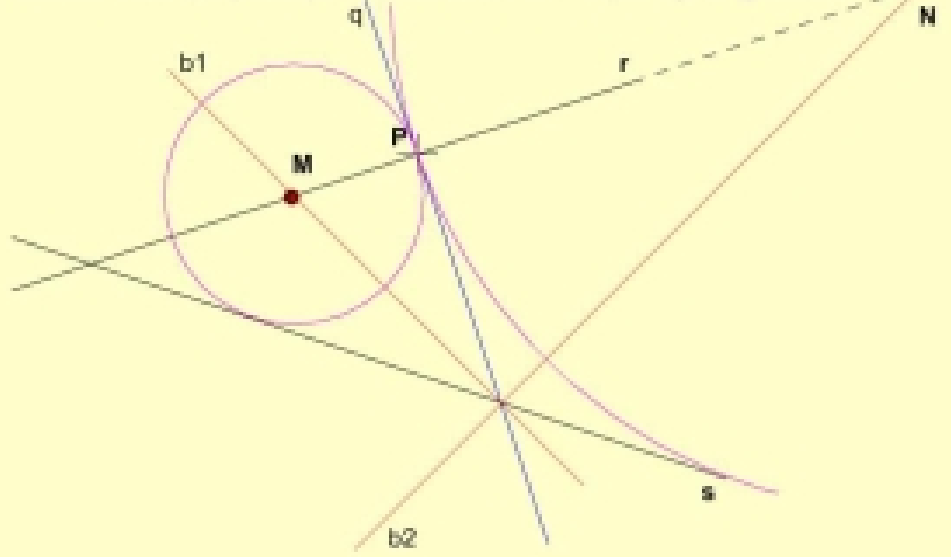

Trace a segunda circunferéncia com centro em N e raio NP. 

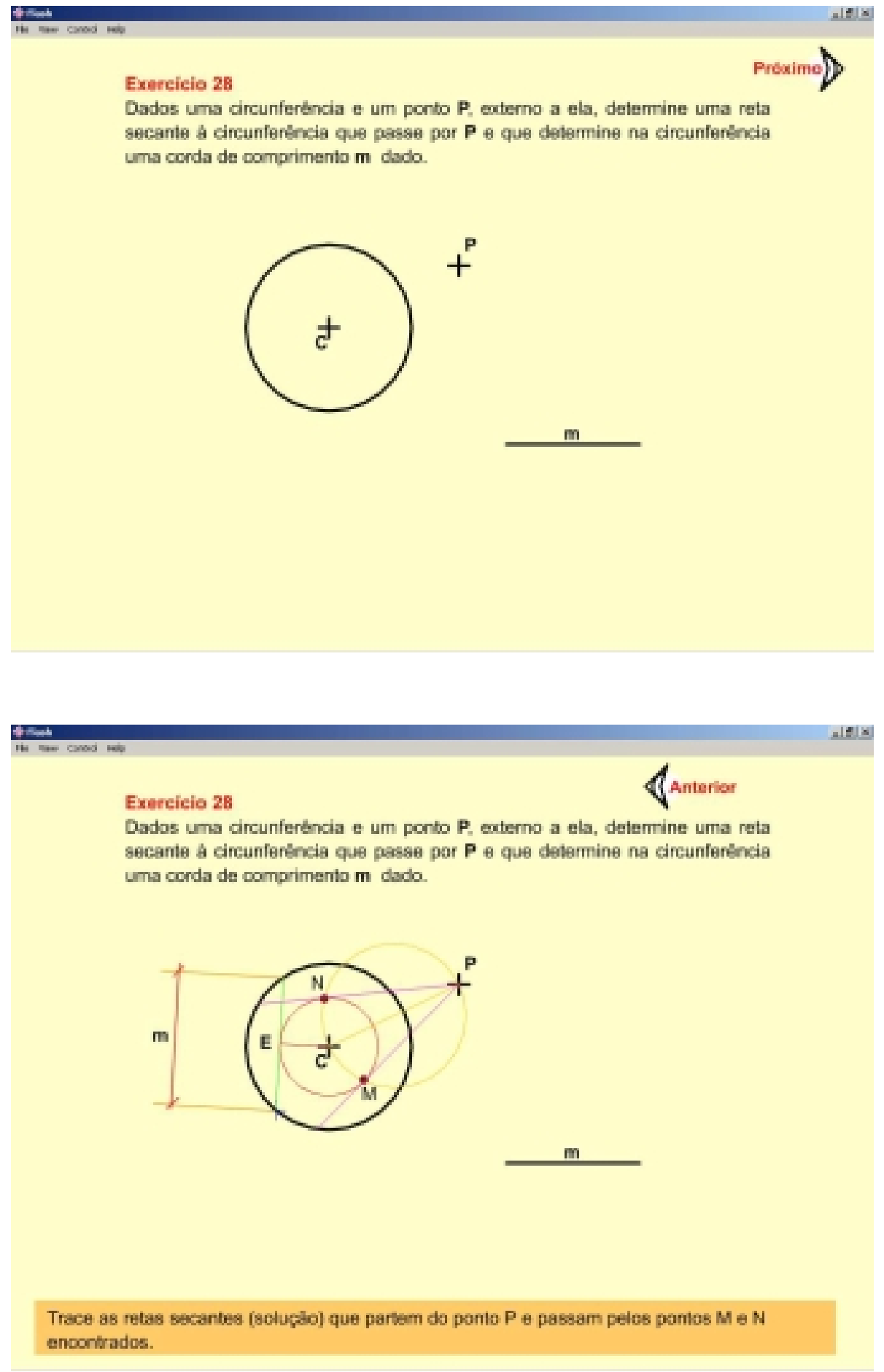

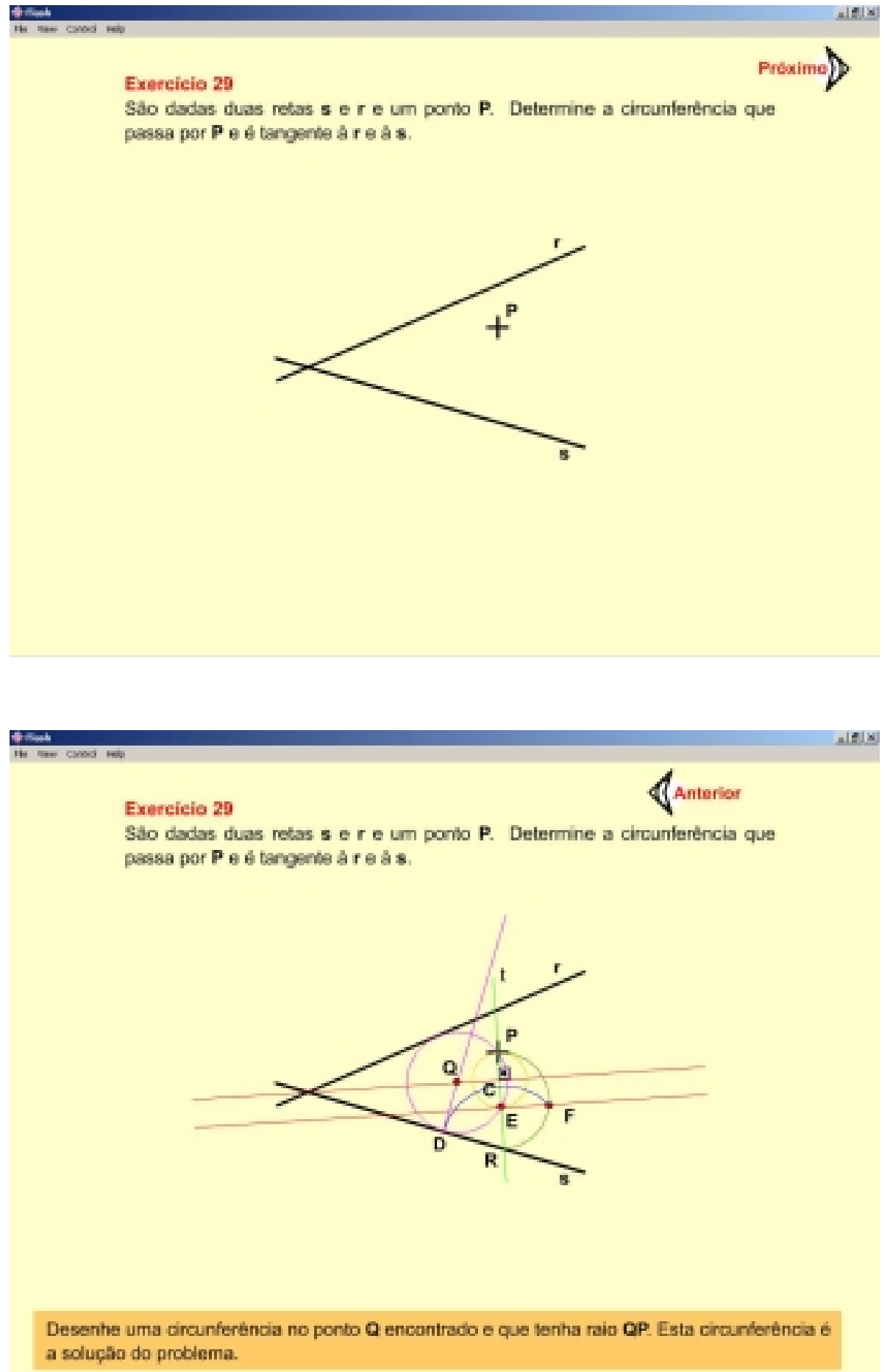

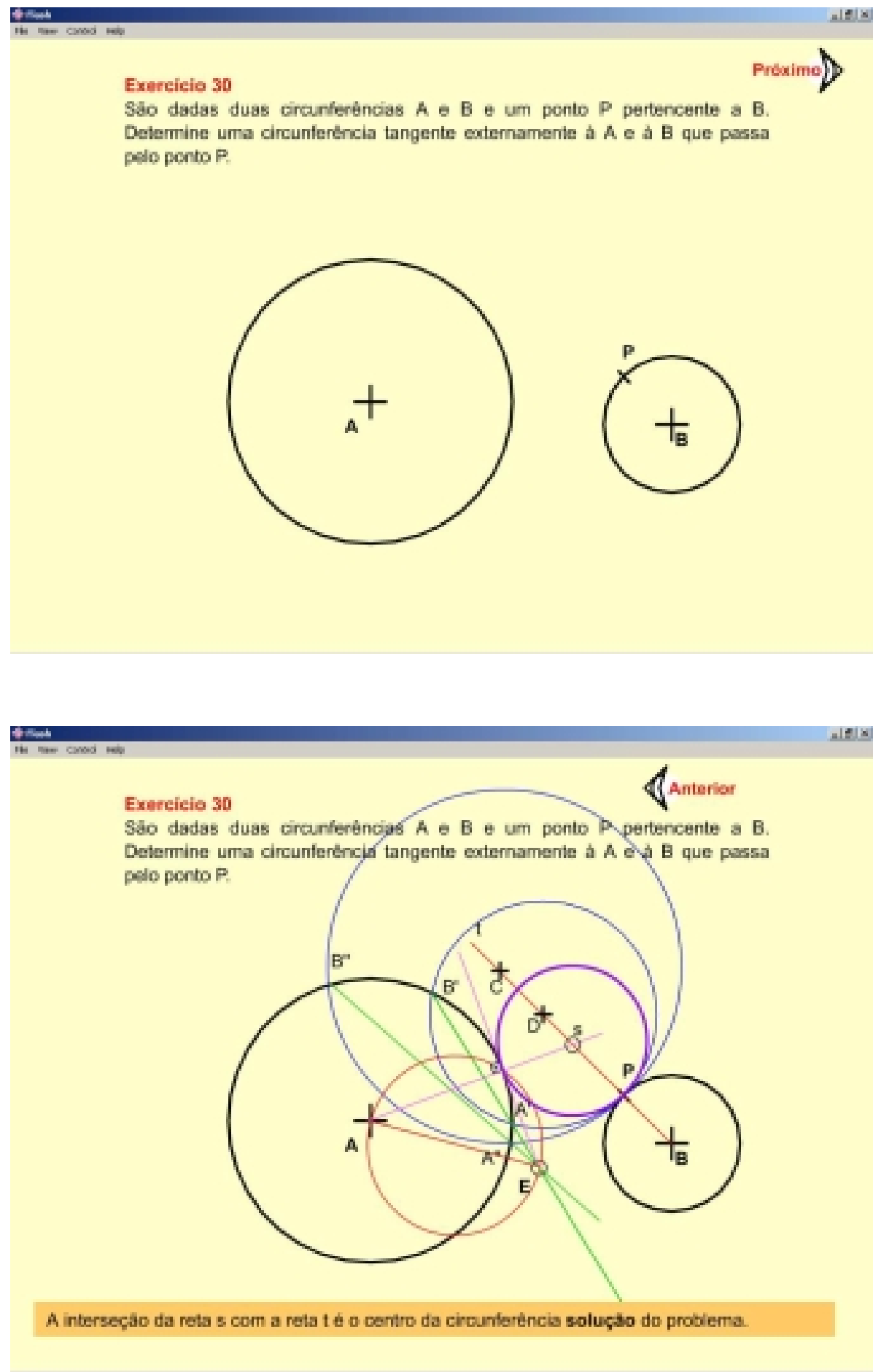
Exercícios de Geometria Cotada

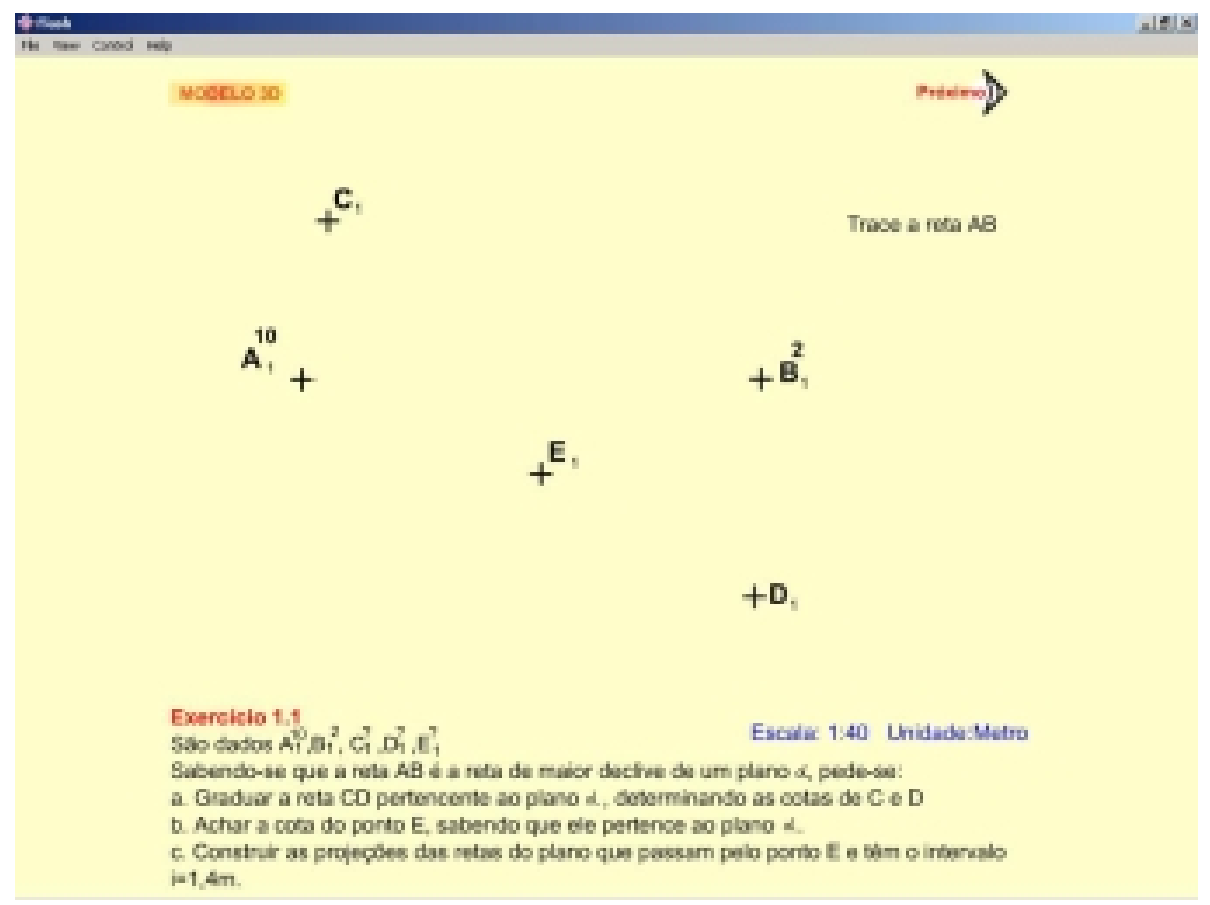

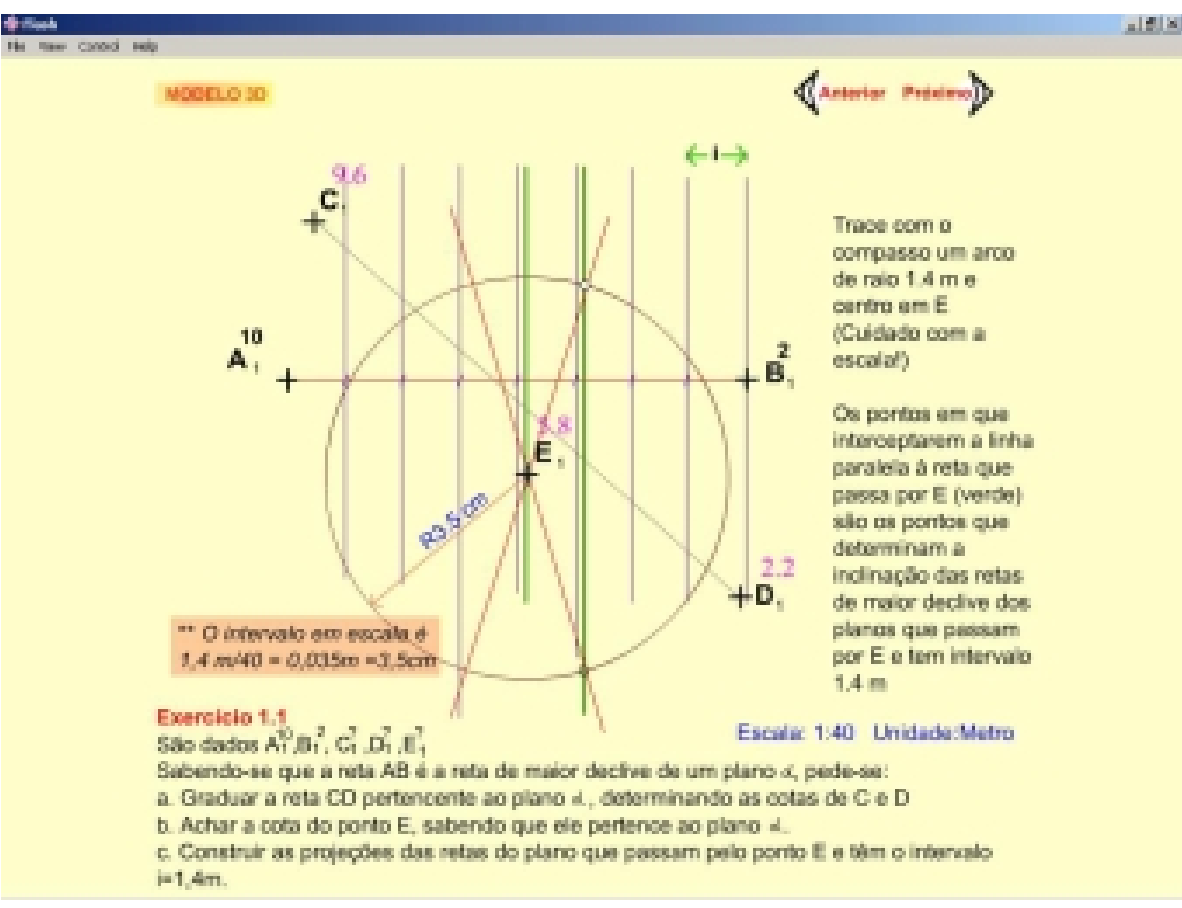



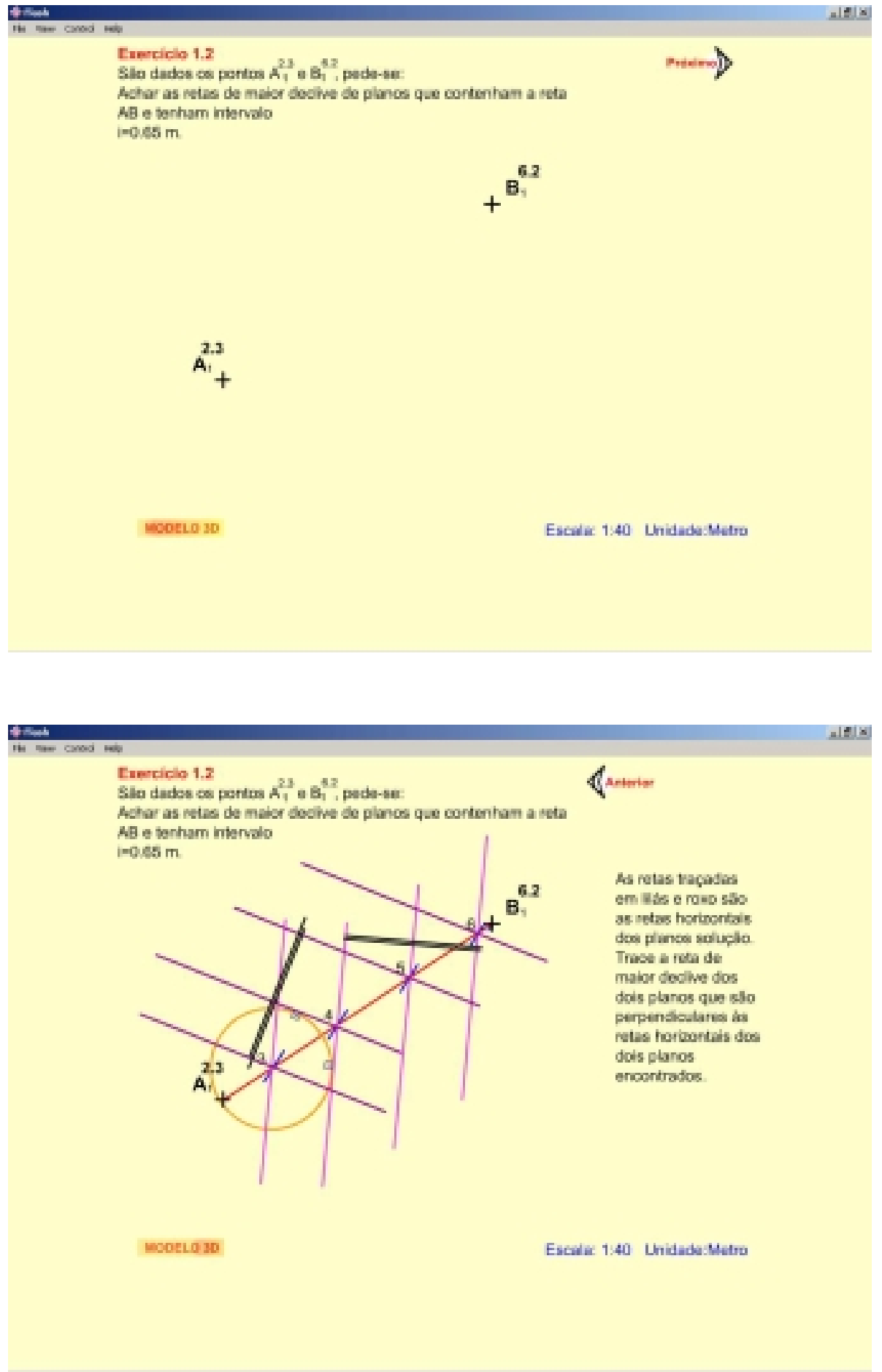

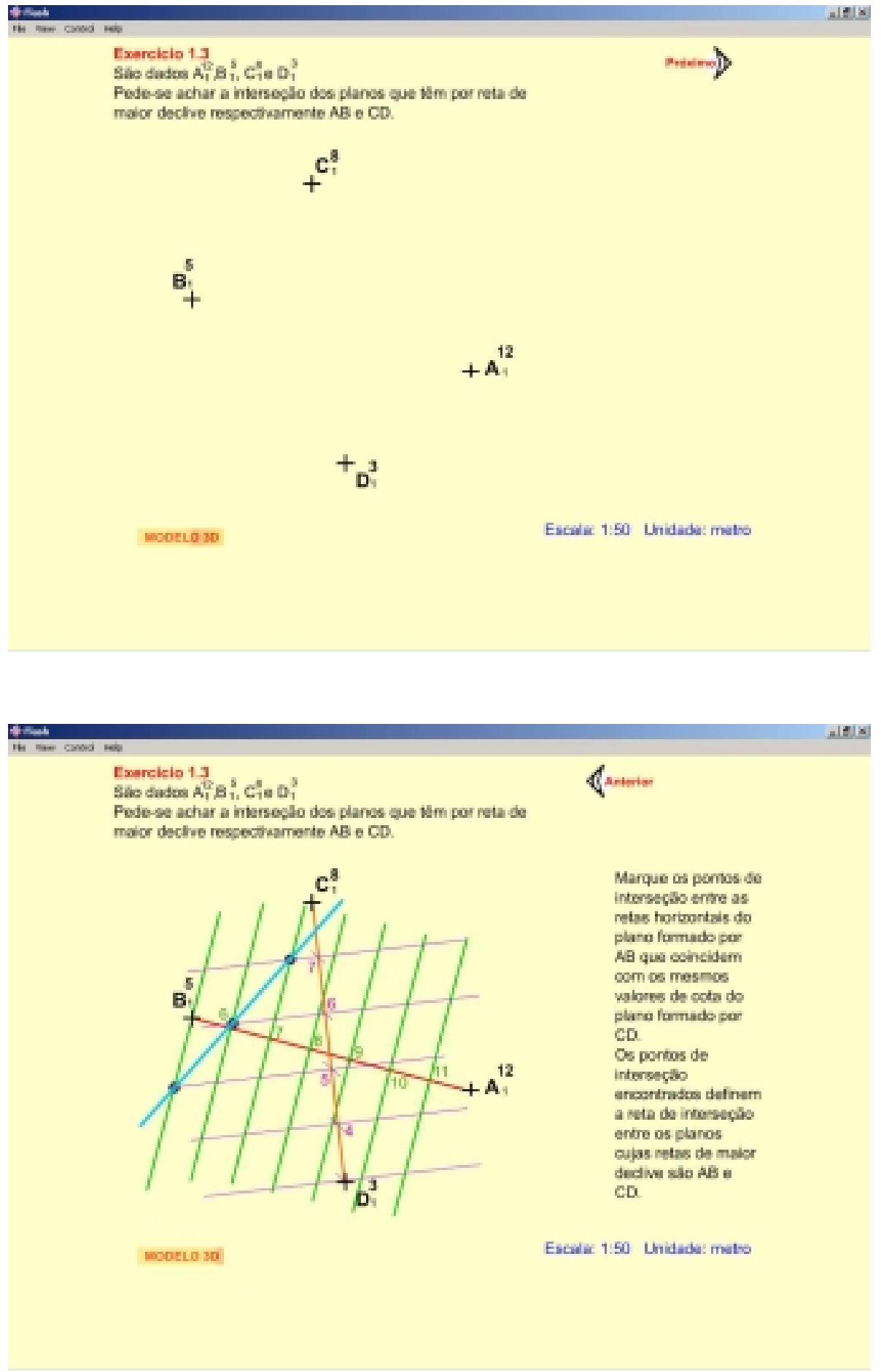

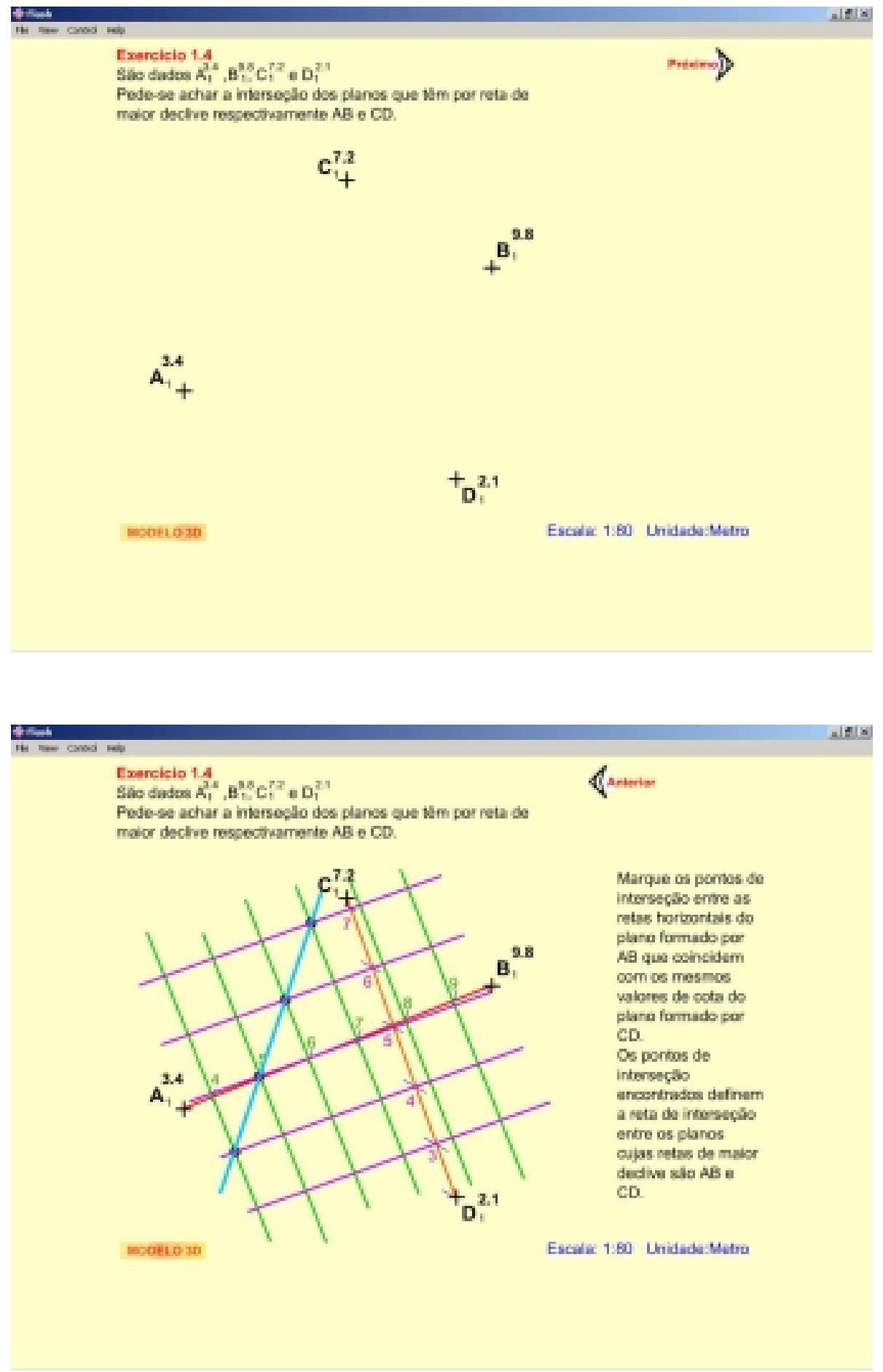

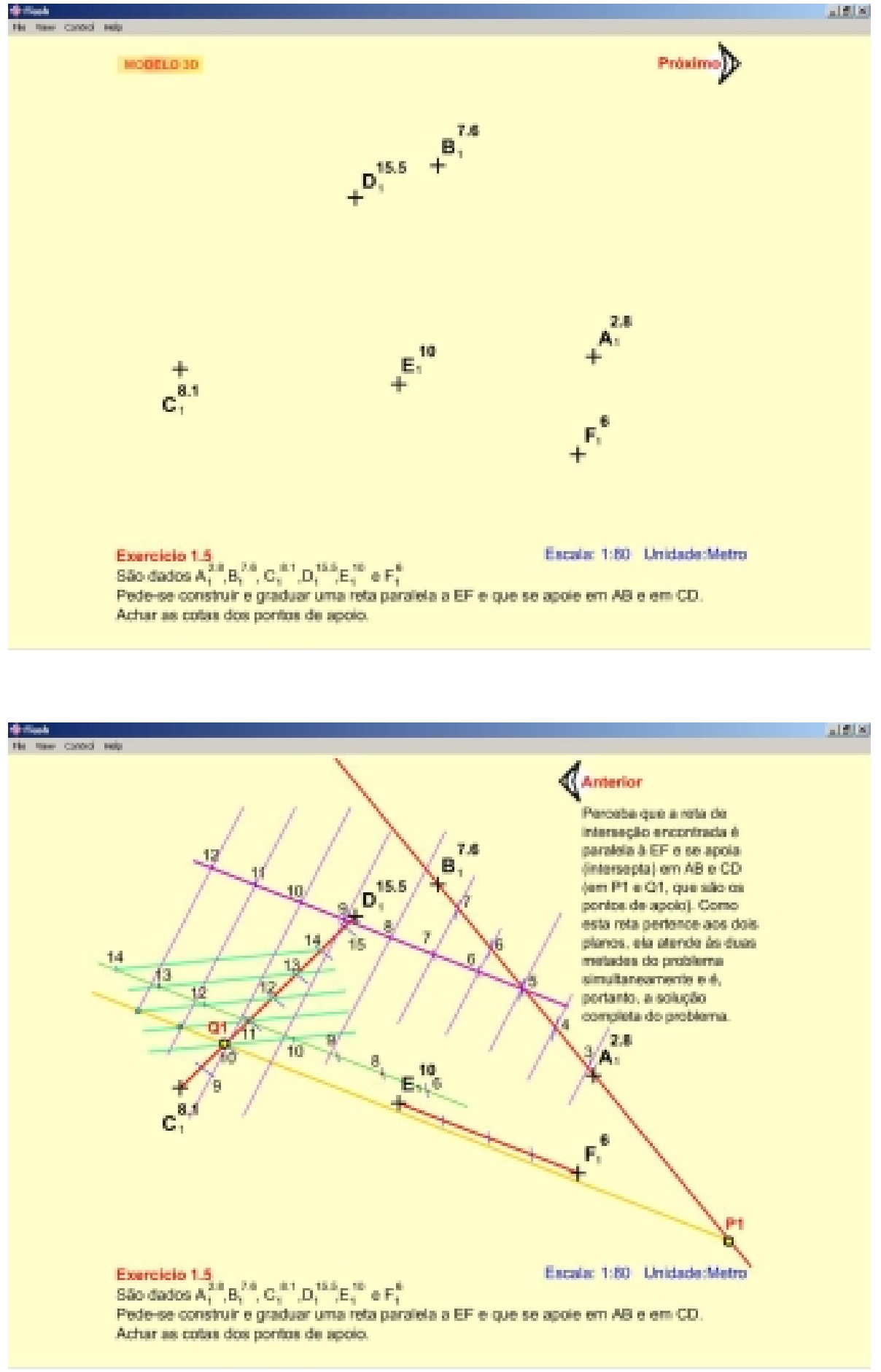


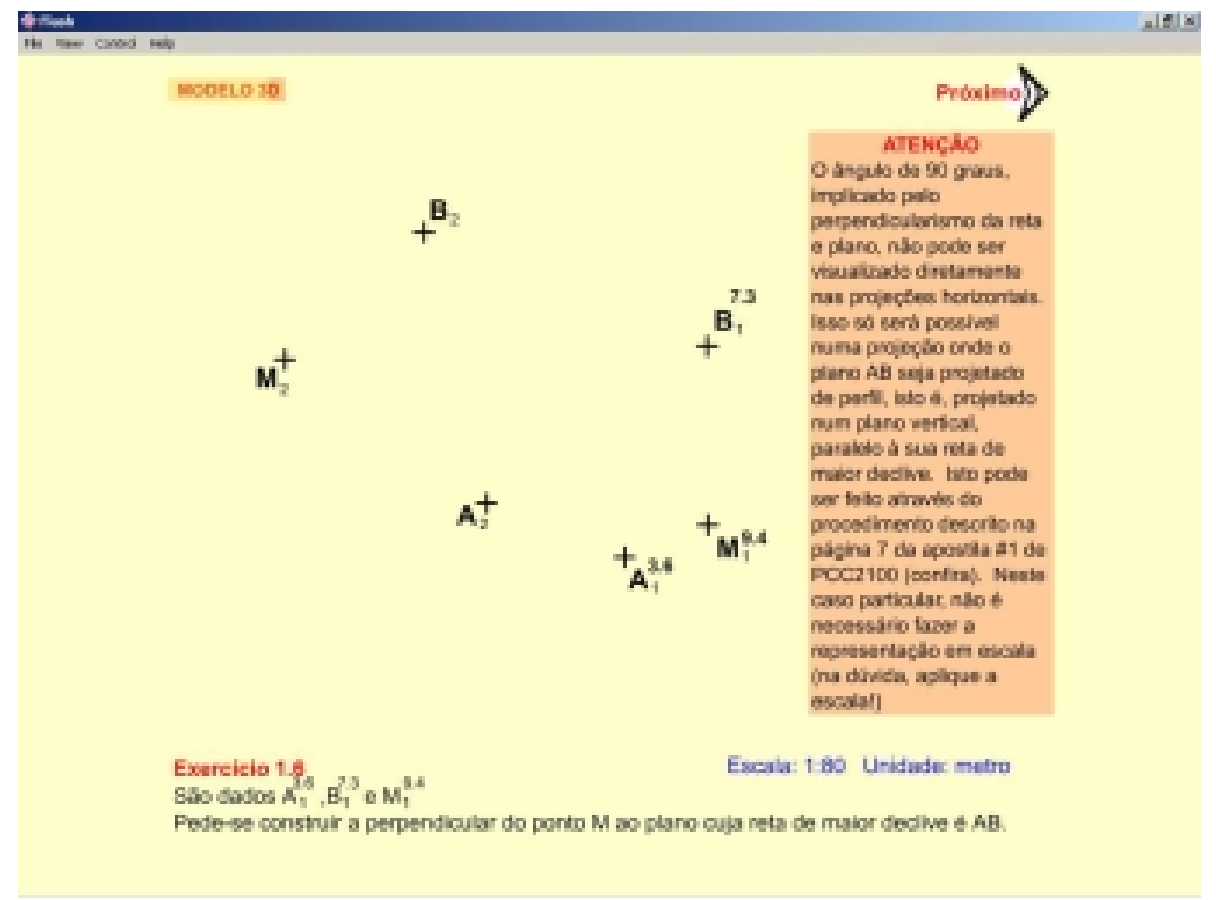

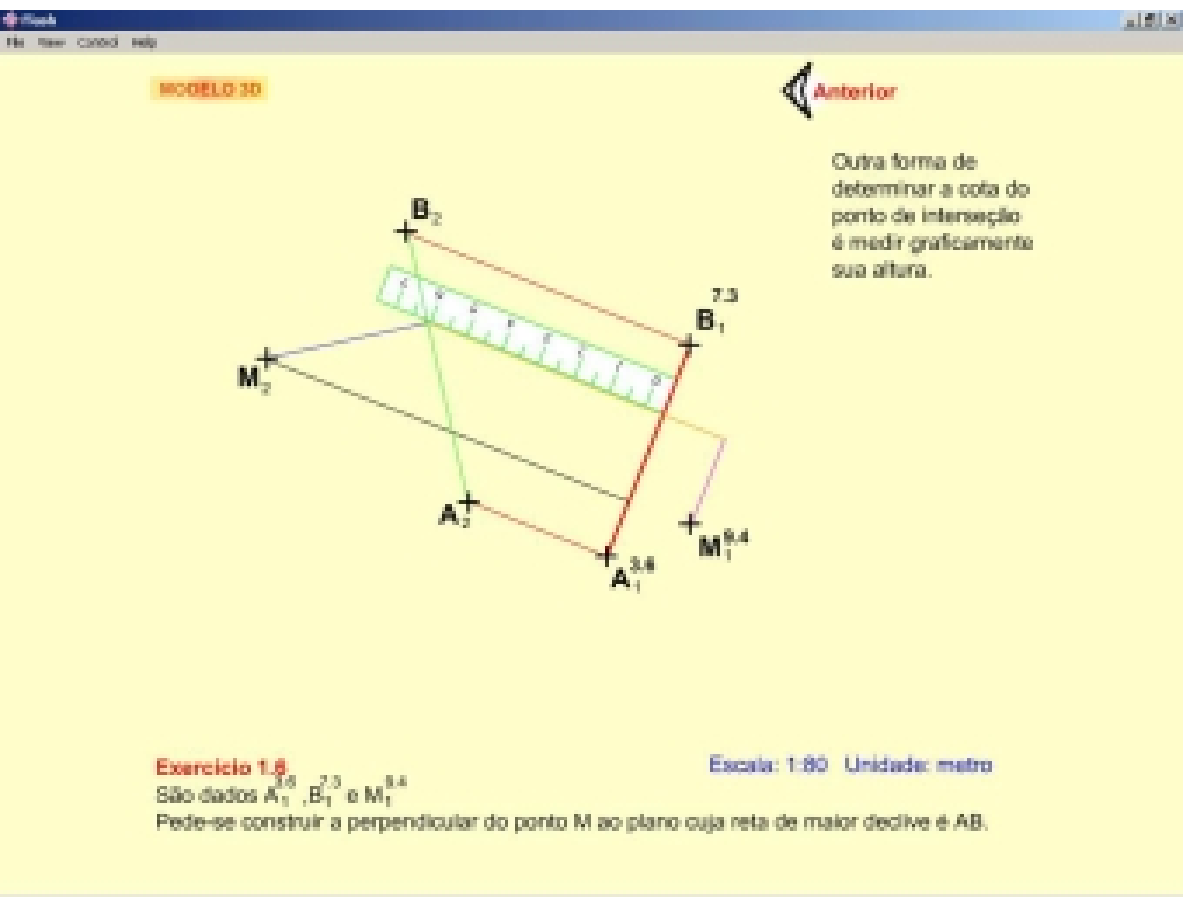



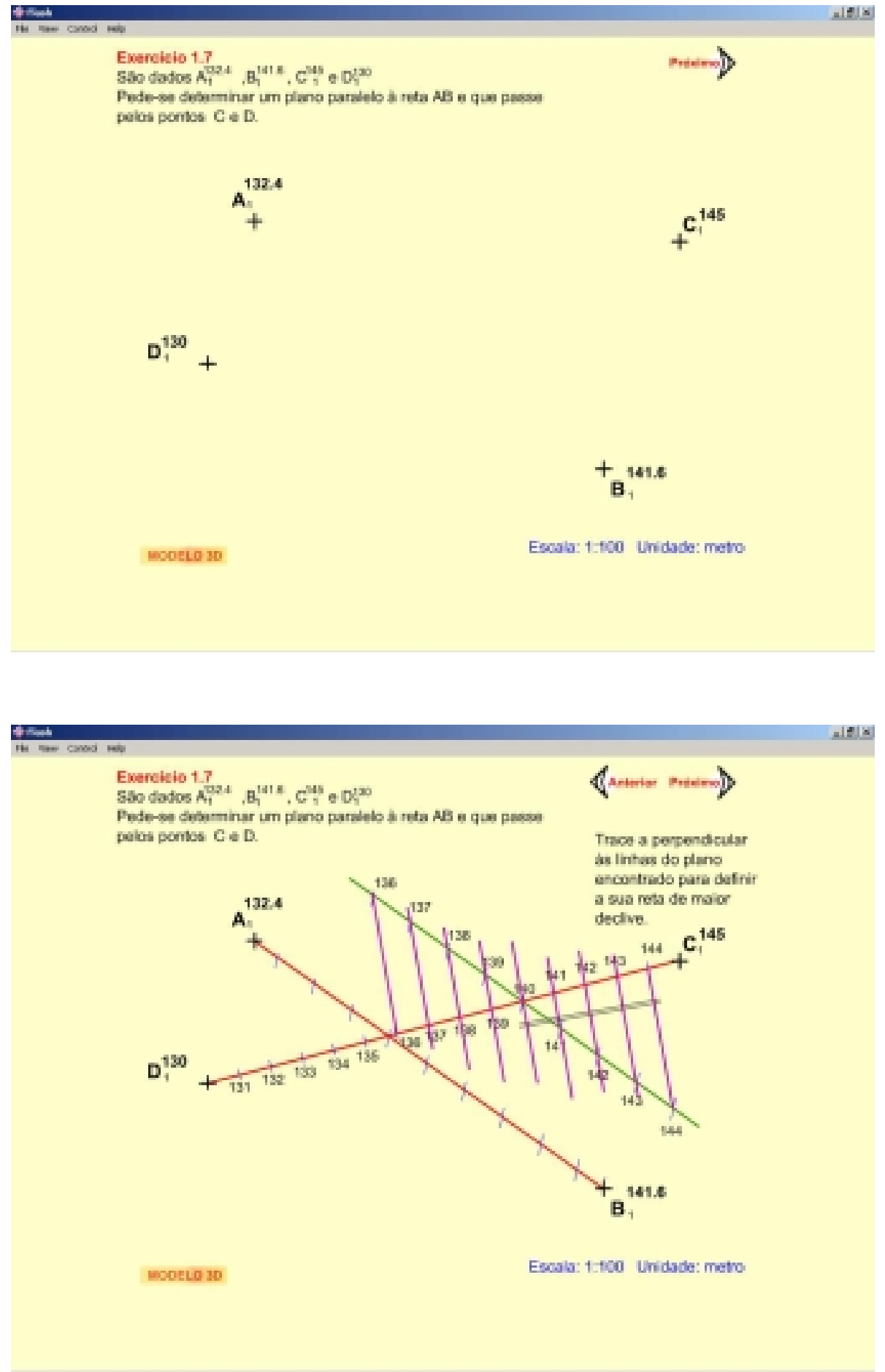

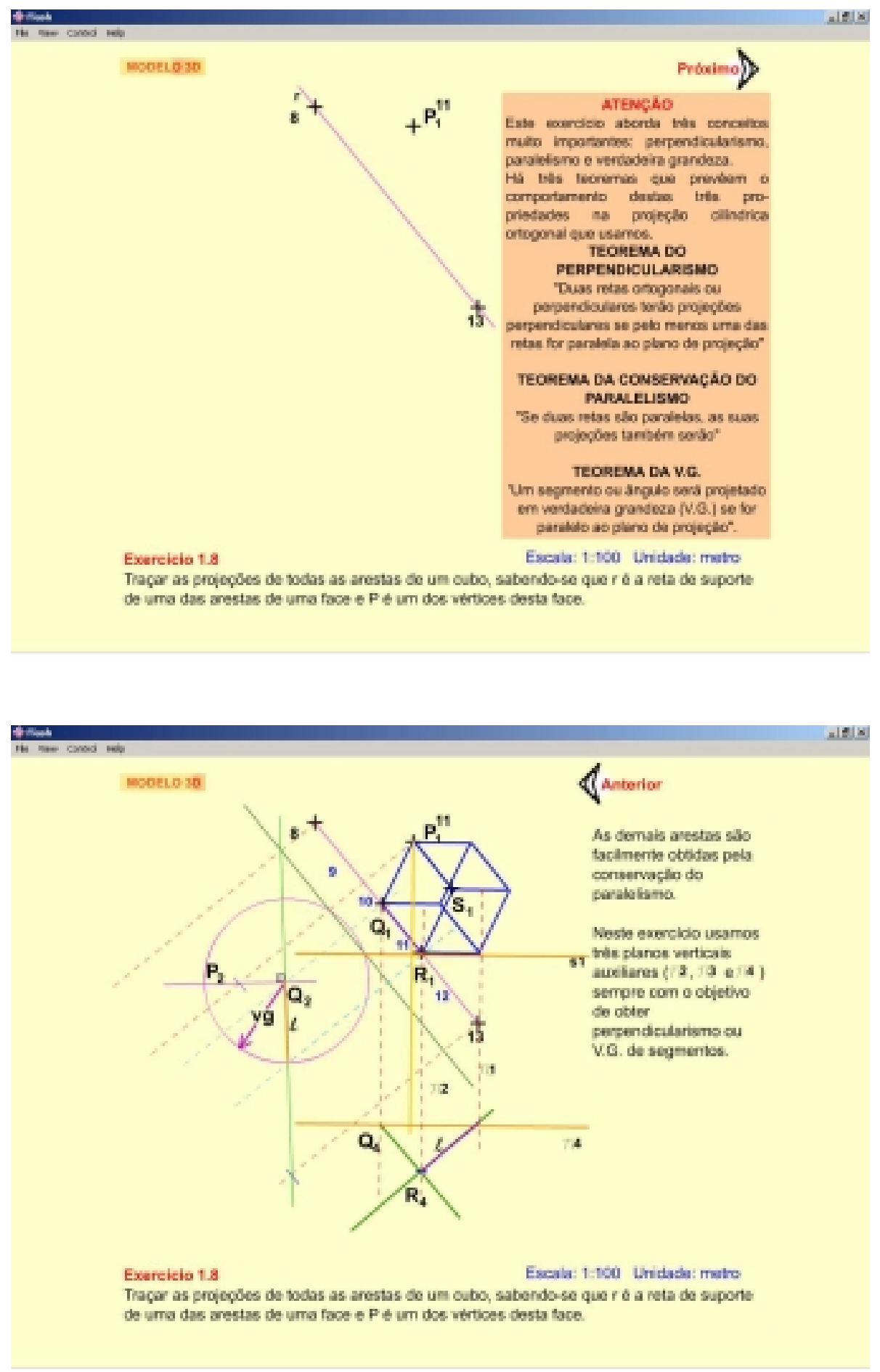

Nota:

As imagens foram feitas com o auxílio do programa “Macromidia Flash®”.

Os créditos destas imagens são de Monice, S. 
Anexo 2 - Formulário de autorização de uso da imagem

\section{AUTORIZAÇÃO DE FILMAGEM}

$\mathrm{Eu}$, autorizo ser filmado como participante do estudo de uso das interfaces dos programas: $i$ Geom e Risko que é realizado na data _______ no departamento de Construção Civil da Escola Politécnica da USP, LabCAD (Laboratório de Desenho Auxiliado pelo Computador). Esta autorização foi concedida antes da minha participação voluntária.

Entendo que a minha atividade se trata apenas de um teste que simula o uso dos programas citados e tem como único propósito gerar informações para uma pesquisa acadêmica. Assim sendo, autorizo o uso da imagem somente para os relatórios e publicações acadêmicas e veto a veiculação das mesmas publicamente ou para qualquer outra finalidade.

Assinatura (legível):

Número do teste:

Observações: 
Anexo 3 - Planilha de monitoramento do teste

\begin{tabular}{|c|c|c|c|}
\hline \multicolumn{3}{|r|}{ Monitoramento do Teste } & Número do teste: 00 \\
\hline & Teтро & Anotações: & \\
\hline 1 & $0: 00$ & início do teste com a interface A e da tarefa 1 & \\
\hline 2 & $0: 44$ & possível ocorrência (pediu uma caneta para uma & otação) \\
\hline 3 & $1: 03$ & término da tarefa 1 e inicio da tarefa 2 & \\
\hline 4 & & término da tarefa 2 e inicio da tarefa 3 & \\
\hline 5 & & $\ldots$ & \\
\hline 6 & & $\ldots$ & \\
\hline 7 & & $\ldots$ & \\
\hline 8 & & $\ldots$ & \\
\hline 9 & $6: 32$ & término do teste com a interface $\mathrm{A}$ e início do te & com a interface $\mathrm{B}$ \\
\hline 10 & & $\ldots$ & \\
\hline 11 & & $\ldots$ & \\
\hline 12 & & $\ldots$ & \\
\hline 13 & & $\ldots$ & \\
\hline 14 & & $\ldots$ & \\
\hline 15 & $15: 22$ & Fim do teste. & \\
\hline 16 & & & \\
\hline 17 & & & \\
\hline 18 & & & \\
\hline 19 & & & \\
\hline 20 & & & \\
\hline 21 & & & \\
\hline 22 & & & \\
\hline 23 & & & \\
\hline 24 & & & \\
\hline 25 & & & \\
\hline 26 & & & \\
\hline 27 & & & \\
\hline 28 & & & \\
\hline 29 & & & \\
\hline 30 & & & \\
\hline 31 & & & \\
\hline 32 & & & \\
\hline 33 & & & \\
\hline 34 & & & \\
\hline 35 & & & \\
\hline
\end{tabular}




\section{APÊNDICE A}

\section{FREQÜÊNCIAS DAS TAREFAS POR EXERCÍCIO}

AVALIADO

Tabela A.1 - Freqüência de tarefas, por exercício, e médias obtidas por tarefa

\begin{tabular}{|c|c|c|c|c|c|c|c|c|c|}
\hline Tarefas & 1 & 2 & 3 & 4 & 5 & 6 & 7 & 8 & 9 \\
\hline Exercícios 1 & \multicolumn{9}{|c|}{ Freqüência por exercício } \\
\hline 24 & 0 & 3 & 0 & 1 & 1 & 4 & 1 & 0 & 0 \\
\hline 25 & 1 & 1 & 0 & 2 & 2 & 5 & 0 & 1 & 0 \\
\hline 26 & 0 & 2 & 0 & 3 & 3 & 6 & 0 & 1 & 0 \\
\hline 27 & 2 & 1 & 0 & 2 & 2 & 0 & 0 & 1 & 0 \\
\hline 28 & 1 & 1 & 1 & 2 & 6 & 5 & 0 & 1 & 0 \\
\hline 29 & 1 & 2 & 0 & 2 & 1 & 7 & 1 & 2 & 0 \\
\hline 30 & 1 & 0 & 2 & 3 & 7 & 6 & 0 & 0 & 0 \\
\hline 1.1 & 5 & 0 & 0 & 9 & 9 & 1 & 8 & 13 & 0 \\
\hline 1.2 & 2 & 0 & 0 & 5 & 10 & 1 & 10 & 0 & 0 \\
\hline 1.3 & 4 & 0 & 0 & 12 & 7 & 0 & 10 & 12 & 0 \\
\hline 1.4 & 4 & 0 & 0 & 2 & 7 & 0 & 11 & 11 & 0 \\
\hline 1.5 & 6 & 0 & 0 & 11 & 12 & 0 & 20 & 10 & 0 \\
\hline 1.6 & 6 & 0 & 0 & 0 & 4 & 0 & 0 & 4 & 0 \\
\hline 1.7 & 4 & 0 & 0 & 1 & 14 & 0 & 0 & 23 & 0 \\
\hline 1.8 & 4 & 0 & 0 & 5 & 15 & 1 & 16 & 4 & 0 \\
\hline Soma & 41 & 10 & 3 & 60 & 100 & 36 & 77 & 83 & 0 \\
\hline Média & 2,73 & 0,67 & 0,20 & 4,00 & 6,67 & 2,40 & 5,13 & 5,53 & 0,00 \\
\hline
\end{tabular}

\footnotetext{
${ }^{1}$ Exercicios extraidos da apostila de desenho (KAWANO, et al., 2000).
} 


\section{APÊNDICE B}

\section{DADOS DO TESTE DE MCNEMAR}

Tabela B.1 - Tempo2 total gasto, por usuário, para executar cada tarefa com o Risko

\begin{tabular}{|c|c|c|c|c|c|c|c|c|c|c|}
\hline Teste & $t 1$ & $t 2$ & $t 3$ & $t 4$ & $t 5$ & t6 & $t 7$ & t8 & t9 & Total $\bar{\beta}$ \\
\hline 1 & $(00: 52) 4$ & $00: 20$ & $00: 18$ & $00: 13$ & $(00: 26)$ & $00: 22$ & $00: 44$ & $00: 28$ & $00: 24$ & 04:07 \\
\hline 2 & $00: 22$ & $00: 22$ & $00: 19$ & $(00: 21)$ & $00: 45$ & $00: 49$ & $01: 29$ & $01: 20$ & $00: 17$ & 06:04 \\
\hline 3 & $(01: 27)$ & $00: 32$ & $00: 10$ & {$[00: 11] \overline{5}$} & 00:43 & $(00: 31)$ & $02: 24$ & $00: 36$ & 00:09 & $06: 43$ \\
\hline 4 & $00: 31$ & $00: 12$ & 00:11 & $00: 10$ & $(00: 40)$ & $00: 17$ & $(00: 38)$ & $(00: 22)$ & $00: 14$ & $03: 15$ \\
\hline 5 & $(00: 24)$ & $00: 12$ & $00: 14$ & $00: 11$ & $00: 33$ & $00: 12$ & $00: 25$ & $00: 15$ & $00: 33$ & $02: 59$ \\
\hline 6 & 00:19 & $00: 25$ & 00:11 & 00:17 & $00: 20$ & $00: 16$ & $00: 31$ & $00: 33$ & $00: 20$ & $03: 12$ \\
\hline 7 & $(00: 40)$ & $00: 20$ & $00: 18$ & $00: 32$ & 01:05 & $00: 23$ & $(01: 24)$ & 01:04 & $00: 17$ & 06:03 \\
\hline 8 & $(00: 21)$ & $00: 27$ & 00:19 & $01: 35$ & [00:00] & $00: 29$ & $00: 46$ & $00: 48$ & $00: 18$ & 05:03 \\
\hline 9 & $00: 26$ & $00: 44$ & $00: 43$ & $00: 50$ & $01: 18$ & $00: 59$ & $01: 26$ & $00: 26$ & $00: 54$ & $07: 46$ \\
\hline 10 & 01:08 & $00: 27$ & $00: 25$ & $00: 10$ & 01:09 & $00: 27$ & 01:08 & $00: 46$ & $00: 50$ & $06: 30$ \\
\hline 11 & $04: 43$ & 00:33 & $00: 12$ & $00: 56$ & $00: 18$ & $00: 17$ & $01: 28$ & 00:41 & $00: 20$ & 09:28 \\
\hline 12 & $(00: 20)$ & $00: 17$ & $00: 11$ & $00: 36$ & $00: 36$ & $00: 23$ & $00: 42$ & $00: 10$ & 00:08 & $03: 23$ \\
\hline 13 & $(00: 18)$ & $00: 26$ & $00: 14$ & $(00: 20)$ & $(00: 17)$ & $(00: 17)$ & $00: 35$ & $00: 30$ & $00: 16$ & $03: 13$ \\
\hline 14 & $00: 26$ & $00: 23$ & $00: 12$ & $00: 17$ & $00: 26$ & 00:19 & $00: 51$ & $00: 18$ & $00: 10$ & $03: 22$ \\
\hline 15 & $(00: 37)$ & $00: 28$ & $00: 14$ & $00: 21$ & $01: 23$ & $00: 44$ & $00: 58$ & $00: 43$ & $00: 23$ & $05: 51$ \\
\hline 16 & $00: 34$ & $00: 32$ & $00: 12$ & $00: 18$ & $00: 15$ & $00: 11$ & $00: 50$ & 01:01 & $00: 27$ & $04: 20$ \\
\hline 17 & 00:09 & $00: 27$ & $00: 16$ & $00: 16$ & $00: 36$ & $00: 21$ & $00: 45$ & $00: 43$ & $00: 27$ & 04:00 \\
\hline Médid 6 & $08: 38$ & $07: 07$ & $04: 39$ & $06: 42$ & 09:27 & $06: 29$ & $15: 02$ & $10: 22$ & 06:27 & $01: 25: 19$ \\
\hline M. tar. $\overline{\bar{D}}$ & $00: 58$ & $00: 25$ & $00: 16$ & $00: 29$ & $00: 44$ & $00: 26$ & $01: 00$ & $00: 39$ & $00: 23$ & $05: 19$ \\
\hline
\end{tabular}

\footnotetext{
2 Tempos em minutos e segundos (mm:ss).

${ }^{3}$ A última coluna apresenta o somatório dos tempos gastos para execução das tarefas corretas.

${ }^{4}$ Os valores dentre ( ) correpondem as tarefas classificadas como incorretas.

${ }^{5}$ Os valores dentre [ ] correspondem as desistências "incorretas" em realizar a referida tarefa.

${ }^{6}$ A penúltima linha apresenta o somatório dos tempos para executar cada uma das tarefas corretas.

${ }^{7}$ A última linha apresenta a média dos tempos gastos para executar cada uma das tarefas corretas.
} 
Tabela B.2 - Tempo total gasto, por usuário, para executar cada tarefa com o $i \mathrm{Geom}$

\begin{tabular}{ccccccccccc}
\hline Teste & $\boldsymbol{t 1}$ & $\boldsymbol{t 2}$ & $\boldsymbol{t 3}$ & $\boldsymbol{t 4}$ & $\boldsymbol{T 5}$ & $\boldsymbol{t 6}$ & $\boldsymbol{t 7}$ & $\boldsymbol{t 8}$ & $\boldsymbol{t 9}$ & Total \\
\hline $\mathbf{1}$ & $00: 16$ & $00: 09$ & $00: 13$ & $00: 08$ & $00: 13$ & $00: 12$ & $00: 21$ & $00: 13$ & $00: 32$ & $\mathbf{0 2 : 1 7}$ \\
$\mathbf{2}$ & $00: 17$ & $00: 15$ & $00: 07$ & $00: 12$ & $00: 13$ & $00: 13$ & $00: 48$ & $00: 16$ & $00: 39$ & $\mathbf{0 3 : 0 0}$ \\
$\mathbf{3}$ & $00: 07$ & $00: 10$ & $00: 06$ & $00: 15$ & $00: 26$ & $00: 06$ & $00: 08$ & {$[02: 19]$} & $00: 13$ & $\mathbf{0 3 : 5 0}$ \\
$\mathbf{4}$ & $00: 07$ & $00: 08$ & $00: 15$ & $00: 05$ & $00: 15$ & $00: 16$ & $00: 16$ & $00: 12$ & $01: 13$ & $\mathbf{0 2 : 4 7}$ \\
$\mathbf{5}$ & $00: 08$ & $00: 08$ & $00: 10$ & $00: 09$ & $00: 10$ & $00: 11$ & $00: 13$ & $00: 10$ & $01: 45$ & $\mathbf{0 3 : 0 4}$ \\
$\mathbf{6}$ & $00: 08$ & $00: 08$ & $00: 08$ & $00: 15$ & $00: 26$ & $00: 12$ & $00: 19$ & $00: 14$ & $00: 26$ & $\mathbf{0 2 : 1 6}$ \\
$\mathbf{7}$ & $00: 11$ & $00: 11$ & $01: 18$ & $00: 10$ & $00: 07$ & $00: 05$ & $00: 16$ & $00: 10$ & $00: 21$ & $\mathbf{0 2 : 4 9}$ \\
$\boldsymbol{8}$ & $00: 06$ & $00: 12$ & $00: 18$ & $00: 25$ & $00: 18$ & $00: 09$ & $00: 16$ & $00: 20$ & $00: 51$ & $\mathbf{0 2 : 5 5}$ \\
$\mathbf{9}$ & $00: 07$ & $00: 42$ & $01: 20$ & $00: 31$ & $00: 14$ & $00: 22$ & $00: 22$ & $00: 16$ & $01: 19$ & $\mathbf{0 5 : 1 3}$ \\
$\mathbf{1 0}$ & $00: 13$ & $00: 18$ & $00: 18$ & $00: 30$ & $00: 19$ & $00: 15$ & $00: 25$ & $00: 23$ & $00: 51$ & $\mathbf{0 3 : 3 2}$ \\
$\mathbf{1 1}$ & $00: 12$ & $00: 16$ & $00: 20$ & $00: 17$ & $00: 18$ & $00: 13$ & $00: 08$ & $00: 12$ & $00: 29$ & $\mathbf{0 2 : 2 5}$ \\
$\mathbf{1 2}$ & $00: 06$ & $00: 06$ & $00: 04$ & $00: 43$ & $00: 46$ & $00: 20$ & $00: 13$ & $00: 35$ & $00: 19$ & $\mathbf{0 3 : 1 2}$ \\
$\mathbf{1 3}$ & $00: 11$ & $00: 17$ & $00: 08$ & $00: 07$ & $00: 18$ & $00: 14$ & $00: 27$ & $00: 09$ & $00: 30$ & $\mathbf{0 2 : 2 1}$ \\
$\mathbf{1 4}$ & $00: 13$ & $00: 18$ & $00: 23$ & $00: 10$ & $00: 53$ & $00: 17$ & $00: 19$ & $00: 10$ & $00: 42$ & $\mathbf{0 3 : 2 5}$ \\
$\mathbf{1 5}$ & $00: 16$ & $00: 17$ & $00: 23$ & $01: 13$ & $00: 16$ & $00: 21$ & $00: 14$ & $00: 11$ & $00: 56$ & $\mathbf{0 4 : 0 7}$ \\
$\mathbf{1 6}$ & $00: 16$ & $00: 18$ & $00: 14$ & $00: 14$ & $00: 17$ & $00: 15$ & $00: 13$ & $00: 20$ & $00: 23$ & $\mathbf{0 2 : 3 0}$ \\
$\mathbf{1 7}$ & $00: 22$ & $00: 22$ & $00: 16$ & $00: 10$ & $00: 25$ & {$[00: 22]$} & $01: 16$ & $00: 31$ & $00: 26$ & $\mathbf{0 4 : 1 0}$ \\
\hline Média & $\mathbf{0 3 : 1 6}$ & $\mathbf{0 4 : 1 5}$ & $\mathbf{0 6 : 0 1}$ & $\mathbf{0 5 : 3 4}$ & $\mathbf{0 5 : 5 4}$ & $\mathbf{0 3 : 4 1}$ & $\mathbf{0 6 : 1 4}$ & $\mathbf{0 4 : 2 2}$ & $\mathbf{1 1 : 5 5}$ & $\mathbf{5 3 : 5 3}$ \\
\hline M. tar. & $\mathbf{0 0 : 1 2}$ & $\mathbf{0 0 : 1 5}$ & $\mathbf{0 0 : 2 1}$ & $\mathbf{0 0 : 2 0}$ & $\mathbf{0 0 : 2 1}$ & $\mathbf{0 0 : 1 4}$ & $\mathbf{0 0 : 2 2}$ & $\mathbf{0 0 : 1 6}$ & $\mathbf{0 0 : 4 2}$ & $\mathbf{0 3 : 0 3}$ \\
\hline & & & & & & & & & &
\end{tabular}


Tabela B.3 - Tempo real gasto, por usuário, para executar cada tarefa com o Risko

\begin{tabular}{cccccccccc}
\hline Teste & $\boldsymbol{t} \mathbf{1}$ & $\boldsymbol{t} \mathbf{2}$ & $\boldsymbol{t 3}$ & $\boldsymbol{t 4}$ & $\boldsymbol{T 5}$ & $\boldsymbol{t} \boldsymbol{6}$ & $\boldsymbol{t} \mathbf{7}$ & $\boldsymbol{t} \boldsymbol{8}$ & $\boldsymbol{t} \boldsymbol{9}$ \\
\hline \hline $\mathbf{1}$ & - & 12,80 & 13,37 & 7,96 & - & 15,43 & 18,64 & 12,16 & 20,00 \\
$\mathbf{2}$ & 14,34 & 14,8 & 14,37 & - & 31,24 & 42,43 & 63,64 & 64,16 & 13,00 \\
$\mathbf{3}$ & - & 24,8 & 5,37 & - & 29,24 & - & 118,64 & 20,16 & 5,00 \\
$\mathbf{4}$ & 23,34 & 4,8 & 6,37 & 4,96 & - & 10,43 & - & - & 10,00 \\
$\mathbf{5}$ & - & 4,8 & 9,37 & 5,96 & 19,24 & 5,43 & - & - & 29,00 \\
$\mathbf{6}$ & 11,34 & 17,8 & 6,37 & 11,96 & 6,24 & 9,43 & 5,64 & 17,16 & 16,00 \\
$\mathbf{7}$ & - & 12,8 & 13,37 & 26,96 & 51,24 & 16,43 & - & 48,16 & 13,00 \\
$\mathbf{8}$ & - & 19,8 & 14,37 & 89,96 & - & 22,43 & 20,64 & 32,16 & 14,00 \\
$\mathbf{9}$ & 18,34 & 36,8 & 38,37 & 44,96 & 64,24 & 52,43 & 60,64 & 10,16 & 50,00 \\
$\mathbf{1 0}$ & $\mathbf{6 0 , 3 4}$ & 19,8 & 20,37 & 4,96 & 55,24 & 20,43 & 42,64 & 30,16 & 46,00 \\
$\mathbf{1 1}$ & 275,34 & 25,8 & 7,37 & 50,96 & 4,24 & 10,43 & 62,64 & 25,16 & 16,00 \\
$\mathbf{1 2}$ & - & 9,8 & 6,37 & 30,96 & 22,24 & 16,43 & 16,64 & - & 4,00 \\
$\mathbf{1 3}$ & - & 18,8 & 9,37 & - & - & - & 9,64 & 14,16 & 12,00 \\
$\mathbf{1 4}$ & $\mathbf{1 8 , 3 4}$ & 15,8 & 7,37 & 11,96 & 12,24 & 12,43 & 25,64 & 2,16 & 6,00 \\
$\mathbf{1 5}$ & - & 20,8 & 9,37 & 15,96 & 69,24 & 37,43 & 32,64 & 27,16 & 19,00 \\
$\mathbf{1 6}$ & $\mathbf{2 6 , 3 4}$ & 24,8 & 7,37 & 12,96 & 1,24 & 4,43 & 24,64 & 45,16 & 23,00 \\
$\mathbf{1 7}$ & 1,34 & 19,8 & 11,37 & 10,96 & 22,24 & 14,43 & 19,64 & 27,16 & 23,00 \\
\hline Média & $\mathbf{4 9 , 9 0}$ & $\mathbf{1 7 , 9 2}$ & $\mathbf{1 1 , 7 8}$ & $\mathbf{2 3 , 6 7}$ & $\mathbf{2 9 , 8 6}$ & $\mathbf{1 9 , 3 6}$ & $\mathbf{3 7 , 2 8}$ & $\mathbf{2 6 , 8 0}$ & $\mathbf{1 8 , 7 6}$ \\
\hline
\end{tabular}

Tabela B.4 - Tempo real gasto, por usuário, para executar cada tarefa com o $i$ Gom

\begin{tabular}{cccccccccc}
\hline Teste & $\boldsymbol{t 1}$ & $\boldsymbol{t} \mathbf{2}$ & $\boldsymbol{t 3}$ & $\boldsymbol{t 4}$ & $\mathbf{T 5}$ & $\boldsymbol{t} \boldsymbol{6}$ & $\boldsymbol{t} \mathbf{7}$ & $\boldsymbol{t} \boldsymbol{8}$ & $\boldsymbol{t} \mathbf{9}$ \\
\hline \hline $\mathbf{1}$ & 10,86 & 5,71 & 10,19 & 5,42 & 7,86 & 6,59 & 17,1 & 8,91 & 28,37 \\
$\mathbf{2}$ & 11,86 & 11,71 & 4,19 & 9,42 & 7,86 & 7,59 & 44,1 & 11,91 & 35,37 \\
$\mathbf{3}$ & 1,86 & 6,71 & 3,19 & 12,42 & 20,86 & 0,59 & 4,1 & - & 9,37 \\
$\mathbf{4}$ & 1,86 & 4,71 & 12,19 & 2,42 & 9,86 & 10,59 & 12,1 & 7,91 & 69,37 \\
$\mathbf{5}$ & 2,86 & 4,71 & 7,19 & 6,42 & 4,86 & 5,59 & 9,1 & 5,91 & 101,37 \\
$\mathbf{6}$ & 2,86 & 4,71 & 5,19 & 12,42 & 20,86 & 6,59 & 15,1 & 9,91 & 22,37 \\
$\mathbf{7}$ & 5,86 & 7,71 & 75,19 & 7,42 & 1,86 & - & 12,1 & 5,91 & 17,37 \\
$\mathbf{8}$ & 0,86 & 8,71 & 15,19 & 22,42 & 12,86 & 3,59 & 12,1 & 15,91 & 47,37 \\
$\mathbf{9}$ & 1,86 & 38,71 & 77,19 & 28,42 & 8,86 & 16,59 & 18,1 & 11,91 & 75,37 \\
$\mathbf{1 0}$ & 7,86 & 14,71 & 15,19 & 27,42 & 13,86 & 9,59 & 21,1 & 18,91 & 47,37 \\
$\mathbf{1 1}$ & 6,86 & 12,71 & 17,19 & 14,42 & 12,86 & 7,59 & 4,1 & 7,91 & 25,37 \\
$\mathbf{1 2}$ & 0,86 & 2,71 & 1,19 & 40,42 & 40,86 & 14,59 & 9,1 & 30,91 & 15,37 \\
$\mathbf{1 3}$ & 5,86 & 13,71 & 5,19 & 4,42 & 12,86 & 8,59 & 23,1 & 4,91 & 26,37 \\
$\mathbf{1 4}$ & 7,86 & 14,71 & 20,19 & 7,42 & 47,86 & 11,59 & 15,1 & 5,91 & 38,37 \\
$\mathbf{1 5}$ & 10,86 & 13,71 & 20,19 & 70,42 & 10,86 & 15,59 & 10,1 & 6,91 & 52,37 \\
$\mathbf{1 6}$ & 10,86 & 14,71 & 11,19 & 11,42 & 11,86 & 9,59 & 9,1 & 15,91 & 19,37 \\
$\mathbf{1 7}$ & $\mathbf{1 6 , 8 6}$ & 18,71 & 13,19 & 7,42 & 19,86 & - & $\mathbf{7 2 , 1}$ & 26,91 & 22,37 \\
\hline Média & $\mathbf{6 , 3 9}$ & $\mathbf{1 1 , 7 1}$ & $\mathbf{1 8 , 4 3}$ & $\mathbf{1 7 , 0 7}$ & $\mathbf{1 5 , 6 8}$ & $\mathbf{8 , 9 9}$ & $\mathbf{1 8 , 1 0}$ & $\mathbf{1 2 , 2 9}$ & $\mathbf{3 8 , 4 3}$ \\
\hline
\end{tabular}

\footnotetext{
${ }^{8}$ Tempo em segundos e centésimos (ss,00).
} 
Tabela B.5 - Resultados referentes aos dados pareados para a Tarefa 1

\begin{tabular}{ccc|c|c} 
& & \multicolumn{3}{c}{ Risko } \\
\multirow{3}{*}{ iGeom } & Classificação & certo & Total \\
\cline { 3 - 4 } & certo & 9 & 8 & 17 \\
\cline { 3 - 4 } & errado & 0 & 0 & 0 \\
\cline { 3 - 4 } & Total & 9 & 8 & 17
\end{tabular}

\section{p-value}

$\%$

n

Tabela B.6 - Resultados referentes aos dados pareados para a Tarefa 2

Risko

\begin{tabular}{|c|c|c|c|c|}
\hline \multirow{4}{*}{ ¿Geom } & \multirow{2}{*}{$\begin{array}{c}\text { Classificação } \\
\text { certo }\end{array}$} & certo & errado & \multirow{3}{*}{$\begin{array}{c}\text { Total } \\
17\end{array}$} \\
\hline & & 17 & 0 & \\
\hline & errado & 0 & 0 & \\
\hline & Total & 17 & 0 & 17 \\
\hline
\end{tabular}

\begin{tabular}{ccc}
\hline $\boldsymbol{p}$-value & $\boldsymbol{\%}$ & $\boldsymbol{n}$ \\
\hline \hline 1,000 & 200,0 & - \\
\hline
\end{tabular}

Tabela B.7 - Resultados referentes aos dados pareados para a Tarefa 3

\begin{tabular}{|c|c|c|c|c|}
\hline & & \multicolumn{2}{|c|}{ Risko } & \multirow{3}{*}{$\begin{array}{c}\text { Total } \\
17\end{array}$} \\
\hline \multirow{3}{*}{ iGeom } & \multirow{2}{*}{$\begin{array}{c}\text { Classificação } \\
\text { certo }\end{array}$} & certo & errado & \\
\hline & & 17 & 0 & \\
\hline & \multirow{2}{*}{$\begin{array}{c}\text { errado } \\
\text { Total }\end{array}$} & 0 & 0 & 0 \\
\hline & & 17 & 0 & 17 \\
\hline
\end{tabular}

\begin{tabular}{ccc}
\hline$p$-value & $\boldsymbol{\%}$ & $\boldsymbol{n}$ \\
\hline \hline 1,000 & 100,0 & - \\
\hline
\end{tabular}


Tabela B.8 - Resultados referentes aos dados pareados para a Tarefa 4

\begin{tabular}{|c|c|c|c|c|}
\hline \multirow{4}{*}{ iGeom } & \multirow{4}{*}{$\begin{array}{c}\text { Classificação } \\
\text { certo } \\
\text { errado }\end{array}$} & \multicolumn{2}{|c|}{ Risko } & \multirow{3}{*}{ Total } \\
\hline & & certo & errado & \\
\hline & & 14 & 3 & \\
\hline & & 0 & 0 & 0 \\
\hline & Total & 14 & 3 & 17 \\
\hline
\end{tabular}

\begin{tabular}{ccc}
\hline $\boldsymbol{p}$-value & $\boldsymbol{\%}$ & $\boldsymbol{n}$ \\
\hline 0,250 & 25,0 & 22 \\
\hline
\end{tabular}

Tabela B.9 - Resultados referentes aos dados pareados para a Tarefa 5

\begin{tabular}{|c|c|c|c|c|}
\hline \multirow{4}{*}{ iGeom } & \multirow[b]{2}{*}{ Classificação } & \multicolumn{2}{|c|}{ Risko } & \multirow{3}{*}{$\begin{array}{c}\text { Total } \\
17\end{array}$} \\
\hline & & certo & errado & \\
\hline & certo & 13 & 4 & \\
\hline & errado & 0 & 0 & 0 \\
\hline & Total & 13 & 4 & 17 \\
\hline
\end{tabular}

\begin{tabular}{ccc}
\hline$p$-value & \% & $\boldsymbol{n}$ \\
\hline \hline 0,125 & 12,5 & 16 \\
\hline
\end{tabular}

Tabela B.10 - Resultados referentes aos dados pareados para a Tarefa 6

\begin{tabular}{|c|c|c|c|c|}
\hline \multirow{4}{*}{ iGeom } & \multirow[b]{2}{*}{ Classificação } & \multicolumn{2}{|c|}{ Risko } & \multirow{3}{*}{$\begin{array}{c}\text { Total } \\
16\end{array}$} \\
\hline & & certo & errado & \\
\hline & certo & 14 & 2 & \\
\hline & errado & 1 & 0 & 1 \\
\hline & Total & 15 & 2 & 17 \\
\hline
\end{tabular}

\begin{tabular}{ccc}
\hline$p$-value & \% & $\boldsymbol{n}$ \\
\hline \hline 1,000 & 100,0 & 511 \\
\hline
\end{tabular}


Tabela B.11 - Resultados referentes aos dados pareados para a Tarefa 7

\begin{tabular}{ccc|c|c} 
& & \multicolumn{3}{c}{ Risko } \\
\multirow{3}{*}{ iGeom } & Classificação & certo & errado & Total \\
\cline { 3 - 4 } & certo & 15 & 2 & 17 \\
\cline { 3 - 4 } & errado & 0 & 0 & 0 \\
\cline { 3 - 4 } & Total & 15 & 2 & 17
\end{tabular}

\begin{tabular}{ccc}
\hline $\boldsymbol{p}$-value & $\boldsymbol{\%}$ & $\boldsymbol{n}$ \\
\hline 0,500 & 50,0 & 33 \\
\hline
\end{tabular}

Tabela B.12 - Resultados referentes aos dados pareados para a Tarefa 8

\begin{tabular}{ccc|c|c} 
& & \multicolumn{3}{c}{ Risko } \\
\multirow{3}{*}{ iGeom } & Classificação & certo & errado & Total \\
\cline { 3 - 4 } & certo & 15 & 1 & 16 \\
\cline { 3 - 4 } & errado & 1 & 0 & 1 \\
\cline { 3 - 4 } & Total & 16 & 1 & 17
\end{tabular}

\begin{tabular}{ccc}
\hline p-value & \% & $\boldsymbol{n}$ \\
\hline \hline 1,000 & 100,0 & - \\
\hline
\end{tabular}

Tabela B.13 - Resultados referentes aos dados pareados para a Tarefa 9

\begin{tabular}{|c|c|c|c|c|}
\hline & & & & \\
\hline & Classificação & certo & errado & Total \\
\hline ¡Geom & certo & 17 & 0 & 17 \\
\hline$\imath$ Geom & errado & 0 & 0 & 0 \\
\hline & Total & 17 & 0 & 17 \\
\hline
\end{tabular}

\begin{tabular}{ccc}
\hline$p$-value & $\%$ & $n$ \\
\hline \hline 1,000 & 100,0 & - \\
\hline
\end{tabular}




\section{APÊNDICE C}

\section{DADOS OBTIDOS NOS QUESTIONÁRIOS PÓS-TESTE}

Tabela C.1 - Frequiência de uso do computador

\begin{tabular}{lccc}
\hline & Questão $\boldsymbol{A}$ & Respostas & \% \\
\hline \hline Nunca usei & 0 & 0,0 \\
Raramente uso & 0 & 0,0 \\
Uma vez por mês & 0 & 0,0 \\
Uma vez por semana & 0 & 0,0 \\
Todos os dias & 17 & 100,0 \\
\hline
\end{tabular}

Tabela C.2 - Dificuldades na realização das tarefas

\begin{tabular}{lc}
\hline \multicolumn{1}{c}{ Questão $\boldsymbol{G}$} & Respostas \\
\hline \hline As tarefas foram difíceis de resolver & 1 \\
A seqüência das tarefas foi complicada & 0 \\
Não entendi o que foi pedido para fazer & 0 \\
Outras dificuldades & 4 \\
Nada respondeu & 12 \\
\hline
\end{tabular}


Tabela C.3 - Dados comparativos para as questões "B x D"

\begin{tabular}{|c|c|c|c|c|c|c|}
\hline item $-A$ & Resp. & $\%$ & Nota & Resp. & $\%$ & Nota \\
\hline & \multicolumn{3}{|c|}{ Risko } & \multicolumn{3}{|c|}{ iGeom } \\
\hline Foi muito mais demorado do que no papel & 1 & 5,9 & $-2,0$ & 1 & 5,9 & $-2,0$ \\
\hline Foi mais demorado do que no papel & 6 & 35,3 & $-6,0$ & 1 & 5,9 & $-1,0$ \\
\hline Demorei o mesmo tempo que no papel & 2 & 11,8 & 0,0 & 2 & 11,8 & 0,0 \\
\hline Foi mais rápido do que resolver no papel & 5 & 29,4 & 5,0 & 6 & 35,3 & 6,0 \\
\hline Foi muito mais rápido que resolver no papel & 3 & 17,6 & 6,0 & 7 & 41,2 & 14,0 \\
\hline Nota final & & & 3,0 & & & 17,0 \\
\hline Média & 3,4 & & & 3,4 & & \\
\hline Variância & 4,3 & & & 8,3 & & \\
\hline Desvio padrão & 2,1 & & & 2,9 & & \\
\hline
\end{tabular}

Tabela C.4 - Teste de Wilcoxon para o item "a"

\begin{tabular}{|c|c|c|c|c|c|}
\hline (j) & $(A j)$ & $(\boldsymbol{B j})$ & $(d j=A j-B j)$ & $(-d j)$ & $(+d)$ \\
\hline 1 & 5 & 5 & 0 & & \\
\hline 2 & 3 & 4 & -1 & $-3,5$ & \\
\hline 3 & 1 & 4 & -3 & $-8,5$ & \\
\hline 4 & 4 & 5 & -1 & $-3,5$ & \\
\hline 5 & 4 & 5 & -1 & $-3,5$ & \\
\hline 6 & 4 & 4 & 0 & & \\
\hline 7 & 2 & 5 & -3 & $-8,5$ & \\
\hline 8 & 2 & 5 & -3 & $-8,5$ & \\
\hline 9 & 4 & 4 & 0 & & \\
\hline 10 & 3 & 3 & 0 & & \\
\hline 11 & 2 & 5 & -3 & $-8,5$ & \\
\hline 12 & 2 & 1 & 1 & & 3,5 \\
\hline 13 & 4 & 5 & -1 & $-3,5$ & \\
\hline 14 & 4 & 4 & 0 & & \\
\hline 15 & 2 & 3 & -1 & $-3,5$ & \\
\hline 16 & 2 & 2 & 0 & & \\
\hline \multirow[t]{2}{*}{17} & 5 & 5 & 0 & & \\
\hline & & & & $-51,5$ & 3,5 \\
\hline$T$ & \multicolumn{2}{|c|}{3,5} & & & \\
\hline$n$ & \multicolumn{2}{|c|}{10} & & & \\
\hline$T$ critico & \multicolumn{2}{|c|}{8} & & & \\
\hline
\end{tabular}


Tabela C.5 - Dados comparativos para as questões "B x D"

\begin{tabular}{|c|c|c|c|c|c|c|}
\hline item $-B$ & Resp. & $\%$ & Nota & Resp. & $\%$ & Nota \\
\hline & \multicolumn{3}{|c|}{ Risko } & \multicolumn{3}{|c|}{ iGeom } \\
\hline Não gostei nada do programa & 0 & 0,0 & 0,0 & 0 & 0,0 & 0,0 \\
\hline Não gostei do programa & 1 & 5,9 & $-1,0$ & 2 & 11,8 & $-2,0$ \\
\hline Indiferente & 1 & 5,9 & 0,0 & 5 & 29,4 & 0,0 \\
\hline Gostei do programa & 8 & 47,1 & 8,0 & 7 & 41,2 & 7,0 \\
\hline Gostei muito do programa & 7 & 41,2 & 14,0 & 3 & 17,6 & 6,0 \\
\hline Nota final & & & 21,0 & & & 11,0 \\
\hline Média & 3,4 & & & 3,4 & & \\
\hline Variância & 14,3 & & & 7,3 & & \\
\hline Desvio padrão & 3,8 & & & 2,7 & & \\
\hline
\end{tabular}

Tabela C.6 - Teste de Wilcoxon para o item "b"

\begin{tabular}{|c|c|c|c|c|c|}
\hline (j) & $(A j)$ & $(B j)$ & $(d j=A j-B j)$ & $(-d j)$ & $(+d)$ \\
\hline 1 & 4 & 3 & 1 & & 5,5 \\
\hline 2 & 4 & 5 & -1 & $-5,5$ & \\
\hline 3 & 2 & 3 & -1 & $-5,5$ & \\
\hline 4 & 4 & 5 & -1 & $-5,5$ & \\
\hline 5 & 5 & 4 & 1 & & 5,5 \\
\hline 6 & 5 & 4 & 1 & & 5,5 \\
\hline 7 & 5 & 4 & 1 & & 5,5 \\
\hline 8 & 5 & 4 & 1 & & 5,5 \\
\hline 9 & 4 & 2 & 2 & & 12 \\
\hline 10 & 4 & 4 & 0 & & \\
\hline 11 & 4 & 4 & 0 & & \\
\hline 12 & 5 & 2 & 3 & & 14 \\
\hline 13 & 5 & 3 & 2 & & 12 \\
\hline 14 & 5 & 3 & 2 & & 12 \\
\hline 15 & 5 & 4 & 1 & & 5,5 \\
\hline 16 & 3 & 3 & 0 & & \\
\hline \multirow[t]{2}{*}{17} & 4 & 5 & -1 & $-5,5$ & \\
\hline & & & & -22 & 83 \\
\hline$T$ & & & & & \\
\hline$n$ & & & & & \\
\hline$T$ critico & & & & & \\
\hline
\end{tabular}


Tabela C.7 - Dados comparativos para as questões "B x D"

\begin{tabular}{|c|c|c|c|c|c|c|}
\hline item - $C$ & Resp. & $\%$ & Nota & Resp. & $\%$ & Nota \\
\hline & \multicolumn{3}{|c|}{ Risko } & \multicolumn{3}{|c|}{ iGeom } \\
\hline É muito difícil de usar & 0 & 0,0 & 0,0 & 0 & 0,0 & 0,0 \\
\hline É difícil de usar & 2 & 11,8 & $-2,0$ & 1 & 5,9 & $-1,0$ \\
\hline Indiferente ou não sei avaliar & 1 & 5,9 & 0,0 & 2 & 11,8 & 0,0 \\
\hline É fácil de usar & 14 & 82,4 & 14,0 & 9 & 52,9 & 9,0 \\
\hline È muito fácil de usar & 0 & 0,0 & 0,0 & 5 & 29,4 & 10,0 \\
\hline Nota final & & & 12,0 & & & 18,0 \\
\hline Média & 3,4 & & & 3,4 & & \\
\hline Variância & 35,8 & & & 13,3 & & \\
\hline Desvio padrão & 6,0 & & & 3,6 & & \\
\hline
\end{tabular}

Tabela C.8 - Teste de Wilcoxon para o item "c"

\begin{tabular}{|c|c|c|c|c|c|}
\hline (j) & $(A j)$ & $(\boldsymbol{B j})$ & $(d j=A j-B j)$ & $(-d j)$ & $(+d)$ \\
\hline 1 & 4 & 5 & -1 & $-3,5$ & \\
\hline 2 & 4 & 5 & -1 & $-3,5$ & \\
\hline 3 & 2 & 4 & -2 & -8 & \\
\hline 4 & 4 & 5 & -1 & $-3,5$ & \\
\hline 5 & 4 & 5 & -1 & $-3,5$ & \\
\hline 6 & 4 & 4 & 0 & & \\
\hline 7 & 3 & 5 & -2 & -8 & \\
\hline 8 & 4 & 4 & 0 & & \\
\hline 9 & 4 & 2 & 2 & & 8 \\
\hline 10 & 4 & 3 & 1 & & 3,5 \\
\hline 11 & 4 & 4 & 0 & & \\
\hline 12 & 4 & 4 & 0 & & \\
\hline 13 & 4 & 4 & 0 & & \\
\hline 14 & 4 & 4 & 0 & & \\
\hline 15 & 4 & 4 & 0 & & \\
\hline 16 & 2 & 3 & -1 & $-3,5$ & \\
\hline \multirow[t]{2}{*}{17} & 4 & 4 & 0 & & \\
\hline & & & & $-33,5$ & 11,5 \\
\hline$T$ & \multicolumn{2}{|c|}{11,5} & & & \\
\hline$n$ & \multicolumn{2}{|c|}{9} & & & \\
\hline$T$ critico & \multicolumn{2}{|c|}{5} & & & \\
\hline
\end{tabular}


Tabela C.9 - Dados comparativos para as questões "B x D"

\begin{tabular}{|c|c|c|c|c|c|c|}
\hline item $-D$ & Resp. & $\%$ & Nota & Resp. & $\%$ & Nota \\
\hline & \multicolumn{3}{|c|}{ Risko } & \multicolumn{3}{|c|}{ iGeom } \\
\hline Desconfio fortemente das construções feitas & 0 & 0,0 & 0,0 & 0 & 0,0 & 0,0 \\
\hline Desconfio da precisão das construções feitas & 2 & 11,8 & $-2,0$ & 1 & 5,9 & $-1,0$ \\
\hline Indiferente ou não sei avaliar & 1 & 5,9 & 0,0 & 0 & 0,0 & 0,0 \\
\hline Confio parcialmente nas construções feitas & 13 & 76,5 & 13,0 & 5 & 29,4 & 5,0 \\
\hline Confio totalmente nas construções feitas & 1 & 5,9 & 2,0 & 11 & 64,7 & 22,0 \\
\hline Nota final & & & 13,0 & & & 26,0 \\
\hline Média & 3,4 & & & 3,4 & & \\
\hline Variância & 29,3 & & & 22,3 & & \\
\hline Desvio padrão & 5,4 & & & 4,7 & & \\
\hline
\end{tabular}

Tabela C.10 - Teste de Wilcoxon para o item "d"

\begin{tabular}{|c|c|c|c|c|c|}
\hline (j) & $(A j)$ & $(B j)$ & $(d j=A j-B j)$ & $(-d j)$ & $(+d)$ \\
\hline 1 & 4 & 4 & 0 & & \\
\hline 2 & 4 & 5 & -1 & $-4,5$ & \\
\hline 3 & 4 & 5 & -1 & $-4,5$ & \\
\hline 4 & 4 & 5 & -1 & $-4,5$ & \\
\hline 5 & 4 & 2 & 2 & & 10 \\
\hline 6 & 4 & 5 & -1 & $-4,5$ & \\
\hline 7 & 2 & 4 & -2 & -10 & \\
\hline 8 & 5 & 5 & 0 & & \\
\hline 9 & 4 & 5 & -1 & $-4,5$ & \\
\hline 10 & 4 & 4 & 0 & & \\
\hline 11 & 2 & 5 & -3 & -12 & \\
\hline 12 & 4 & 5 & -1 & $-4,5$ & \\
\hline 13 & 4 & 4 & 0 & & \\
\hline 14 & 3 & 5 & -2 & -10 & \\
\hline 15 & 4 & 4 & 0 & & \\
\hline 16 & 4 & 5 & -1 & $-4,5$ & \\
\hline \multirow[t]{2}{*}{17} & 4 & 5 & -1 & $-4,5$ & \\
\hline & & & & -68 & 10 \\
\hline$T$ & & & & & \\
\hline$n$ & & & & & \\
\hline$T$ critico & & & & & \\
\hline
\end{tabular}


Tabela C.11 - Dados comparativos para as questões "C x E"

\begin{tabular}{lcccc}
\hline \multicolumn{1}{c}{ Credibilidade dos programas } & Resp. & Nota & Resp. & Nota \\
\hline \hline & \multicolumn{2}{c}{ Risko } & \multicolumn{2}{c}{ iGeom } \\
\cline { 2 - 6 } Encontrar os comandos desejados & 0 & 0,0 & 0 & 0,0 \\
Entender o funcionamento dos comandos e inst. de desenho & 2 & $-2,0$ & 1 & $-1,0$ \\
Houve erros do programa & 1 & 0,0 & 0 & 0,0 \\
Faltam explicações na tela & 13 & 13,0 & 5 & 5,0 \\
Outras dificuldades & 1 & 2,0 & 11 & 22,0 \\
& & & & \\
\hline Média & 3,4 & & 3,4 \\
Variância & 29,3 & \multicolumn{3}{c}{22,3} \\
Desvio padrão & 5,4 & \multicolumn{3}{c}{4,7} \\
\hline
\end{tabular}

Tabela C.12 - Dados comparativos para a questão "F"

\begin{tabular}{lcccc}
\hline \multicolumn{1}{c}{ Preferência de uso em um curso } & Resp. & \% & Resp. & \% \\
\hline \hline & \multicolumn{2}{c}{ Risko } & \multicolumn{2}{c}{ iGeom } \\
\cline { 2 - 6 } Em sala de aula & 15 & 88,2 & 2 & 11,8 \\
Na sua casa para estudar ou realizar trabalhos e exercícios & 6 & 35,3 & 11 & 64,7 \\
Para fazer as provas & 9 & 52,9 & 8 & 47,1 \\
& & & & \\
\hline Média & 10,0 & \multicolumn{3}{c}{7,0} \\
Variância & 21,0 & \multicolumn{2}{c}{21,0} \\
Desvio padrão & 4,6 & \multicolumn{2}{c}{4,6} \\
\hline
\end{tabular}




\section{APÊNDICE D}

\section{RELÁTOS OBTIDO NOS QUESTIONÁRIOS \\ PÓS-TESTE}

A seguir são apresentados os comentários feitos pelos participantes do teste prático a respeito das interfaces utilizadas e das tarefas propostas. Estes comentários estão documentados, por escrito, nos próprios questionários. Objetivando manter a fidelidade na transcrição dos comentários, nenhuma alteração ou correção ortográfica foi feita sobre o texto original, ele apenas foi digitalizado!

\section{Referentes ao aplicativo Risko:}

"O aluno é capaz de realizar o exercício tanto no PC quanto à mão, pois tem acesso às mesmas ferramentas (esquadro, compasso,...)”

"O aluno fixará melhor os conceitos de desenho com este software (poucas funções automáticas)."

"Requer tempo excessivo para entender o funcionamento das ferramentas. Uma interface mais amigável, com textos explicativos, reduziria este (tempo de adaptação)."

"Para exercícios/provas/trabalhos mais longos, este software não é apropriado, devido à falta de (ferramentas automáticas).”

"Seria necessário melhorar a maneira de usar os comandos: esquadros são difíceis de posicionar; pontos são ruins de desenhar, pois falta maior precisão que o uso com o mouse não confere." 
"Difícil alinhamento dos esquadros."

"O usuário, a principio, não sabe que o ponto verde indica a eminência de um vínculo, assim como que o ponto vermelho indica que um vínculo já foi criado."

"O tamanho dos pontos não é adequado. Como os mesmos são muito pequenos, torna-se difícil a visualização."

"Seria interessante a presença de um (help), pois nenhum usuário tem a obrigação de descobrir como funcionam os instrumentos de desenho."

"A borracha poderia ser maior para facilitar e agilizar a tarefa de apagar."

"Uma explicação sobre todas as características dos instrumentos de desenho aumentaria muito mais o potencial de utilização dos mesmos!!!”

"O software oferece alguns recursos que somente são descobertos à medida que o mesmo é utilizado por um certo período de tempo. (falta do help)."

"Quanto a precisão, quando faço o ponto, tive a impressão que o lápis se deslocou, mas isso foi resolvido prestando a atenção ao ponto."

“Os comandos do programa são bem intuitivos. Um simples texto com instruções sobre como utilizar os comandos (ponta do lápis, borracha, esquadros) sanará esse problema."

“A cor do snap não facilita muito sua identificação. Talvez uma outra cor ou mesmo alguma indicação externa ao esquadro."

"Os números estão pequenos."

"Para marcar ponto na reta, eu achei este programa um pouco impreciso."

“Demorei um pouco para localizar a borracha no lápis, talvez fosse melhor ter uma borracha separada."

"Mover os esquadros foi meio difícil por não poder dissociar (pelo menos eu não consegui) os movimentos de translação (deslocamento) e rotação dos esquadros."

"Com o compasso me atrapalhei um pouco quando queria movê-lo e ele rodava, não ficou muito claro onde clicava para uma ação e onde o fazia para a outra ação."

"Achei a linguagem visual muito boa como forma de ensinar desenho, remete a objetos cujo funcionamento a principio já se domina." 
"Para traçar a reta perpendicular pude apoiar o esquadro na reta já construída, mas se eu quisesse cruzar a primeira reta, precisaria pensar melhor como lidar com o jogo de esquadros.”

"Apesar de os elementos utilizados serem auto-explicativos (esquadro, lápis, etc.) acho que trabalha um pouco menos claramente alguns conceitos geométricos necessários para utilização do outro programa. Por um lado torna o programa mais acessível aos iniciantes em desenho, por outro o torna limitado."

"O zoom ficou estranho: os equipamentos de desenho sumiam da tela caso eu me aproximasse muito do ponto/desenho."

"Melhor para fixar conceitos."

“No Risko, não é claro quando você (trava) numa função. Por exemplo: no compasso, não há uma indicação visual se você esta alterando sua abertura ou se você está de fato traçando com ele. Deveria existir um (highlight) na ponta do compasso e na perna."

"A escala dos esquadros é difícil de ler, tanto em tamanho quanto na cor."

"Não há controle dimensional no compasso."

"A ferramenta borracha poderia apagar elementos inteiros."

"Será que o ponto sobre a reta estava realmente na reta."

"Faltou uma maneira mais direta com relação à questão de apagar algum elemento. Não é porque estamos utilizando um software com instrumentos de desenho, que temos que efetivamente passar a borracha do lápis em cima de toda a linha ou circunferência. Basicamente é uma deficiência do trabalho em papel que foi desnecessariamente incorporada no software."

"Não tive certeza de criar o ponto exatamente em cima da reta ou apenas (bem perto) dela."

"Dificuldade em manejar os esquadros, só no começo."

"Achei o programa Risko muito interessante."

"É muito intuitivo, fácil de usar. Acho que devia haver instruções na tela, como (arrastar o lápis pela parte amarela).”

"Acho que seria interessante adicionar uma (grade) numerada, para aumentar a precisão.” 
"A tela fica muito cheia após a criação dos desenhos. Seria ideal a presença de icones que (chamassem) os instrumentos."

"Não é trivial o uso dos comandos, apesar dos instrumentos serem intuitivos."

"Quando fui apagar um objeto na tela, no caso a circunferência, outro objeto que estava sobreposto foi atingido também."

"As ações no programa não são bem determinadas: fazer um ponto, deslocar a régua."

“Gostei muito da idéia do programa! É uma proposta totalmente nova (para mim) e bem pensada. Envolve mais raciocínio e conhecimento que os programas comuns."

"Faltam explicações na tela clique na ponta para riscar."

“Manusear os instrumentos: esquadros (foi fácil de posicionar) e lápis (difícil de riscar)."

“Achei o Risko um programa muito intuitivo, especialmente para pessoas que não têm noções avançadas de desenho geométrico. Entretanto é difícil manusear os instrumentos, o que diminui a confiabilidade do desenho (paralelas, perpendiculares). Deveria ter legendas nos instrumentos.”

"Como faltam menus, não procurei um link para (ajuda), que poderia ter explicações sobre como deslizar o esquadro."

\section{Referentes ao aplicativo $i$ Geom:}

"Dificuldade de encontrar o comando remover objetos."

"O software é extremamente fácil de se utilizar!"

"Seria interessante a presença de um (help) para usuários que não são da área, mas que gostariam de utilizar o software no aprendizado de geometria."

“Não gostei do comando apagar ser um sub-comando do editor, pois estou acostumado a ter acesso mais direto a ele."

"Só demorei a encontrar a borracha."

“As explicações dos comandos somem muito rapidamente, não dá tempo de lê-los, o que afetou o entendimento dos comandos, visto que nem todos os ícones são claros o suficiente (o desenho do ícone)." 
"Não sei se seleciono o comando ou executo a ação para então selecionar o comando."

"Melhor para desenhar mais completo."

"As explicações nos botões facilitam o uso."

"A interface é menos amigável, mas mais eficiente."

"Leitura das explicações na tela tamanho da letra, tempo disponível para leitura, instabilidade (cada hora aparece em um lugar, etc.)."

"Interface parecida com os programas comuns."

"Mais prático."

"Penso que só foi fácil usar este programa pelo conhecimento que já tenho de programas $C A D . "$

"A explicação que aparece quando o mouse está sobre o botão, desaparece muito rápido!”

"Fácil de usar, mas os ícones são um pouco confusos e mal distribuídos. A legenda dos botões é difícil de ler. É fácil selecionar pontos e retas porque o programa as (ilumina) no (Risko também).”

\section{Referentes as tarefas propostas no teste:}

"Não lembrei como traçar retas paralelas."

"No iGeom, as explicações não foram suficientes para realizar todas as tarefas."

"Manusear os instrumentos." 